University of Rhode Island

DigitalCommons@URI

Open Access Dissertations

1998

\title{
Analogue Versus Authentic Data: Prereferral Intervention Strategy Utilization, Effectiveness and Self-Efficacy Beliefs
}

Mary Ellen K. Tillostson

University of Rhode Island

Follow this and additional works at: https://digitalcommons.uri.edu/oa_diss

\section{Recommended Citation}

Tillostson, Mary Ellen K., "Analogue Versus Authentic Data: Prereferral Intervention Strategy Utilization, Effectiveness and Self-Efficacy Beliefs" (1998). Open Access Dissertations. Paper 925.

https://digitalcommons.uri.edu/oa_diss/925

This Dissertation is brought to you for free and open access by DigitalCommons@URI. It has been accepted for inclusion in Open Access Dissertations by an authorized administrator of DigitalCommons@URI. For more information, please contact digitalcommons-group@uri.edu. 
ANALOGUE VERSUS AUTHENTIC DATA: PREREFERRAL INTERVENTION STRATEGY UTILIZATION, EFFECTIVENESS AND SELF-EFFICACY BELIEFS BY

MARY ELLEN K. TILLOTSON

A DISSERTATION SUBMITTED IN PARTIAL FULFILLMENT OF THE REQUIREMENTS FOR THE DEGREE OF DOCTOR OF PHILOSOPHY

IN

PSYCHOLOGY

41240972

UNIVERSITY OF RHODE ISLAND

1998 


\section{ABSTRACT}

A literature has formed which has historically utilized an analogue approach to the study of prereferral intervention use and perceptions of acceptability and effectiveness. This methodology, however, may lack ecological validity if variables that mediate intervention selection and perceived efficacy are not linked to research design. If analogue research is to remain viable, supporting evidence of the concordance of naturalistic findings is expected. The current study utilizes an analogue and concomitant authentic approach to study the equivalence of these methods. A sample of 345 special education referral forms served as authentic data. Ninety-seven elementary general and special education teachers responded to an analogue survey for both academic and behavioral problems designed to mirror referral forms. Matched by grade and referral type, results suggest that while the selection of prereferral intervention strategies are not significantly different for analogue versus authentic data methods, the ratings of effectiveness do show differences according to methodology. Specifically, interventions are rated as more effective when presented via an analogue scenario compared with an equivalent authentic prereferral situation. Interventions are rated as more effective for academic referrals than for behavioral referrals. Special educators rate interventions as substantially more effective than do regular educators. In general, Process Instructional Adaptations (PIA) in the classroom are utilized with academic problems whereas Behavioral Conditioning Interventions (BCI) are applied most frequently with students with behavioral problems. A low percentage of students, however, were referred for behavioral problems in the case of authentic data. In the case of both authentic and analogue data, teachers do use interventions which they do not find to be effective and they also do not use interventions with frequency that they find to be quite effective. Self-efficacy perceptions are also related to some aspects of intervention effectiveness ratings. Teachers who demonstrate external efficacy perceptions reported lower levels of effectiveness for interventions they chose for behavioral problems while internal 
teachers rated interventions for students with behavioral problems to be effective. Implications with respect to the ecological validity of the analogue approach are discussed. The context of educational reform and the changing educational environment is also discussed. 


\section{Acknowledgments}

I would like to dedicate this dissertation to my daughter, Abigail. Her presence has sustained my work and she is a constant reminder of the nature, joy and the blessings of God throughout this research effort. Her gleeful wonder of learning new things and her unconditional love have truly set an example for me to follow throughout my life.

This project has been made possible by many individuals who deserve my warmest thanks. I wish to thank my major professor, Dr. Janet Kulberg for her caring, support and guidance. I have appreciated her intellect and her wisdom as this project developed form. I wish to thank all my committee members. Dr. Richard Sullivan for his mentorship while I struggled as a young college instructor. His words of encouragement strengthened me. Dr. Allan Berman for being such a great assistantship supervisor and Dr. Paul de Mesquita for his encouragement and insights. A special thanks to Dr. Al Lott and Dr. Sandra Hicks for their input during my defense.

I wish to thank my family and friends for their unending support and love. My mother gave her time, her love and her encouragement through many difficult moments. She has always believed in me. My husband, Roy, who offered his support and caring throughout my education and for being such a great Daddy at the same time! To all of the beautiful and supportive women who have given their wisdom and truth as a guide for me (Barbara, Erika, Krista, Kathy M., Robyn, Ann, Kathleen, Kathy K., Diane, Penni, and Christi). Thank you David for your support and spiritual friendship. Thanks to Pam and Jess for their extraordinary baby-sitting talents!

I would like to specially thank the teachers of Warwick without whose generous participation this project would not be realized. Thank you to Mr. Jeff Sharkey, Mr. Steve Lowry of the Special Services Department of the Warwick Public School Department and Mr. Robert Bushell who provided me access for completion of this project. To Mr. William 
McDevitt who encouraged and cheered me on. To Ms. Judith Daniels for her immediate and warm support. Thank you to the school psychologists of Warwick for their review of my project and helpful suggestions.

Finally, I would like to thank Casey Reidy, my Aunt who instilled in me a love of reading and all things intellectual. I remember your guidance fondly and with love. 


\section{CHAPTER}

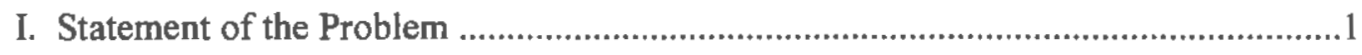

Prereferral intervention ...........................................................................

Variables which impact upon intervention selection .......................................2

Definition of analogue research methodology ................................................3

Research Goals ................................................................................... 3

II. Justification for and Significance of the Study ................................................

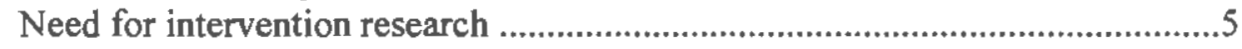

Changing context of educational environment ..............................................5

The role of self efficacy in teaching ...............................................................5

The role of school psychologist ..............................................................6

The validity of current research methods ......................................................

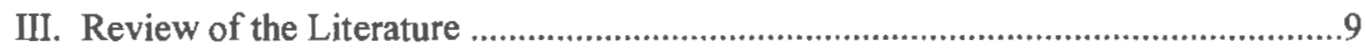

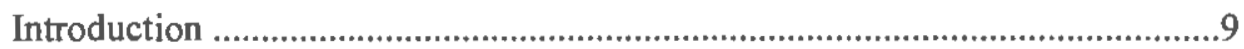

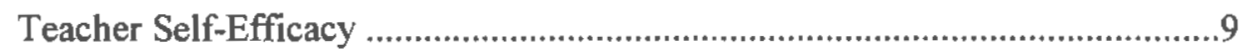

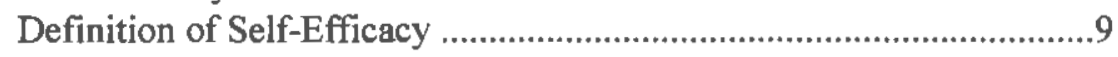

Current Research Approaches .......................................................11

Self-Efficacy in Education ...............................................................12

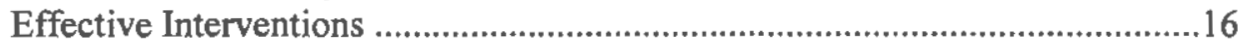

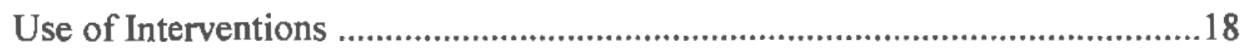

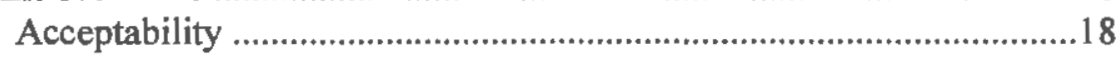

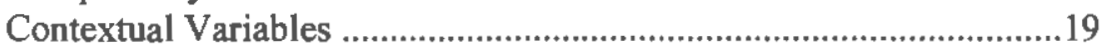

Efficacy and Intervention Selection ..............................................20

Consultation and Intervention Use .................................................21

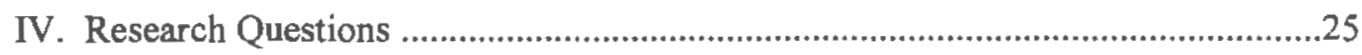

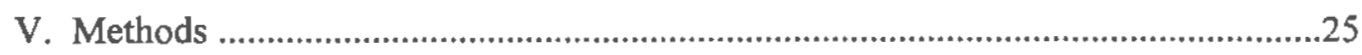

The School System ................................................................................25

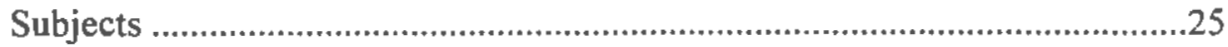

Measures ...............................................................................................27

Classroom Alternatives Support Team Request Form (CASTRF) ......27

Records Review .....................................................................27

Teacher Questionnaire .................................................................27

Teacher Efficacy Scale-TES (Guskey \& Passaro, 1994)....................28

Procedure 
Authentic Data Collection .............................................................30

Interrater Reliability ..................................................................... 31

Analogue Data Collection .............................................................32

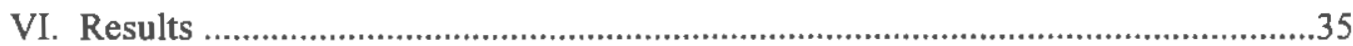

Intervention Selection and Effectiveness ...................................................35

What is the nature of intervention selection and teachers' beliefs about the effectiveness of those interventions? .....................................................35

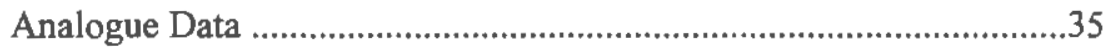

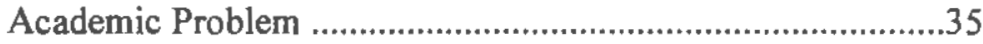

Behavior Problem ..................................................................37

Academic versus Behavior Problem ....................................40

Special Education versus General Education Teachers .........41

Authentic Data ...........................................................................42

Academic Problem .............................................................43

Behavior Problem ...............................................................46

Academic versus Behavior Problem .....................................48

Frequency ...........................................................48

Effectiveness .......................................................49

Academic versus Behavior Problem-Collapsed Data................50

Analogue Versus Authentic Data ..................................................................50

What is the relationship between analogue and authentic data? Are selected interventions rated similarly effective for analogue and authentic data? Will

Real life mirror the hypothetical? .........................................................50

Intervention Selection .......................................................................

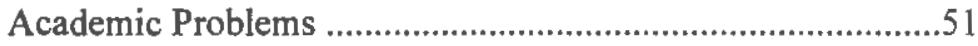

Behavior Problems ..........................................................55

Intervention Effectiveness ...........................................................53

Academic Problem ............................................................53

Behavior Problem ............................................................53

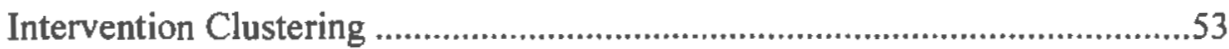

Do teachers tend to use interventions which are similar to each other along

various dimensions? ............................................................................53

Analogue Data Factor Scores .....................................................5.

Authentic Data Factor Scores .........................................................55

Efficacy and Prereferral Interventions ..................................................60

Is the Teacher Efficacy Scale reliable and valid? What is the relationship

between perceived efficacy and teacher variables? ...............................60

The Teacher Efficacy Scale ...........................................................60

Efficacy and Referrals to Special Education ........................62

Efficacy and Experience .................................................62

Efficacy and Teacher Type ..............................................62

Efficacy and Intervention Use and Effectiveness .......................................6.63

What is the relationship between teachers' expectations and internal efficacy perceptions and their selection of interventions and

effectiveness ratings? .....................................................................63

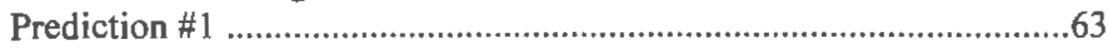

Analogue Data .............................................................63

Efficacy and Frequency of Intervention Selection ...........63

Efficacy and Effectiveness of Interventions ......................64 
Efficacy and Intervention Types .......................................65

Authentic Data.....................................................................68

Efficacy and Frequency of Intervention Selection.............68

Efficacy and Effectiveness of Interventions........................70

Prediction \#2 ................................................................ 70

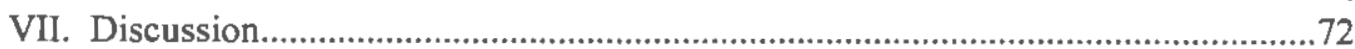

Analogue versus Authentic Findings...........................................................

Academic versus Behavioral Interventions....................................................72

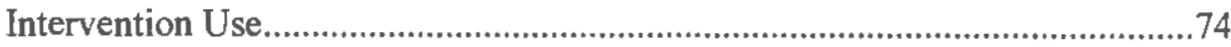

General versus Special Educators.................................................................75

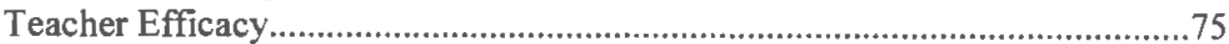

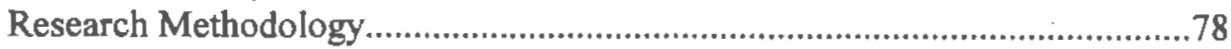

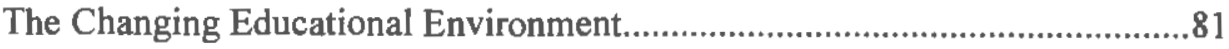

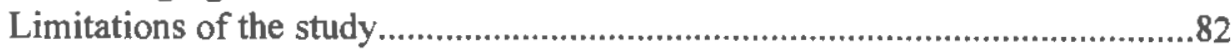

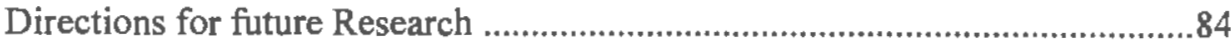

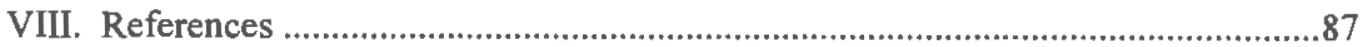

\section{APPENDICES}

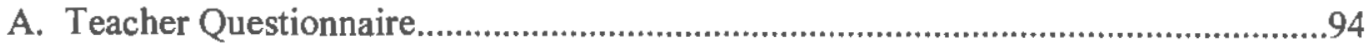

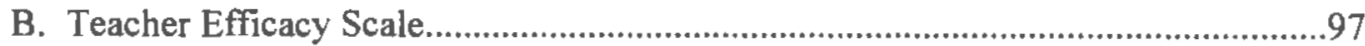

C. Classroom Alternatives Support Team Request Form-Elementary...........................99

D. Letter Granting Permission to Access Archival Records........................................101

E. Interrater Reliability Coding Scheme............................................................103

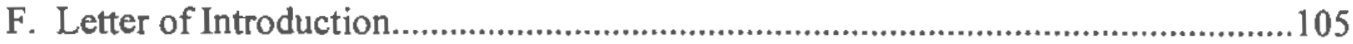

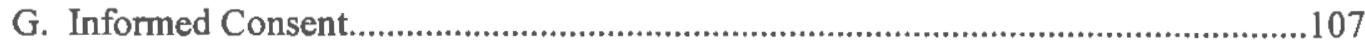

H. Approval from the Institutional Research Board on Human Subjects....................109

I. Study Information Form (Revised Consent)..........................................................112

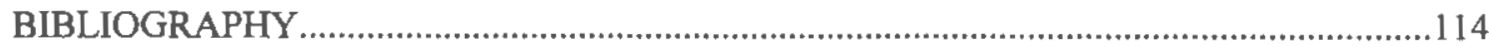




\section{LIST OF TABLES}

Table 1

PAGE

Correlations and Kappa Coefficients Estimating

Interrater Reliability for Each Intervention by Rater

Table 2

Observed Frequencies of Evaluation Choice FOR STUDENT A

Table 3

Frequency of Selection and Effectiveness

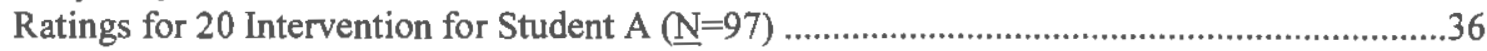

Table 4

Observed Frequencies of Evaluation Choice FOR STUDENT B .38

Table 5

Frequency of Selection and Effectiveness

Ratings by Intervention for Student B

Table 6

Comparison of Academic versus Behavior Referral

Effectiveness Ratings-Paired Sample t-tests

Table 7

Comparison of Analogue Academic Referral

Effectiveness Ratings for Special and General Educators .44

Table 8

Comparison of Analogue Behavioral Referral

Effectiveness Ratings for Special and General Educators

Table 9

Authentic Frequency and Effectiveness Ratings

for Academic Interventions $(\mathrm{N}=258$ ).

Table 10

Authentic Frequency and Effectiveness Ratings for Behavioral Interventions $(\mathrm{N}=82)$. .48

Table 11

$\chi^{2}$ Comparisons of Authentic and Analogue Intervention

Frequency Selection for Academic and Behavioral Referrals.

Table 12

Correlations among Authentic and Analogue Intervention

Effectiveness Ratings-Academic Referrals 
Table 13

Correlations among Authentic and Analogue Intervention

Effectiveness Ratings-Behavioral Referrals

Table 14

Factor Loadings, Communalities $\left(\mathrm{h}^{2}\right)$, Percents of Variance for Maximum

Likelihood Extractions and Varimax Rotation for Teachers' Ratings of

Intervention Effectiveness for Authentic Data ( $N=345)$ .56

Table 15

Factor Scores and Correlations-Analogue Data Effectiveness Ratings 58

Table 16

Frequencies of Analogue Intervention Type .58

Table 17

Frequencies of Authentic Intervention Type

Table 18

Factor Scores for Authentic Effectiveness Ratings 60

Table 19

Factor Loadings for the Teacher Efficacy Scale:

Current Findings Compared with Guskey \& Passaro (1994)

Table 20

Descriptive Statistics for the Teacher Efficacy Scale

Table 21

Correlations between Self-Efficacy Scores and Ratings of

Effectiveness of Interventions for Behavioral Referrals .66

Table 22

Partial Correlations Controlling for Years of Teaching

Experience for Academic versus Behavioral Referrals and

Internal and External Efficacy Scores

Table 23

Efficacy Split Scores

Table 24

Crosstabs of Intervention Type by Efficacy Type

Table 25

Descriptive Statistics for Teacher Variables by Intervention Type. 


\section{LIST OF FIGURES}

PAGE

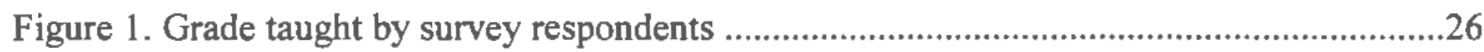

Figure 2. Effectiveness of interventions-analogue data ...............................................40

Figure 3. Effectiveness of interventions-analogue-academic referrals ...................................43

Figure 4. Effectiveness of interventions-analogue-behavior referrals ....................................43

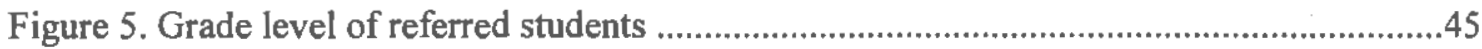

Figure 6. Frequency of intervention selection-authentic data ..............................................49

Figure 7. Effectiveness of interventions-authentic data .............................................51

Figure 8. Efficacy type and intervention preference-academic referrals ...............................69

Figure 9. Efficacy type and intervention preference-behavior referrals ...............................69 


\section{CHAPTER I}

Statement of the Problem

\section{Prereferral Intervention}

Since the 1975 passage of the Education for all Handicapped Children Act (PL 94-142), Individuals with Disabilities Education Act (IDEA, PL 101-476), and Section 504 of the Rehabilitation Act of 1973, schools are called upon increasingly to provide accommodations and interventions in regular education settings for all children, including those with disabilities. General classroom teachers, therefore, have become important in not only identifying at-risk children, but they have also become crucial in identifying and implementing appropriate educational adaptations and interventions for students with disabilities (Council for Exceptional Children, 1992).

Assessment and decision-making studies have repeatedly suggested that the teacher decision to refer a student for a leaming disabilities evaluation is highly predictive of future special education placement (Algozzine, Christenson, \& Ysseldyke, 1982; O’Reilly, Northcraft, \& Sabers, 1989; Ysseldyke, Thurlow, Graden, Wesson, Algozzine, \& Deno, 1983) and increasing numbers of students are being identified as educationally handicapped (Algozzine \& Korinck, 1985; Foster, Schmidt, \& Sabatino, 1976). In fact, over 2.2 million students during the 199192 school year were classified as learning disabled and provided with special education services as compared with almost 800,000 in the 1976-77 school year (U.S. Department of Education, 1992).

These findings, as well as the force of the mainstreaming movement, have been influential in the development of initiatives to develop prereferral intervention teams to screen those children for whom regular education modifications might increase educational efficacy. Prereferral intervention systems are thought, then, to hold real promise in unifying 
comprehensive service delivery approaches in the schools (Henning-Stout, Lucas, \& McCary, 1993; Gutkin \& Curtis, 1990; Gutkin, Henning-Stout, \& Piersel, 1988).

According to Ysseldyke, Pianta, Christenson, Wang, and Algozzine (1983), teachers usually contend that they decide to refer students for special education evaluations only after they have tried, perhaps unsuccessfully, a number of alternative interventions prior to referral. Additionally, with the increasing move toward an inclusive model of service delivery and special education's Regular Education Initiative (REI) (Will, 1988) within the public school system, some states (Hyman \& Kaplinski, 1994, State of Rhode Island, 1992) have, in fact, mandated that prereferral intervention teams be set up in the schools for the purpose of providing consultation regarding prereferral strategies to the referring teacher. Schrag and Henderson (1996) report that, by 1989, 23 State Departments of Education required some type of prereferral intervention and many more had recommended prereferral interventions. Given the call for school psychologists to become more closely involved with the process of consultation and team problem-solving within prereferral intervention teams (Hyman \& Kaplinski, 1994), it is increasingly important for consultants to discern the utilization rates and perceived efficacy of various types of intervention strategies utilized in service of this movement.

\section{Variables which Impact upon Intervention Selection}

Research in the arena of intervention development has produced an impressive body of behavioral change technology, yet studies reveal that teachers do not always use interventions that have been empirically validated. Rather, they may choose strategies that are familiar or convenient (Martens, Peterson, Witt, \& Cirone, 1986) or they may choose strategies based upon other reasons or variables. A literature is currently forming that examines the variables which influence teacher choice of intervention. It should be noted, however, that we still know little about the relationship between actual intervention use and how teachers feel about their ability 
to enact change. For example, it may be that a teacher's acceptability of change may be linked to personal feelings of self efficacy (de Mesquita \& Drake, 1994) given that teachers' sense of efficacy may be one of the best predictors of their willingness to adopt new educational practices and to stick with them (Berman, McLaughlin, Bass, Pauly, \& Zellman, 1977). Melby (1995), for example, found that teachers with a low sense of efficacy are mired in classroom problems and this efficacy presumably, partly, determines how academic activities are structured (Bandura, 1997a). It is unclear, however, the exact nature or strength of this relationship between self-efficacy and specific intervention use.

\section{Definition of Analogue Research Methodology}

Of the studies investigating intervention acceptability, utilization, and attitudes, many have been conducted employing an analogue or hypothetical, self-report approach (Elliott, 1988a). That is, the preponderance of literature has focused upon teacher surveys of, for example, acceptability (Elliott, Witt, Galvin, \& Peterson, 1984; Elliott, 1988b) and opinions utilizing analogue case history study (Algozzine, Ysseldyke, Christenson, \& Thurlow, 1983; Elliott, Turco, \& Gresham, 1987) or questionnaires unconnected to authentic situations. There exists a dearth of research examining authentic or real data in this area. Gresham and Lopez (1996) suggest that what we know about teachers' acceptability of treatments is primarily based upon hypothetical rather than their actual experience with treatment use. Researchers are now, increasingly, calling for some reconciliation between this analogue method of study and the examination of actual teacher experience (Waguespeck \& Moore, 1993).

\section{Research Goals}

The purpose of the current study, then, is to attempt such a reconciliation between analogue and authentic experience by determining the types of interventions teachers utilize prior to referring children for special education evaluations. In other words, are the interventions which teachers say that they would utilize prior to referral the kinds of 
interventions which they actually use prior to an evaluation? Is there comparability in terms of their decisions regarding the effectiveness of interventions chosen in real life and in an analogue situation? If analogue methodology is a valid form of inquiry, it would be expected that a carefully constructed comparative analysis of analogue versus authentic data would reveal comparable results. Additionally, questions are asked about the relationship between teachers' attitudes regarding their own efficacy and the effectiveness of a spectrum of these interventions utilizing archival as well as analogue data. 


\section{CHAPTER II}

Justification for and Significance of the Study

Need for Intervention Research

School psychologists report a pressing need for information in the arena of school-based interventions (McKee, Witt, Elliott, Pardue, \& Judycki, 1987). Information about the development of effective interventions for academic or behavior problems is considered to be crucial because school psychologists consider their training to have been inadequate in these areas. Additionally, presumably the role and responsibilities of our educational system are changing to accommodate previously excluded individuals with disabilities into the mainstream. The resultant milieu necessitates different strategies and adaptations in order to serve a variety of learners with a host of special needs.

\section{Changing Context of the Educational Environment}

As a consequence of the inclusion movement, teachers are now providing modifications in the classroom for students who have been diagnosed and require special education services. Teachers are also expected to formulate and execute intervention strategies in their classrooms before a referral is made for special education services. With or without the support of available consultative services from a Prereferral Intervention Team or from a qualified consultant, teachers may be finding this role increasingly taxing. In fact, there is evidence that regular classroom teachers often feel they lack the knowledge or skills to successfully educate exceptional leamers in their classes (Heron \& Harris, 1987; Knoff, 1985). These factors may help explain Martens and Witt's (1988) assertion that teachers prefer to refer.

\section{The Role of Self-Efficacy in Teaching}

We do know that self-efficacy is related to teaching performance. Saklofske, Michayluk, and Randhawa (1988) found, for example, that student teachers with a higher sense of efficacy do a better job in formulating lesson plans, encouraging student participation in class 
discussions, and managing their classrooms. While the relationship between the acceptability of educational reforms and corresponding efficacy beliefs has begun to be explored (de Mesquita \& Drake, 1994), few studies have examined the link between teachers' efficacy beliefs and specific intervention use. One of the purposes of the current study is to examine the relationship between intervention use and teachers' sense of self-efficacy.

\section{The Role of the School Psychologist}

Much of the prereferral intervention literature, which has emerged due to the aforementioned increasing demands on the time and repertoire of classroom teachers, addresses the problems of intervention choice (Ysseldyke, Pianta, et al., 1983) and, increasingly, acceptability and implementation of strategies (Witt \& Martens, 1983; Witt, Elliott, \& Martens, 1984; Witt, Martens, \& Elliott, 1984). Studies which have been designed to assess the efficacy of prereferral intervention teams have found that after engaging in consultation services teachers are significantly less likely to refer a student for a special education evaluation (Fuchs, Fuchs, \& Bahr, 1990).

Given the potential increasing need for supportive services for teachers, as well as school psychologists' desire to expand their roles in regular education and intervention design (Smith, 1984; Smith \& Lyon, 1985), the field of consultation has blossomed. Gutkin and Curtis (1990) have argued that we must shift our efforts in school psychology to develop a unified, comprehensive service delivery model to include a synthesis between consultative approaches and other existing service systems. The role of the school psychologist as consultant is important in the development of this model of service delivery (Gutkin \& Curtis, 1990; Zins, Kratochwill, \& Elliott, 1993).

According to Gutkin et al. (1988), the availability of consultative services has been found to result in more children being served by psychologists, a higher proportion of identified students obtaining educational objectives in their classroom, a lower proportion of referred 
children tested for special education services and, of those tested, a higher proportion of children found to be eligible for services. Reschly (1988) argues that the traditional assessment role of psychologists should be altered to accommodate assessment for the purpose of intervention rather than diagnosis alone.

\section{The Validity of Current Research Methods}

Although an increasing number of studies have examined the effectiveness of prereferral teams and the implementation of interventions in meeting the needs of at-risk learners in the least restrictive environment, much of the current research may be failing to address authentic issues in the classroom. As Sindelar, Griffin, Smith, and Watanabe (1992) state, future research on prereferral interventions investigating the use of actual traditional classroom interventions is needed to accompany research which focuses on the efficacy of laboratorybased interventions (Bahr, 1994). This call, for what is in essence a need for social validity in school psychology research may help to narrow the gap between the research literature and the daily practice of consultation (Gresham \& Lopez, 1996). We know from social psychology that people's attitudes and their behaviors are often quite different (Hughes, Grossman, \& Barker, 1990). Additionally, since much of the literature has focused on analogue research with the use of hypothetical case examples and interventions which teachers rate on the basis of usefulness or acceptability, the integration of this information along with data supporting the actual use of these interventions in the classroom is lacking.

The use of analogue assessment in research, and now increasingly in academic assessment (Gettinger, 1988), is one method of assessing beliefs, attitudes, and learning. Analogue assessment generally refers to a methodology in which a subject responds to stimuli which simulate those found in the natural environment. As Gettinger (1988) states, analogue assessment in academics provides a controlled situation in which behaviors of interest are likely to occur. Analogue approaches in assessment and research assume that the more similar 
to a natural event the analogue instrument and context are, the more valid such an approach. Also, an analogue approach will presumably have greater reliability the better able the analogue instrument approximates the findings in a naturalistic study. The exploration of validity and reliability of this analogue approach is another one of the major purposes of this study. 


\section{CHAPTER III \\ Review of the Literature \\ Introduction}

The primary variables of interest in the current investigation which have been examined in the literature include: teacher self-efficacy, intervention use and intervention effectiveness. In addition to a working definition of self-efficacy, current research approaches utilizing selfefficacy are outlined along with the current status of self-efficacy in educational research. The literature base on effective interventions is contextualized in terms of the use of and acceptability of interventions by individual teachers. The variables which contribute to and prohibit the use of interventions in the classroom are also considered. In the current study, interventions which are used are assumed to be at least partially acceptable to teachers. The literature, however is lacking in terms of examining extensively the role of actual use in the study of treatment acceptability. A limited literature concerned with the relationship between self-efficacy and intervention use is also presented.

\section{Teacher Self-Efficacy}

\section{Definition of Self-Efficacy}

Social leaming theory holds that behavior is determined by past experience which has been influenced by observational learning, association and reinforcement (Bandura, 1977). In a related social cognitive theory of behavior, Albert Bandura (1982) offered the concept of selfefficacy as a mechanism in human agency. Self-efficacy is defined as a perception concerned with judgments of how well one can execute courses of action required to deal with prospective situations. In other words, perceived self-efficacy is concerned with one's beliefs in one's capability to produce certain attainments (Bandura, 1997a).

Self-efficacy theory involves two complementary components: Outcome Expectancy and Efficacy Expectations. Outcome expectancy refers to the idea that, in general, certain 
behaviors lead to specific outcomes. One's belief about one's own competency to bring about a specific outcome is referred to as an Efficacy Expectation. Self-efficacy expectations, according to Benz, Bradley, Alderman, and Flowers (1992) also involve the nature of the task as well as "the amount of effort expended and the degree of persistence maintained in the face of difficulty" (p. 274).

Bandura (1997a) holds that individuals with a strong sense of personal efficacy tend to take a more active role in problem solving. Self-efficacy, in other words, mediates behavior. Bandura (1986) also believes that people develop a fairly stable conception of self-efficacy in different life domains. Self-efficacy, in this theory, refers to the expectations that we hold about abilities to accomplish certain tasks. Our likelihood of engaging in various activities depends on whether or not we believe we will be efficacious in those tasks. We tend to avoid activities and situations we believe exceed our coping capabilities, but we readily undertake activities and select social environments we judge ourselves capable of handling (Bandura, 1982).

Self-efficacy in dealing with the environment is seen as a generative capability in which component cognitive, social and behavioral skills must be organized into integrated courses of action to service many purposes rather than a fixed act (Bandura, 1982). Aptly, he writes, "A capability is only as good as its execution" (Bandura, 1982, p. 122). In relationship to education, Bandura (1997a) writes, “...in fact, the task of creating learning environments conducive to development of cognitive competencies rests heavily on the talents and selfefficacy of teachers" (p. 240). We understand, of course, that the development of these learning environments certainly involves integration of cognitive, social and behavioral skills for students as well as for teachers. For the purposes of the current study, the execution of this capability is formulated in terms of intervention choice in relationship to a number of factors including self-efficacy. 


\section{Current Research Approaches}

Current social psychological research conceptualizes self-efficacy as a variable-specific construct. One is thought to vary in terms of self-efficacy as a function of the behavior with which one is engaged. Perceived self-efficacy is in essence one's beliefs about one's capacities to implement actions for performance in a particular area and is important in mediating behavior change (Schunk, Hanson, \& Cox, 1987). Self-efficacy beliefs, then, are highly specific, control-related perceptions of one's ability to perform a particular behavior. They are not general feelings of control (Taylor, Peplau, \& Sears, 1997). If you want to know about someone's feelings of efficacy related to a given task or activity, you would want to survey variables related to that activity rather than to general feelings of effectiveness.

Self-efficacy has been studied in a variety of domains with respect to many performance issues and different subjects. Schunk (1985), for example, has developed a model of motivated classroom learning which outlines the relative effects of student characteristics including aptitude and experience. Findings suggest that expectancies such as efficacy and outcome expectancy relate to task engagement variables and efficacy cues. He writes that "students enter classroom activities with various aptitudes and prior experiences which affect their initial sense of self-efficacy for learning. During task engagement, students may assess self-efficacy by utilizing cues made cognitively salient by educational practices..." (p. 208).

Various self-efficacy measures have been developed for the study of self-efficacy in different domains. A Health Teaching Efficacy Scale, for example, was developed by Kingery, Holcomb, Jibaja-Rusth, Pruitt, and Buckner (1994) to measure health teachers' perceived ability to implement teaching strategies in the classroom. The measure, while reportedly unidimensional is both task specific as well as setting specific and is consistent with Bandura's recommendations for scale construction (Bandura, 1997b). A Computer Self-Efficacy Scale was developed by Murphy, Coover, and Owen (1989) to measure individual's perceptions of 
their computer-related knowledge and skills. This measure was utilized in a survey study of the relationship between university employees performance with computers and self-efficacy (Harrison, Raimer, Hochwarter, \& Thompson, 1997). Additionally, a self-efficacy measure of science teaching efficacy beliefs examines the relative effects of personal self-efficacy and outcome expectancy on instruction (Enochs, Scharmann, \& Riggs, 1995).

The concept of self-efficacy, furthermore, is believed to be a multidimensional construct. In other words, a person does not necessarily demonstrate one general level of self-efficacy across situations but may show varying attitudes about personal or environmental efficacy. Bandura (1997a) gives the hypothetical example of developing a measure of high-jump efficacy for athletes. Greater predictiveness will result from adding contextual conditions that aid or hinder performance to the measure. Thus, we might be able to develop a General Personal Athletic Efficacy Scale, for example, to be contrasted with, a General, Muddy Rainy-Day HighJump Efficacy Measure. Bandura clarifies that task demands are neither determinants nor decontextualized traits but "...rather, situational conditions are the performance requirements against which perceived efficacy is judged" (p. 43).

\section{Self-Efficacy in Education}

Because one's level of self-efficacy is thought to vary from situation to situation and to be made of outcome and efficacy expectations (Guskey \& Passaro, 1994), a multidimensional model of teacher efficacy was developed in the field of education by Ashton and Webb (1982) in order to explain the role of outcome expectation and efficacy expectations on specific situations encountered by the teacher. Their research suggests that teacher self-efficacy is distinguished by a personal versus teaching efficacy distinction. Gibson and Dembo (1984) developed a scale to measure teacher efficacy according to this bidimensional description. They operationalize teaching efficacy as the beliefs that teachers hold with respect to their ability to obtain certain learning outcomes. They found that teaching efficacy consists of two 
components: personal teaching efficacy and outcome expectancy. The former refers to the individual's confidence in their own teaching abilities while the latter refers to the belief that effective teaching can influence student learning,

More current study in this area, however, has found that the distinction may be more clearly described as an internal versus external self-efficacy dimension (Guskey \& Passaro, 1994). In this conceptualization, those with a greater sense of internal efficacy perceive positively and optimistically their personal influence, power and impact in teaching and leaming situations. Those with a greater sense of external efficacy are more likely to believe that influence, power, and the impact of elements that lie outside the classroom to be beyond the control of individual teachers (Guskey \& Passaro, 1994).

A recent study extends these findings to suggest that self-efficacy beliefs may be mediated by teacher age, experience and opportunities for collaboration and resources. In their study of newly hired public school teachers, Chester and Beaudin (1996) examined the efficacy beliefs of novice teachers and teachers who had previously taught and had experienced a career interruption or were moving from one school district to another. They were interested in changes in self-efficacy beliefs of individuals in these groups over the course of an academic year. They found that although no individual teacher or assignment characteristic was a significant predictor of change in efficacy beliefs, age and experience did contribute to predicting change in self-efficacy beliefs. Specifically, teachers who were older at the time of their hiring (older novices) showed increases in their self-efficacy beliefs over the course of the academic year studied. Self-efficacy beliefs, however, decreased for younger novices. Also, the self-efficacy beliefs of all experienced but newly hired teachers tended to decline over time. On the other hand, they found that greater opportunities for collaboration and greater supervisor attention were associated with positive changes in self-efficacy beliefs. 
Years of experience, however, has not been a reliable predictor of efficacy perceptions. Mixed results have been found in examining the relationship between teaching experience and measures of efficacy. In many cases, efficacy has been found to grow weaker with years of teaching experience (Broussard, Book, \& Byers, 1988; Dembo \& Gibson, 1985; Safran, 1985).

Others have found higher efficacy scores with increasing experience. Benz et al. (1992), for example, examined differences between measures of personal teaching efficacy among preprofessional and professional groups. They measured the efficacy beliefs of teachers at varying levels of experience: from entering secondary teacher-education students to faculty to supervising teachers. The authors report that, based on tentative patterns, classroom teachers have a lower sense of efficacy than entering students specifically in the areas of motivation and socialization. That is, young teachers are more likely to report feeling efficacious in helping students to develop positive interactions among each other and in motivating low-achieving students to greater academic achievement. More experienced groups, however, showed higher efficacy in the areas of planning and evaluation; they were more likely to feel efficacious in terms of incorporating achievement of basic skills objectives into their lesson plans, explaining the difference between grade equivalents and percentile rankings to others and developing evaluation procedures to accompany textbook and curricular objectives. The authors conclude that assessing efficacy beliefs of classroom teachers can provide data on their development which may provide some venue for heiping classroom teachers construct beliefs that will positively affect their decision making in the classroom.

A teacher's sense of self-efficacy has also been identified within the field of educational research as a potentially powerful variable in terms of instructional effectiveness. Hughes et al. (1990) examined the relationship between self-efficacy expectations for resolving classroom 
problems and teacher's participation in consultation. Their findings suggest that teachers with a greater sense of self efficacy are less likely to have positive expectations for consultation in resolving classroom problems and are less likely to report changing their behavior after engaging in consultation. This finding is consistent with the finding elsewhere that when faced with problems, teachers with high efficacy may be expected to invest their efforts at resolving problems directly (Chwalisz, Altmaier, \& Russell, 1992).

It may be the case that efficacy is influenced by teacher experience but the literature also suggests that the choice of efficacy domain measurement also may influence results as little consistency among studies is found with respect to measuring instruments. It may the case that other factors which covary with years of experience such as socialization (Dembo \& Gibson, 1985) may account for the variance in efficacy differences.

Saklofske, Michayluk and Randhawa (1988) proposed that teacher efficacy would be related to certain teaching behaviors. They studied the growth of 65 interns enrolled in a degree-seeking program in Education. In addition to measuring efficacy with the Gibson and Dembo (1984) Efficacy Scale, the authors also collected ratings of student-teachers by their supervisors on such categories of teaching behavior as: professional attributes, lesson planning, unit planning, structuring behaviors, questioning behaviors, reacting behaviors, classroom management behaviors and lesson-presenting behaviors. They found that Personal Teaching Efficacy but not Outcome Expectancy was related to lesson presenting behaviors, classroom management behaviors and questioning behaviors. Limitations of this study include the use of teacher interns who tended to show quite high efficacy perhaps because of their limited experience and the exceptionally high ratings of interns by supervisors. Given these limitations, the study's authors suggest that more work is needed in examining the relationship between efficacy and teachers' behaviors as well as students' learning. 
In an investigation of teacher efficacy and student problems as factors in special education referral, Soodak and Podell (1993) found that a teacher's sense of efficacy was related to decisions about the appropriateness of a student's placement in the regular education setting. Specifically, regular educators with a great sense of personal efficacy were more likely to judge that a regular education setting was appropriate for children with problems as compared with a special education placement. Teachers were less likely to view the regular education setting as an appropriate place for students with problems particularly when they felt that teaching, in general, cannot overcome external factors in the student's life. They did not find the same results for special educators. The authors also found that students with behavior problems were less likely to be referred than students with either learning problems alone or learning and behavior problems. The authors conclude that teachers' perceived effectiveness is important to decision making skills and referral decisions, in particular. It may be that a teacher's sense of control over a problem interacts with scores on self efficacy measures. Also, some have suggested that a teacher's belief regarding the stability of child factors may also influence teacher's behavior (Waguespeck \& Moore, 1993).

\section{Effective Interventions}

A prereferral intervention choice may be conceptualized in order to address the specific and idiosyncratic needs of an individual leamer, or to address the more systemic needs of a classroom or organization (Johnson, Stoner, \& Green, 1996). Margolis, Fish and Wepner (1990), for example, state that, "for mildly handicapped learners, dramatic instructional adjustments often prove unnecessary. Rather, conventional instructional strategies that simultaneously serve the needs of many students while readily conforming to the structure of practices of regular classrooms often suffice" (p. 168). In this section the literature addressing the use of effective interventions is explored. 
Some studies have concluded that classroom teachers are often resistant to the use of "effective" interventions, as identified by this literature, and opt for alternative strategies with which they are more familiar or that they perceive as more convenient (Martens, et al., 1986). Fuchs, Fuchs, and Bishop (1992) suggest that, in general, the degree of tension between routinized structure and instructional adaptation may be increasing due to the increasing diversity of the public school classroom, passage of PL 94-142, and the increasing numbers of students with disabilities in general education settings.

The amount of time available to the service provider and skills required for implementation of treatment alternatives are seen as important aspects of intervention choice. Clearly, interventions which are perceived to be less intrusive are more desirable for teachers. Teachers are also more likely to use more reward than punishment. When punishment is utilized, it is reported to be mild (Martens \& Witt, 1988). Martens and Witt (1988), in their analogue study of the role of consultation and interventions, found that interventions involving early re-direction and prompting are easy to use, used more frequently, and are more effective than alternative interventions.

Martens et al. (1986) discovered in their survey of teachers, that strategies most likely to be utilized in the classroom include verbal redirection, manipulation of material rewards, consultation with a specialist, removal from the classroom, and time out. Little information, however, has been obtained to determine the extent to which teachers actually make use of the wide range of intervention alternatives at their disposal. The variables which influence the use of interventions are complex and the research has just started to examine the use or acceptability of interventions among the important factors in teachers' decisions. Factors hypothesized to influence the choice of interventions include: parent and child factors, cost, time, the consequences of success and failure, organizational influences, severity of presenting 
problems, resources available to teacher, and effects of interventions on others (Conoley \& Gutkin, 1986).

Fuchs et al. (1992) propose that methodologies which have been used to study instructional adaptation (such as one-to-one study and laboratory studies utilizing volunteers) may be insufficient to study the process by which instructional adaptation actually occurs within naturally occurring classrooms. In general, however, their work suggests that teachers who are skilled in managing disturbing behavior may have a greater capacity for establishing their classroom routines to permit ongoing, routine adaptation. Additionally, they have found that organizational variables such as participative decision making may support instructional adaptation which, in turn, promotes student achievement (Fuchs, et al., 1992).

\section{$\underline{\text { Use of Interventions }}$}

\section{Acceptability}

A consideration of intervention utilization must also be accompanied by a consideration of the acceptability of a diversity of interventions. For example, Sevick and Ysseldyke (1986) state that teachers rated interventions as highly desirable that would provide more information on the student, were teacher-directed and involved contingency management. They rated lowest the interventions involving tutoring, retention, and placement in another classroom.

Witt et al. (1984), in a study of the acceptability of behavioral interventions, found that the amount of time involved in implementing a behavioral intervention significantly affected the teachers' judgments of intervention acceptability. In other words, teachers rated interventions which required less teacher time as more acceptable (when the intervention was intended to increase positive student behaviors) than interventions requiring greater teacher time and planning. This study, like many studies involving treatment acceptability, utilized an analogue design to examine the relationship between teachers' judgments regarding the acceptability of interventions and the amount of time involved in the implementation of the intervention. Other 
independent variables considered in this study included: the type of intervention, whether the focus of the intervention was targeted at reducing or increasing target behaviors, and the severity of the behavioral problem.

In a later thesis, Witt (1986) suggests that most of the intervention technology which has been developed for the classroom has been underutilized. He states that despite an "arsenal" of management techniques, these interventions are not frequently considered for use by teachers. The research literature has focused on measuring the effectiveness of interventions but have failed to consider the usefulness of these interventions. Witt, Martens et al. (1984), therefore, calls for the development of interventions which have external validity. He suggests that research must address the reasons why teachers have failed to utilize intervention research findings in the classroom. We have a scientific research base outlining effective interventions and have developed sophisticated methods of measuring effectiveness. Witt (1986) rightly states, however, that we need to set as our goal “...to develop interventions that are selected by harried classroom teachers, that are then implemented as they were designed, and that are minimally intrusive while restoring the system to ecological validity" (p. 42).

\section{Contextual Variables}

Martens, Witt, Elliott and Darveaux (1985) found, in a study of teachers' judgments concerning the acceptability of school-based interventions, that an intervention requiring more time was rated as more acceptable than one requiring less time, in contrast to previous research. In other words, interventions requiring moderate amounts of time to implement were rated as more acceptable than less time-consuming alternatives. It should be noted that, in their study, the less time-consuming intervention consisted of an action implemented by someone other that the teacher (sending the child to the office) and may have been considered to be an indirect intervention. The more time-consuming intervention (response-cost procedure) was, conversely, a procedure implemented directly by the teacher. They infer that teachers are 
saying that direct teacher intervention is more acceptable than indirect intervention, even if more time is needed. Also, teachers rated interventions as more acceptable when applied to behavior problems of greater severity. They suggest that school-based consultants need to take into consideration teacher perceptions of intervention acceptability so they can suggest interventions which have a high probability of being implemented.

\section{Efficacy and Intervention Selection}

In terms of the relationship between use of interventions and self-efficacy, Melby (1995) found that teachers who choose to use more restrictive and punitive modes of discipline tend to report a lower sense of personal self-efficacy. They also focus more on subject matter than students ${ }^{2}$ development, distrust their ability to manage their classrooms and are stressed and angered by student's misbehavior than are those teacher's with a greater sense of self-efficacy. Elsewhere it is suggested that, teachers who utilize techniques such as cooperative learning in the classroom are more likely to report higher levels of self-efficacy (Guskey, 1988)

In a study conducted by de Mesquita and Drake (1994), teachers' attitudes about education reform were examined in relationship to their self-efficacy beliefs in a school system in which mandated educational reforms were being implemented. Results suggested that efficacy was related to attitudes toward innovative reform practices. The sample of teachers surveyed in this study demonstrated moderately positive beliefs about personal and teaching efficacy. They also felt capable of implementing most aspects of mandated reforms. These mandated reforms involved the need for collaborating with colleagues and support staff, effectively communicating between home and school, and applying developmentally appropriate instructional practices. Results also suggested that they felt less efficacious with respect to implementing performance assessment and heterogeneous instructional groupings associated with nongradedness. 


\section{Consultation and Intervention Use}

As Conoley and Gutkin (1986) suggest, consultants provide indirect services to consultees. In the case of the school psychologist providing consultant services to a teacher, it is important not only to know which interventions are effective when and for whom, but it is equally important to decipher the acceptability of interventions. As they write, "after all, a potentially effective treatment that is not implemented by a classroom teacher is no treatment at all" ( $p$. 416). In this statement, they imply that acceptability of intervention is closely linked to the concept of intervention use, a major variable in the current study.

Witt, Elliott, et al. (1984) conclude that psychologists should take into consideration teacher concerns regarding intervention acceptability when working toward consultation goals rather than to rely solely upon a more empirically-based approach to recommending the "best" or seemingly most effective of interventions. They make an assumption, however, in their remarks that the literature concerned with behavioral interventions somehow is able to offer particularly potent interventions which, regardless of contextual variables, are reliably effective if properly implemented. They raise an interesting question, however, regarding the psychologist's role in consultation regarding behavioral interventions. Should we focus upon changing teacher's beliefs around what is acceptable or would we be better served to select or modify strategies that are optimally acceptable to teachers? It is hoped that the cumulative results of the present study and others like it will enable the researcher to better answer this question in consultation with a school department which desires to create an optimally effective prereferral intervention program.

Lambert (1976), in a study of the relationship between children's problems and classroom interventions from the perspective of classroom teachers, found that teachers are just as likely to view other-initiated interventions as acceptable as in-class interventions for children with a wide variety of student problems. In this study, psychologists serving as consultants with 47 
teachers gathered information about both children's problems and classroom intervention choice via a semi-structured interview and consultant rating of a variety of teacher variables such as teachers' instructional style, individualization of instruction and use of pupil information in planning and conducting the program. Children's problems were defined by teachers during interviews with the consultant. Problems were then grouped into logical categories. The categories described either extrinsic (those that required assistance within the school setting that the teacher could not provide as a part of the regularly planned program) or intrinsic interventions (those that could be instituted in the classroom program). In addition to the finding that classroom teachers are just as likely to expect that extrinsic interventions would be as appropriate as intrinsic interventions for a variety of student problems, the author also concludes that teachers conceptualize fewer rather than multiple alternative interventions to student problems. This study, however, demonstrates several methodological problems ranging from a failure to implement an interrater reliability scheme for the categorization of interventions and children's presenting problems to conclusions which assume facts not clearly presented. For example, the author concluded that classroom teachers lack precision of pupil problem identification post hoc while presenting a rather vague and imprecise taxonomy of problem identification.

On the other hand, Algozzine et al.(1983), in a study of teacher's preferences, found that, from a list of 40 interventions, teachers preferred interventions that were directly implemented by the teacher rather than consultation, outside placement, or grade retention. Four factors emerged in intervention-type. They included interventions that were: 1) teacher-directed interventions, 2) consultative interventions, 3) external, placement-oriented interventions, and 4) nonteacher-directed interventions. The authors suggest that the emergence of these factors may suggest teacher characteristics which guide preference for interventions. They state that, "based on their preferences for some intervention choices, it may be that some teachers are 
teacher-directed, some consultative-oriented, others placement-oriented, and still others oriented toward teacher noninvolvement" (p.196). They say that additional research would be necessary in order to understand the potential educational implications of this hypothesis. In order to explore this hypothesis of Algozzine et al. (1983), a factor analysis of interventions in this study will be conducted in order to determine if the same or similar factors emerge from the list of potential interventions conducted by classroom teachers. This analysis may help to provide further support for a teacher preference type for interventions as they currently exist in this study in the public school system. 


\section{CHAPTER IV}

Research Questions

Given the information presented regarding teacher self-efficacy, treatment use and effectiveness, and in light of the dearth of integrative analogue and actual data, the following research questions are suggested:

1) What is the nature of intervention selection and teachers' beliefs about the effectiveness of those interventions?

2) What is the relationship between analogue and authentic data? To be more specific, are selected interventions rated similarly effective for analogue and authentic data? Will real life mirror the hypothetical?

3) Do teachers tend to use interventions which are similar to one another along various dimensions (i.e., active/passive or instructional/noninstructional)?

4) Is the Teacher Efficacy Scale reliable and valid? What is the relationship between perceived efficacy perceptions and teacher variables?

5) What is the relationship between teachers' external and internal self-efficacy perceptions, and their selection of interventions and effectiveness ratings? For example, given the theoretical context of this question it is predicted that:

Prediction \#1:

The degree of internal self-efficacy will be positively related to the number of interventions chosen and ratings of intervention effectiveness.

Prediction \#2:

The degree of external self-efficacy will be positively related to the selection of a greater number of passive/noninstructional versus active/instructional interventions, if interventions cluster together (as in research question \#3 above). 


\section{Chapter V}

\section{METHOD}

The School System

The public school system participating in this study is a non profit municipal agency which serves the educational needs of approximately 12,000 students in grades Kindergarten through 12 th grade. This suburban community consists of an economically diverse student population with a variety of ethnic groups served.

\section{Subjects}

The subjects consisted of 97 elementary school teachers who responded to a Teacher Questionnaire (Appendix A) and Teacher Efficacy Scale (Appendix B). The 97 survey respondents ranged in age from 23 to 62 years of age $(\underline{\mathrm{M}}=42.01, \underline{\mathrm{S}}=9.51)$ with from 1 to 33 years of teaching experience $(\underline{M}=14.51, \underline{S D}=8.48)$. As might be expected for the population of elementary school teachers, $91.8 \%$ of subjects completing questionnaires were female. Figure 1 indicates the frequencies of grade level taught by survey participants. The greatest number of respondents were 1st grade teachers with a total of $26.8 \%$ of respondents teaching either 1 st or 2nd grade.

Special education teachers $(\underline{n}=17)$ as well as regular education teachers $(\underline{n}=80)$ were represented in the sample. While no differences were found between regular and special education teachers in terms of their average ages, differences in years of experience between regular and special education teachers were found, $t(95)=2.41, \mathrm{D}^{<.05}$. Regular education teachers $(\underline{M}=15.44, \underline{S D}=8.42)$ in this sample were somewhat more experienced than special education teachers $(\underline{M}=10.12, \underline{S D}=7.5)$. 
Forty-eight percent of respondents indicated that they participate in a prereferral intervention team such as the Classroom Altematives Process/Classroom Alternatives Support Team (CAP/CAST) mandated by the State Department of Education. Forty-nine percent of respondents do not participate in a CAP/CAST service. Of participating individuals, the average length of participation is 3 years, 6 months with a standard deviation of 2 years, 1 month and a range of from 1 month of participation to 7 years of participation. Thirty-three percent of the entire sample indicated that they have had some type of specific training in the development and use of prereferral interventions strategies via workshops, conferences or inservices, whereas $31 \%$ indicated that they had had no training. More than one-third of participants (36\%) did not respond to this question. Fifty-nine percent of responding teachers indicated that, in general, they do not find the CAP/CAST process to be helpful.

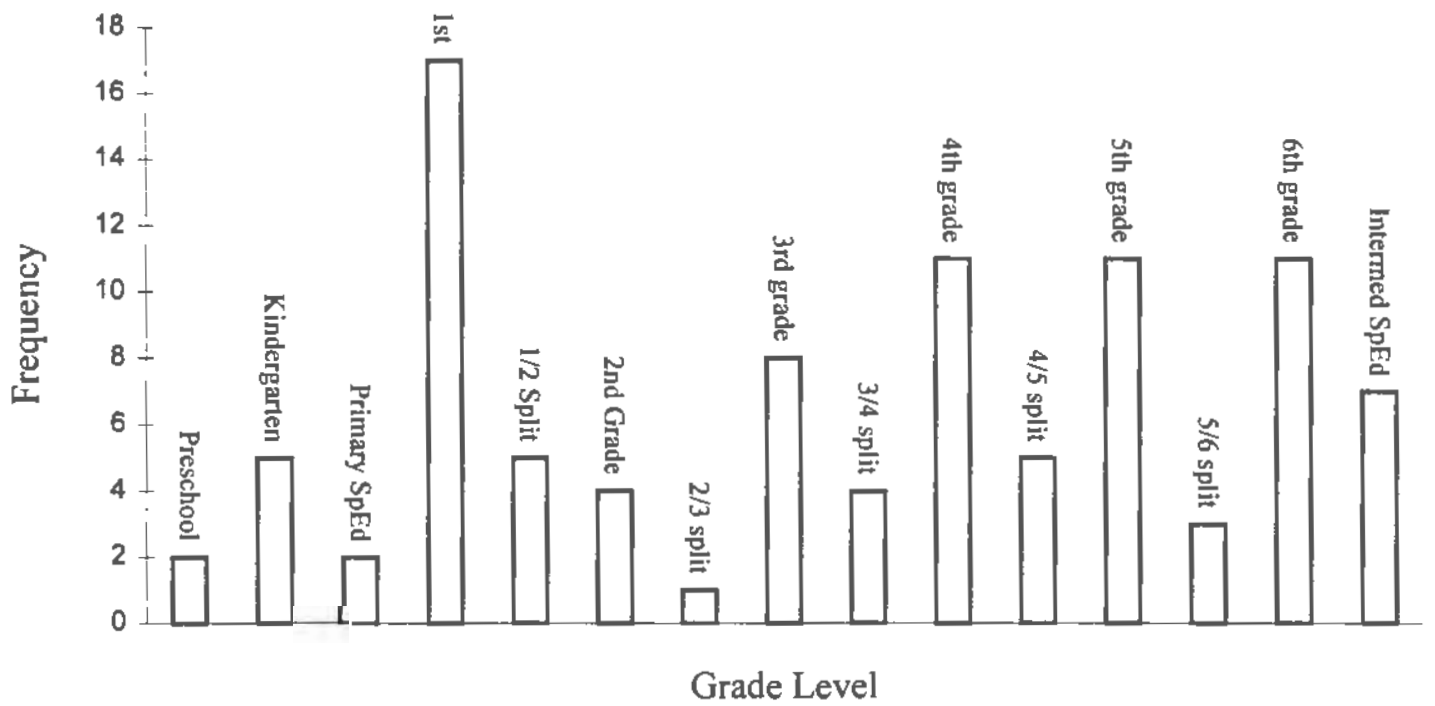

Figure 1. Grade taught by survey respondents 


\section{Measures}

\section{Classroom Alternatives Support Team Request Form (CASTRF)}

For each student in this public school system who has been referred for a multidisciplinary team or special education evaluation, school policy requires report of pre-referral interventions attempted by the referring teacher. This CASTRF form (Appendix C), created by the school system in order to document these prereferral intervention actions, is archived for each student who has been referred and is housed at the school system's administration building within the special services offices. This form requires the referring teacher to document the reason for referral and a statement about the problems the student is experiencing. The teacher also indicates the prereferral intervention strategies which have been utilized, and the results or effectiveness of those intervention(s). Information from the CASTRF document serves as the basis for the "real" or authentic data for this study.

\section{$\underline{\text { Records Review }}$}

Archival data accompanying the CASTRF form from student files were collected in order to provide information regarding demographic variables. The following information was collected by means of a review of the child's confidential special education folder: student's grade level, student age, Verbal, Performance and Full Scale IQ scores and reason for referral (academic or behavior).

\section{$\underline{\text { Teacher Questionnaire }}$}

A Teacher Questionnaire survey (Appendix A) created to mirror the CASTRF was designed for the purposes of this study. As research has strongly indicated the need for the development of prereferral programs addressing the academic difficulties and social problem behaviors of students (Bahr, 1994), each survey contains both an academic problem and a 
behavior problem in the form of an analogue or case example. The case examples were originally formulated after the preliminary review by the principal investigator of archival CASTRF forms. The archival data were examined for types of problems for which students had been referred and accompanying descriptions of concomitant student behavior. These hypothetical case examples were then submitted to and examined by two school psychologists in the public school system to determine face validity. After feedback was considered, revisions were made to the case examples.

In order to ensure comparability of authentic (CASTRF) to analogue (Teacher Questionnaire) data, teachers completing the questionnaire were required to indicate, in the case of both an academic referral and a behavioral referral, if they had ever made an actual referral for the type of problem in the hypothetical example and for which type of evaluation. This question served as a way to ensure the comparability of referral type when matched with authentic data.

Additionally, the questionnaire contains sections in which the teacher is asked to choose the interventions which would be selected for the presenting problems. They are also asked to rate, on a 1-5 point Likert-type scale, for each intervention chosen, the likely effectiveness of each intervention. This section, created to mirror the CASTRF form provides the basis for the subsequent comparability of intervention use and effectiveness when compared to authentic data.

\section{Teacher Efficacy Scale-TES (Guskey \& Passaro, 1994)}

The Teacher Efficacy Scale (TES) is a 21-item self-report scale which is designed to assess teachers' sense of personal and teaching efficacy (Appendix B). The scale consists of a number of first-person declarative statements as well as general statements designed to tap opinions about teacher efficacy. Responses to each item are made along a 6-point Likert-type 
scale from 1 "strongly disagree" to 6 "strongly agree." The authors hold that the scale, which was originally adapted from a teacher efficacy measure designed by Gibson and Dembo (1984) and Woolfolk and Hoy (1990), reflects teacher efficacy as a multidimensional construct. The scale presumably consists of two relatively independent efficacy dimensions: internal versus extemal, much like the concept of locus of control (Rotter, 1966). As Bandura (1997a) states, this multiple item, bidimensional approach is a vast improvement over previous approaches to measurement and reduces problems of reliability, restricted variability of scores and validity. It should be noted, also, that specific efficacy measures tend to be generally better predictors across activities than either omnibus or more circumscribed locus of control measures or measures of perceived personal control (Bandura, 1997a).

According to the authors, the internal factor appears to represent perceptions of personal influence, power and impact in teaching and leaming situations which are positive and optimistic. The extemal factor, on the other hand, relates to perceptions of the influence, power, and impact of elements that lie outside the classroom and beyond the direct control of individual teachers. These extemal and intemal factors are described by the authors as somewhat related but appear to operate independently. The following items from the Teacher Efficacy Scale are considered to measure internal efficacy: Items $1,7,8,11,12,14,15,16,18$, and 19. The following items are considered to measure external efficacy: Items $2,3,4,5,6,9$, $10,13,17,20$, and 21 .

The measure, which was developed with a pool of 342 experienced $(\mathrm{K}-12)$ and preservice teachers in rural and suburban school districts, was chosen for its value in contributing information about teachers' beliefs about their own self-efficacy in using interventions. Reliability and validity information, however, is absent with respect to this potentially very useful measure. The authors do not address the issues of reliability or validity in their 
published study and unfortunately, to date, no reliability or validity studies have been published utilizing this measure.

Procedure

\section{Authentic Data Collection}

Authentic data, in the form of the CASTRF form and record review, were collected from the archival records at the Special Services Administration Office. Approval from the Director of Special Education of the School Department was obtained via letter (Appendix D). It should be noted that archival data for each referred student used in the current study were collected over the past several years, in response to the State Department of Education's mandate for the implementation of prereferral intervention procedures in this school system. At the building level, information regarding each student referred was systematically collected via the CASTRF from each teacher prior to a referral for a special education evaluation and subsequently forwarded to the administration offices. These data were provided by teachers involved in elementary referrals for multidisciplinary evaluations of suspected problems across a variety of academic and behavioral domains. Students were either already diagnosed with one of the various handicapping conditions defined by PL 94-142 and data were collected as a part of a three-year re-evaluation or were newly referred due to concerns regarding the presence of a handicapping condition.

A random sample of 240 CASTRF forms, selected anonymously without any identifying student information, was collected initially from the archival file cabinets at the administration building. CASTRF forms not indicating either an academic or behavioral reason (e.g., speech, occupational therapy only) for referral were not collected. The CASTRF form, which contained the referring teacher's name, was then coded according to the code list created at the mailing of the original survey, and the teacher's name was then removed completely from the 
CASTRF form. Upon inspection of this sample, only a small number contained identification codes on CASTRF forms that could also be matched to the teacher's identification code from the survey information. From this point on, 105 additional CASTRF forms were collected for use only from those teachers who had returned surveys. This was done in order that many more of the 97 surveys would match with at least one or more CASTRF forms. In total, 345 CASTRF forms were collected. Of these forms collected, 87 (25\%) were referred for behavioral problems and $258(75 \%)$ were referred for academic problems. Only 73 matches between one survey and one academic CASTRF form were found while only approximately 32 matches between one survey and one behavior CASTRF form were found.

Archival data accompanying the CASTRF form from student files were collected in order to provide information regarding demographic variables.

\section{Interrater Reliability}

Information regarding the perceived effectiveness of applied interventions is of particular interest for the purposes of this study. The CASTRF form provides the basis for evaluating intervention effectiveness for authentic data. The CASTRF form, which has been collected for several years by the school system, requires teachers to comment regarding the results or effectiveness of each of the interventions they have chosen prior to a referral for a special education evaluation. Review of the archival forms, however, indicated that teachers most frequently use qualitative descriptions of the effectiveness of the interventions which they have chosen. This situation necessitated the development of a coding system in order to assign quantitative ratings to their observations in order to provide quantitative comparability for the purposes of statistical analyses.

A coding scheme was developed (Appendix E) in order to rate teachers' comments regarding the effectiveness of chosen interventions. A 5 point Likert-type Scale ("1," Not 
Effective to "5," Very Effective) was utilized in order to ensure comparability to the Teacher Questionnaire ratings. Three raters ( 2 school psychologists and one college student) were then trained in the coding scheme. Cone and Foster (1993) recommend that 20-25\% of data be reviewed for the purposes of interrater reliability reports. Therefore, each rater applied the coding scheme to the same random sample of 48 CASTRF forms. Pearson product correlation coefficients ranged from .989 to .670 . Kappa coefficients ${ }^{1}$ ranged from .878 to .767 . All comparisons were statistically significant at the $\mathrm{p}<.001$ level. Table 1 contains Pearson's $\underline{\text { s }}$ and kappa coefficients for the interrater observation comparisons.

\section{Analogue Data Collection}

A coded Teacher Questionnaire survey (Appendix A) and Teacher Efficacy Scale (Appendix B) were distributed to all elementary school teachers $(\underline{N}=326)$ in the school system. Participation was requested via a letter of introduction (See Appendix F) and was specified as voluntary. In order to minimize social evaluative concerns, the questionnaire was coded, labeled with a nondescript title, and, presumably completed in private (Bandura, 1997a). Consent to participate, at the initial mailing, was obtained via a signed informed consent form (Appendix G). Two copies of the noncoded consent form were distributed to each participant. One was returned to the researcher; the other was to be for the participant's records. In order to assure confidentiality, consent forms were separated immediately upon receipt from surveys and before data analysis.

\footnotetext{
' While Pearson's I provides a measure of the strength of relationship between two ratings, it does not provide information regarding the percentage of agreement between two raters. Cone and Foster (1993) recommend that a kappa coefficient, designed to correct for chance agreement be reported for interrater observations. Cohen's kappa (Cohen, 1960) provides a measure of the difference between the observed proportion of cases in which raters agree and that expected by chance by "normalizing" by taking into consideration the maximum difference possible for total observations. The null hypothesis in this case would state that "there is no difference between the observed proportion of cases in which raters agree and chance." Significant variation from this at the $\underline{p}<.001$ would indicate good interrater reliability.
} 
Table 1

Correlations and Kappa Coefficients Estimating Interrater Reliability of Each Intervention by Rater

\begin{tabular}{|c|c|c|c|c|c|c|c|c|c|}
\hline \multicolumn{10}{|c|}{ Intervention } \\
\hline & 1 & \multicolumn{2}{|l|}{2} & \multicolumn{2}{|c|}{3} & \multicolumn{2}{|l|}{4} & \multicolumn{2}{|l|}{5} \\
\hline Rater: & 12 & 12 & 2 & \multicolumn{2}{|c|}{ I 2} & & 2 & 1 & 2 \\
\hline \multirow[t]{2}{*}{2} & \multirow{2}{*}{$\begin{array}{l}.927^{\mathrm{a}} \\
.871^{\mathrm{b}}\end{array}$} & \multicolumn{2}{|c|}{.950} & .991 & . & \multicolumn{2}{|c|}{999} & \multicolumn{2}{|c|}{.887} \\
\hline & & \multicolumn{2}{|l|}{.903} & \multicolumn{2}{|l|}{.891} & \multicolumn{2}{|l|}{.950} & & \\
\hline \multirow[t]{3}{*}{3} & \multirow{2}{*}{$\begin{array}{ll}.996^{\mathrm{a}} & .925 \\
.842^{\mathrm{b}} & .817\end{array}$} & \multirow{2}{*}{$\begin{array}{l}.947 \\
.805\end{array}$} & \multirow{2}{*}{.901} & \multirow{2}{*}{\multicolumn{2}{|c|}{$\begin{array}{ll}.989 & .993 \\
.780 & .671\end{array}$}} & \multirow[t]{2}{*}{.999} & \multirow[t]{2}{*}{.999} & \multirow{2}{*}{\multicolumn{2}{|c|}{$.890 \quad .968$}} \\
\hline & & & & & & & & & \\
\hline & 6 & \multicolumn{2}{|l|}{7} & \multicolumn{2}{|l|}{8} & \multicolumn{2}{|l|}{9} & \multicolumn{2}{|l|}{10} \\
\hline Rater: & 12 & 1 & 2 & 1 & 2 & 1 & 2 & 1 & 2 \\
\hline \multirow[t]{2}{*}{2} & \multirow{2}{*}{$\begin{array}{l}.796^{\mathrm{a}} \\
.841^{\mathrm{b}}\end{array}$} & \multirow{2}{*}{\multicolumn{2}{|c|}{$\begin{array}{l}1.00 \\
1.00\end{array}$}} & .997 & & .948 & & .953 & \\
\hline & & & & .785 & & .969 & & .862 & \\
\hline 3 & $.894^{\mathrm{a}} \quad .894$ & .999 & .999 & .997 & .998 & .953 & .999 & .948 & .992 \\
\hline & & .820 & .891 & .969 & .938 & .863 & & & \\
\hline & 11 & 12 & & 13 & & 14 & & 15 & \\
\hline Rater: & 12 & 1 & 2 & 1 & 2 & 1 & 2 & 1 & 2 \\
\hline 2 & $.946^{\mathrm{a}}$ & .966 & & .939 & & .915 & & .999 & \\
\hline & .867 & & .880 & & .933 & & .939 & & \\
\hline 3 & $.959^{*} \quad .998$ & .994 & .959 & .988 & .946 & 1.00 & .915 & .998 & .999 \\
\hline & $.878^{b} .842$ & .840 & .881 & .881 & 1.00 & .933 & .908 & .969 & \\
\hline & 16 & 17 & & 18 & & 19 & & 20 & \\
\hline Rater: & 12 & 1 & 2 & 1 & 2 & 1 & 2 & $i$ & 2 \\
\hline 2 & $.690^{\mathrm{a}}$ & .694 & & .902 & & .969 & & 1.00 & \\
\hline & $.744^{b}$ & .680 & & & & .901 & & 1.00 & \\
\hline 3 & $.941^{2} .646$ & .867 & .725 & .996 & .898 & .921 & .878 & 1.00 & 1.00 \\
\hline & $.860^{b} .748$ & .781 & .678 & & .744 & .831 & .760 & 1.00 & 1.00 \\
\hline
\end{tabular}

$\underline{n}=48$ observations per cell

all comparisons are significant at the $\mathrm{p}<.001$ level

${ }^{\text {aP }}$ Pearson I (first entry for all columns)

${ }^{b}$ Cohen's kappa coefficient (second entry for all columns) 
After an initial mailing of the survey to the teachers' mailboxes at each elementary school, only 53 questionnaires had been retumed for a return rate of $16.3 \%$. Subsequent feedback from faculty indicated a reluctance on the part of some individuals to provide sensitive information regarding their use of interventions and feelings along with their signatures given some past perceived difficulty with the school system administration. A revised proposal, therefore, was submitted by the principal investigator to the Institutional Review Board on Human Subjects at the University in order to gain permission to resample the teachers with a revised informed consent form that would not require a signature. Permission was granted (Appendix $\mathrm{H}$ ) and the coded questionnaire was sent again to teachers with a new informed consent form that did not require a signature (Appendix I). A final return rate of $29.8 \%$ was obtained with a total of 97 questionnaires which has constituted the analogue data for the current study. 


\section{CHAPTER VI}

RESULTS

Intervention Selection and Effectiveness:

WHAT IS THE NATURE OF INTERVENTION SELECTION AND TEACHERS' BELIEFS ABOUT THE EFFECTIVENESS OF THOSE INTERVENTIONS?

\section{Analogue Data}

\section{Academic Problem}

Participants were asked to read an Analogue case example of Student A, a youngster with an academic-type problem, and then to answer a series of questions related to this case. Eightyseven percent $(87 \%)$ of respondents reported that they had referred a child like the one in the example sometime in the past. For all survey participants, $86 \%$ of respondents would have referred the child for an academic evaluation only, while the remaining $13 \%$ reported they would refer for an academic evaluation as well as at least one other type of evaluation (i.e., speech/language, occupational therapy). No teacher indicated that "No Evaluation" would be an acceptable option for Student A. No significant differences were noted between teachers who had ever referred a child in the past for an evaluation (referring teachers) and teachers who had not referred a child in the past for an academic problem (non-referring teachers) with respect to the type of evaluation that would be recommended as evaluated in a $2 \times 2$ Chi Square analysis, $\chi^{2}(1, \underline{n}=95)=2.52, \underline{p}=.112$. Table 2 indicates the observed frequencies of evaluation

Table 2

\section{Observed Frequencies of Evaluation Choice FOR STUDENT A}

\begin{tabular}{lllll}
\hline & Acadernic & Combination & Missing & Total \\
\hline Referring Teacher & 75 & 10 & 1 & 85 \\
Nonreferring Teacher & 7 & 3 & & 11 \\
Missing & 1 & & 1 & 1 \\
Totals & 83 & 13 & & 97 \\
\hline
\end{tabular}


choice with respect to referring and non-referring teachers. It should be noted that missing data were excluded for the purposes of this evaluation.

Respondents were asked to select, from a list of possible interventions, those which would be selected for use with Student A. Table 3 contains the frequency of choice of each of 20 interventions expressed as a percentage. The four most frequently chosen interventions for this type of problem were "Parent Conference" (88.7\%), "Have Student Restate Directions" $(85.6 \%)$, "Change in Seating" $(84.5 \%)$, and "Consult Specialists" $(81.4 \%)$. The three least frequently chosen interventions were "Other" (4.1\%), "Keep After School" (12.4\%) and "Change Text or Materials" (32.0\%). Of the participants who chose "Other" as an intervention

\section{Table 3}

Frequency of Selection and Effectiveness Ratings for 20 Interventions for Student $\mathrm{A}(\mathrm{N}=97$ )

\begin{tabular}{lccr}
\hline Intervention & Frequency of Use & \multicolumn{2}{c}{ Effectiveness $^{2}$} \\
\hline 1. Change in Seating & 84.5 & 2.91 & .96 \\
2. Change in Groups & 56.7 & 2.81 & 1.03 \\
3. Have Student Restate Directions & 85.6 & 3.56 & 1.04 \\
4. Oral vs. Written Tests/Reports & 36.1 & 3.22 & .83 \\
5. One-to-One Instruction & 75.3 & 4.15 & .93 \\
6. After School Help & 40.2 & 3.45 & .89 \\
7. Tutoring & 34.0 & 3.09 & .70 \\
8. Use of Organizational Charts & 74.2 & 3.58 & .98 \\
9. Reduction of Work Assignments & 52.6 & 3.59 & .94 \\
10. Modify Worksheet/Assignments & 76.3 & 3.90 & .89 \\
11. Keep After School & 12.4 & 2.09 & .94 \\
12. Reward System & 38.1 & 3.15 & .96 \\
13. Modify Materials/Presentation & 71.1 & 3.82 & .88 \\
14. Change Text/Materials & 32.0 & 3.60 & .84 \\
15. Student Conference & 64.9 & 3.04 & .89 \\
16. Call/Note Parents & 75.3 & 3.24 & 1.00 \\
17. Parent Conference & 88.7 & 3.36 & .92 \\
18. Consult Specialists & 81.4 & 3.43 & .96 \\
19. Behavior Management & 38.1 & 3.64 & .90 \\
20. Other & 4.1 & 3.00 & .00 \\
& & & \\
\hline
\end{tabular}

\footnotetext{
${ }^{1}$ Percentage of teachers choosing this intervention

${ }^{2}$ Mean/Standard Deviation
} 
choice and indicated the type of intervention, "Teach Study Skills" and "Testing for Proper Placement" were noted.

Effectiveness ratings for interventions are also reported in Table 3. Many of the interventions selected received ratings of "3" or greater on a Likert Scale from 1 (Not Effective) to 5 (Very Effective). It appears as if interventions chosen are rated as at least somewhat effective, in many cases. The most effective interventions are reported to be "Oneto-One Instruction" $(\underline{\mathrm{M}}=4.15, \underline{\mathrm{S}}=.93)$, "Modify Worksheet/Assignments" $(\underline{\mathrm{M}}=3.90, \underline{\mathrm{SD}}=.89)$ and "Modify Materials/Presentation" $(\underline{M}=3.82, \underline{\mathrm{SD}}=.88)$. Interventions which were reported to be least effective included: "Keep After School" $(\underline{M}=2.09, \underline{S D}=.94)$, "Change in Groups" $(\underline{M}=2.81, \underline{S D}=1.03)$, and "Change in Seating" $(\underline{M}=2.91, \underline{\mathrm{SD}}=.96)$. It is interesting to note that, while "Change in Seating" is one of the most frequently chosen interventions, it is one of the least effective of the rated interventions. "Keep After School" is, however, one of the least likely interventions to be chosen and it is rated as one of the least effective of interventions. Also, many of the interventions chosen most frequently are not rated as among the most effective.

\section{Behavior Problem}

Participants were then asked to read an analogue case example of Student B, a youngster with a behavior-type problem, and to answer a series of questions related to this case. Fewer teachers had ever referred a youngster with the types of problems outlined in the hypothetical case example. Only $70.1 \%$ had referred a student with these types of problems whereas $27.8 \%$ had never referred a youngster with these types of problems. It should be noted, however, that despite the lowered percentage of referring teachers, teachers agreed that the type of evaluation which would be most appropriate for this student would be either an evaluation for behavioral problems $(68 \%)$ or a referral for both behavioral problems and some other type of evaluation such as academic, speech/language, or occupational therapy(21.6\%). A small number of 
respondents reported that they would refer this individual for no evaluation $(\underline{n}=5)$ or for an academic evaluation only $(\underline{n}=2)$. Significant differences were found between referring and nonreferring teachers with respect to the type of evaluation which would be recommended, $\chi^{2}(3$, $\underline{\mathrm{n}}=92)=11.80, \underline{p}<.05$. As Table 4 suggests, non-referring teachers are more likely to report that "No Evaluation" would be an option for Student B whereas referring teachers never selected "No Evaluation" as an option.

Respondents were again asked to select, from a list of possible interventions, those which would be selected for use with Student B in the case example. The percentage of teachers

Table 4

Observed Frequencies of Evaluation Choice FOR STUDENT B

\begin{tabular}{lllllll}
\hline & None & Behavior & Academic & Combination & Missing & Total \\
\hline Referring Teacher & 0 & 49 & 2 & 16 & 1 & 68 \\
Nonreferring Teacher & 4 & 16 & 0 & 5 & 2 & 27 \\
Missing & 1 & 1 & & & & 2 \\
Totals & 5 & 66 & 2 & 21 & 3 & 97 \\
\hline
\end{tabular}

choosing each intervention is reported in Table 5. The three most frequently chosen interventions for this type of problem were "Behavioral Management Techniques" (92.8\%), "Parent Conference" (92.8\%), and "Change in Seating" (90.7\%). The three least frequently chosen interventions were "Other" (1.0\%), "Change Text/Materials" (8.2\%) and "Oral vs. Written Tests/Reports" (11.3\%). Of the participants who indicated that they had used "Other," the following interventions were noted: "Refer to Parent/Child Counseling" and "Homework Notebook."

Effectiveness ratings were examined for Student B and also appear in Table 5. Results indicate that teachers rated "Behavior Management Techniques" $(M=3.94, \underline{S D}=.99)$ as the most effective of interventions chosen for this case example. Other interventions which were also 
rated as somewhat effective were: "Reward System" $(\underline{M}=3.53, \underline{S D}=1.02)$, "Parent Conference" $(\underline{\mathrm{M}}=3.43, \underline{\mathrm{SD}}=.99)$, and "Consult with Specialist" $(\underline{\mathrm{M}}=3.37, \underline{\mathrm{S}}=1.11)$. Interventions with the lowest effectiveness ratings included: "Tutoring" $(\underline{\mathrm{M}}=2.00, \underline{\mathrm{SD}}=1.03)$, "Keep After School" $(\underline{M}=2.27, \underline{\mathrm{SD}}=88)$, "Oral vs. Written" $(\underline{\mathrm{M}}=2.33, \underline{\mathrm{SD}}=1.27)$, and "Change Text/Materials" $(\underline{M}=2.60, \underline{S D}=84)$. Both "Behavior Management Techniques" and "Parent Conference" were chosen as among the most frequently selected interventions as well as among the most effectively rated interventions. Similarly, "Oral vs. Written Test/Reports" and "Change Text/Materials" were some of the least chosen interventions and were also rated among the least effective.

Table 5

Frequency of Selection and Effectiveness Ratings by Intervention for Student B

\begin{tabular}{|c|c|c|c|}
\hline Intervention & Frequency of Use $\mathrm{e}^{1}$ & \multicolumn{2}{|c|}{ Effectiveness $^{2}$} \\
\hline 1. Change in Seating & 90.7 & 2.99 & 1.01 \\
\hline 2. Change in Groups & 51.5 & 2.81 & .89 \\
\hline 3. Have Student Restate Directions & 2.68 & 2.80 & .92 \\
\hline 4. Oral vs. Written Tests/Reports & 11.3 & 2.33 & 1.27 \\
\hline 5. One-to-One Instruction & 21.6 & 3.05 & 1.43 \\
\hline 6. After School Help & 24.7 & 2.45 & 1.05 \\
\hline 7. Tutoring & 12.4 & 2.00 & 1.03 \\
\hline 8. Use of Organizational Charts & 47.4 & 3.24 & .93 \\
\hline 9. Reduction of Work Assignments & 21.6 & 3.18 & .96 \\
\hline 10. Modify Worksheet/Assignments & 21.6 & 3.05 & .80 \\
\hline 11. Keep After School & 37.1 & 2.27 & .88 \\
\hline 12. Reward System & 83.5 & 3.53 & 1.02 \\
\hline 13. Modify Materials/Presentation & 20.6 & 3.18 & 1.21 \\
\hline 14. Change Text/Materials & 8.2 & 2.60 & .84 \\
\hline 15. Student Conference & 84.5 & 3.04 & .94 \\
\hline 16. Call/Note Parents & 79.4 & 3.24 & .92 \\
\hline 17. Parent Conference & 92.8 & 3.43 & .95 \\
\hline 18. Consult Specialists & 67.0 & 3.37 & 1.11 \\
\hline 19. Behavior Management & 92.8 & 3.94 & .99 \\
\hline 20. Other & 1.0 & 3.00 & .00 \\
\hline
\end{tabular}




\section{Academic versus Behavior Problems}

In general, the effectiveness ratings for interventions chosen for Student B are somewhat lower than those reported for Student A. Figure 2 depicts the differences in mean effectiveness ratings for Academic versus Behavioral Referrals.

Multiple t-tests to examine the differences between academic and behavior referrals in terms of mean effectiveness rating scores ${ }^{2}$ are found in Table 6. Ten of the 19 comparisons between analogue academic and behavior mean effectiveness ratings were found to be significant. In all but one of the ten cases, the rating of effectiveness of the intervention chosen for the academic referral was significantly greater than the rating of the effectiveness of the intervention chosen for the behavior referral. It would appear that many of the interventions which are found to be more effective for a student with an academic problem than with a behavior problem are interventions which are implemented in the classroom or encourage additional intensive work outside the classroom: For example, "Have Student Restate Directions," "One-to-One Instruction," "Reduction of Work Assignments," "Modify

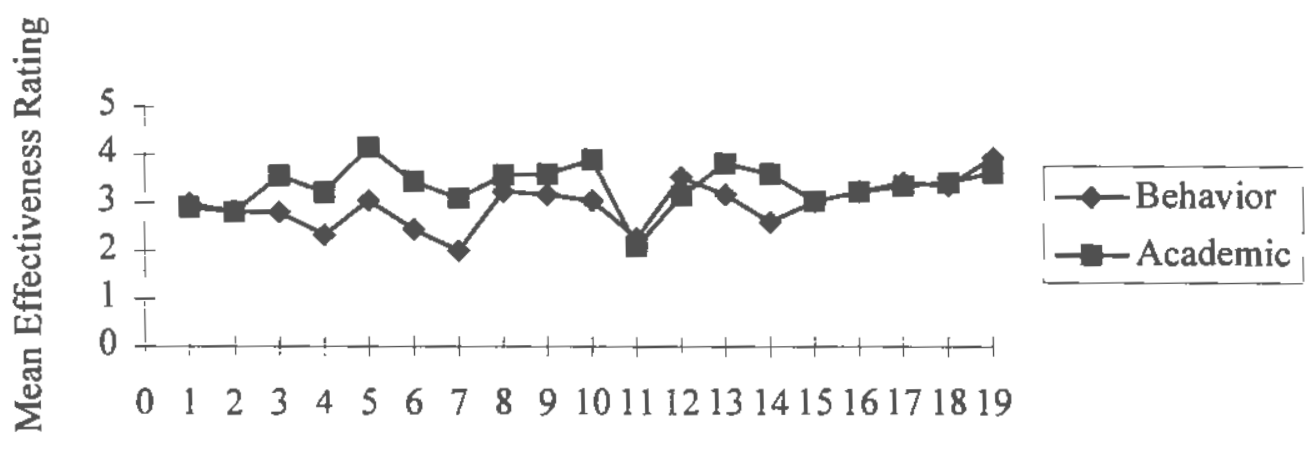

Interventions 1-19

Figure 2. Effectiveness of interventions-analogue data

\footnotetext{
${ }^{2}$ Given the differences in the number of observations among each of the 19 interventions and the non-independence of effectiveness ratings (a violation of assumptions for MANOVA), $t-$ tests were conducted to ensure statistical parsimony.
} 
Worksheet/Assignments," "Modify Materials/Presentation," and "Change Text/Materials" are more effective for students with academic than behavior problems. It should be noted, however, that the effectiveness of "Reward System" $(\underline{M}=3.53, \underline{\mathrm{S}}=1.02)$ as an intervention for an analogue student with a behavior problem was rated more effective than the same intervention for a student with an academic problem, $\mathrm{t}(33)=-2.42, \mathrm{p}<.05$, two-tailed.

Table 6

Comparison of Academic versus Behavior Referral Effectiveness Ratings-Paired Sample t-tests

\begin{tabular}{llllllll}
\hline Intervention & \multicolumn{2}{c}{ Academic $^{1}$} & \multicolumn{2}{c}{ Behavior $^{2}$} & $\underline{\mathrm{t}}$ & $\underline{\mathrm{n}}$ & sig \\
1. Change in seating & 2.91 & .96 & 2.99 & 1.01 & -.725 & 77 & .470 \\
2. Change in groups & 2.81 & 1.03 & 2.81 & .89 & .000 & 42 & 1.00 \\
3. Have student restate directions & 3.56 & 1.04 & 2.80 & .92 & 3.61 & 24 & $.001^{*}$ \\
4. Oral vs. written tests/reports & 3.22 & .83 & 2.33 & 1.27 & 2.89 & 8 & .052 \\
5. One-To-One instruction & 4.15 & .93 & 3.05 & 1.43 & 3.69 & 19 & $.002^{*}$ \\
6. After school help & 3.45 & .89 & 2.45 & 1.05 & 3.68 & 19 & $.002^{*}$ \\
7. Tutoring & 3.09 & .70 & 2.00 & 1.03 & 3.83 & 10 & $.003^{*}$ \\
8. Use of organizational charts & 3.58 & .98 & 3.24 & .93 & 2.32 & 37 & $.026^{*}$ \\
9. Reduction of work assignments & 3.59 & .94 & 3.18 & .96 & 2.14 & 16 & $.049^{*}$ \\
10. Modify worksheets/assignments & 3.90 & .89 & 3.05 & .80 & 4.95 & 20 & $.000^{*}$ \\
11. Keep After School & 2.09 & .94 & 2.27 & .88 & -.48 & 10 & .640 \\
12. Reward System & 3.15 & .96 & 3.53 & 1.02 & -2.42 & 33 & $.021^{*}$ \\
13. Modify materials/presentation & 3.82 & .88 & 3.18 & 1.21 & 2.67 & 16 & $.017^{*}$ \\
14. Change Text/Materials & 3.60 & .84 & 2.60 & .84 & 3.35 & 9 & $.008^{*}$ \\
15. Student Conference & 3.04 & .89 & 3.04 & .94 & .00 & 56 & 1.00 \\
16. Call/Note Parents & 3.24 & 1.00 & 3.24 & .92 & .00 & 61 & 1.00 \\
17. Parent Conference & 3.36 & .92 & 3.43 & .95 & -.68 & 76 & .496 \\
18. Consult Specialists & 3.43 & .96 & 3.37 & 1.11 & .68 & 59 & .497 \\
19. Behavior Management & 3.64 & .90 & 3.94 & .99 & -1.93 & 35 & .062 \\
\hline
\end{tabular}

${ }^{1}$ Mean Effectiveness Rating/Standard Deviation for Student A

${ }^{2}$ Mean Effectiveness Rating/Standard Deviation for Student B $\underline{N}=97$

${ }^{*} \mathrm{p}<.05$

Special Education Versus General Education Teachers

Significant differences between the effectiveness ratings of special education and general education teachers were noted. In general, special educators rated many interventions as more effective than did general educators on both academic referrals and behavior referrals. 
Differences are presented graphically in Figure 3 for the effectiveness ratings of interventions selected for the Analogue academic referrals and in Figure 4 for the effectiveness ratings of interventions selected for the Analogue behavior referrals. Table 7 summarizes the t-test comparisons between the mean ratings of special educators and general education teachers for Student A. Table 8 summarizes the t-test comparisons between mean ratings of special education teachers and general education teachers for Student B.

Results show that, for Student A, special educators rated "Change in Group," "One-to-One Instruction," "Organizational Charts," "Reducing Work Assignments," "Modifying Worksheets/ Assignments," and "Modifying Materials," as significantly more effective when they are chosen as interventions for academic problems than did general education teachers.

Additionally, for Student B, special educators also rated "One-to-One Instruction," as well as "Reward System," "Student Conference," and "Behavioral Management Strategies," as more effective when they are chosen as interventions for behavior problems than did general education teachers.

\section{Authentic Data}

A total of 345 Classroom Alternatives Support Team Request Form (CASTRF) forms were collected for the purposes of the authentic data analyses. The average student age at the time of referral was 8 years, 4 months ( $\underline{S D}=2$ years) with a range from between 4 years, one month old to 13 years, 8 months old. The average Full Scale IQ score of referred students was 93.7, $\underline{\mathrm{SD}}=14.9$. Figure 5 represents the number of students referred at each grade level. As was the case with grade taught by referring teachers for the analogue data, the greatest number of referrals occurred at the first grade level. 


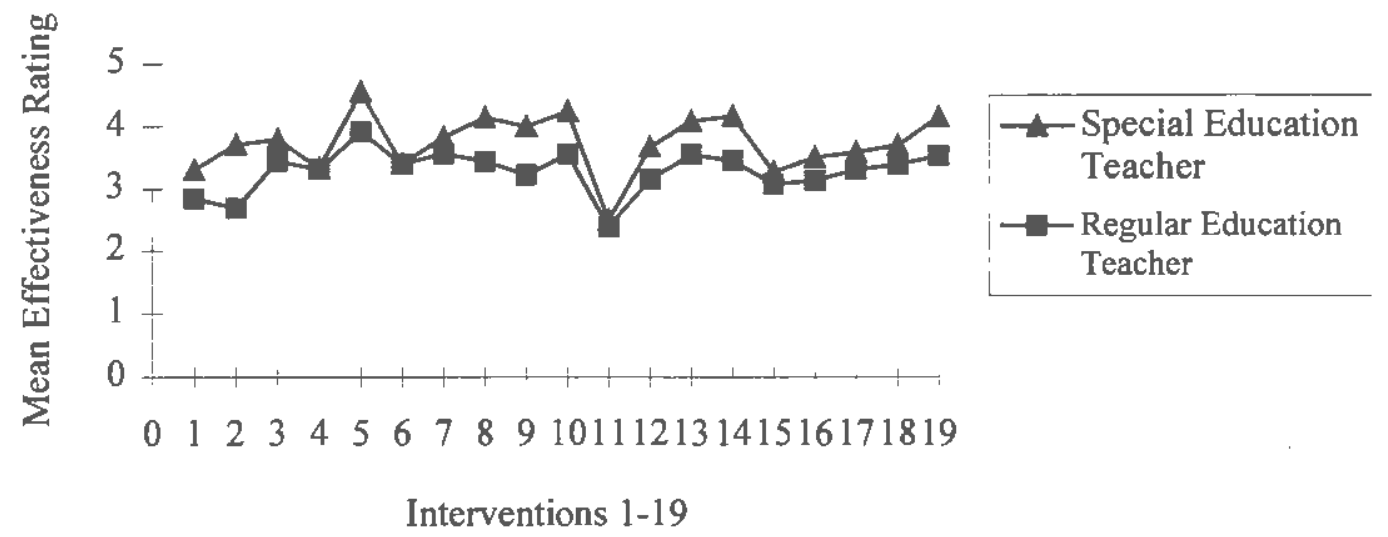

Figure 3. Effectiveness of interventions-analogue-academic referrals

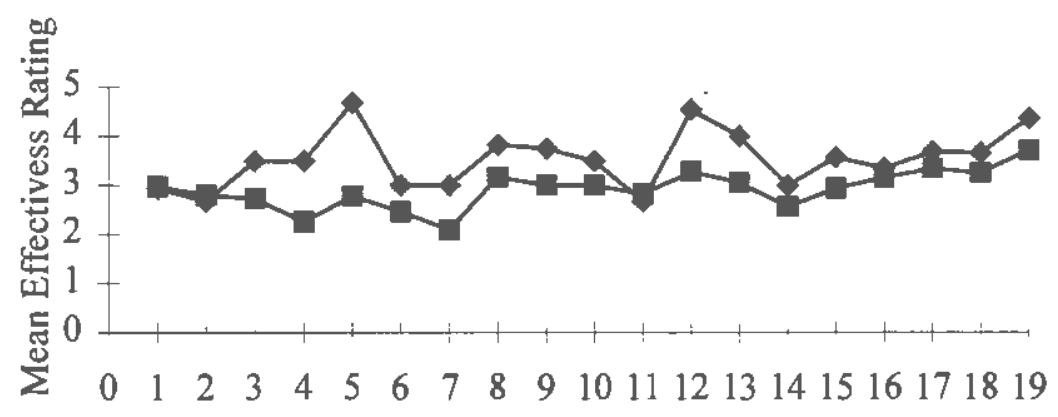

$\rightarrow-$ Special Education Teacher

$\longrightarrow$ - Regular Education 1 Teacher

Interventions 1-19

Figure 4. Effectiveness of interventions-analogue-behavior referrals

\section{Academic Problem}

For the purposes of the current study, 258 CASTRF or authentic forms were examined that resulted from the referral of a student with a predominantly academic problem. Table 9 indicates the frequency of the selection of academic interventions from the Authentic data 
Table 7

Comparison of Analogue Academic Referral Effectiveness Ratings-For Special and General $\underline{\text { Educators }}$

\begin{tabular}{|c|c|c|c|c|c|c|c|}
\hline \multirow[t]{2}{*}{ Intervention } & \multicolumn{2}{|c|}{$\begin{array}{c}\text { General } \\
\text { Educators }\end{array}$} & \multicolumn{2}{|c|}{$\begin{array}{c}\text { Special } \\
\text { Educators }\end{array}$} & \multirow[t]{2}{*}{$\underline{\mathrm{t}}$} & \multirow[t]{2}{*}{$\underline{\mathrm{df}}$} & \multirow[t]{2}{*}{ p } \\
\hline & $\underline{\mathrm{M}}$ & $\underline{\mathrm{SD}}$ & $\underline{\underline{M}}$ & $\underline{\mathrm{SD}}$ & & & \\
\hline 1. Change in seating & 2.85 & 1.01 & 3.30 & .48 & -1.39 & 79 & .166 \\
\hline 2. Change in groups & 2.69 & .95 & 3.71 & .95 & -2.67 & 53 & $.010^{*}$ \\
\hline 3. Restate directions & 3.45 & .94 & 3.80 & .77 & -1.35 & 80 & .182 \\
\hline 4. Oral vs. written & 3.31 & .82 & 3.33 & 1.63 & -.05 & 36 & .962 \\
\hline 5. One-To-One instruction & 3.92 & .83 & 4.56 & .73 & -2.18 & 70 & $.033^{*}$ \\
\hline 6. After school help & 3.40 & .81 & 3.40 & 1.14 & .00 & 38 & 1.00 \\
\hline 7. Tutoring & 3.57 & .88 & 3.83 & .75 & -.68 & 32 & .504 \\
\hline 8. Use of charts & 3.44 & .91 & 4.15 & .80 & -2.60 & 74 & $.011^{*}$ \\
\hline 9. Reduction of work & 3.23 & .77 & 4.00 & 1.07 & -2.44 & 46 & $.019^{*}$ \\
\hline 10. Modify assignments & 3.56 & .91 & 4.25 & .62 & -2.49 & 69 & $.015^{*}$ \\
\hline 11. Keep After School & 2.38 & .96 & 2.50 & 2.12 & -.14 & 13 & .892 \\
\hline 12. Reward System & 3.16 & 1.05 & 3.67 & .82 & -1.12 & 36 & .269 \\
\hline 13. Modify presentation & 3.55 & .78 & 4.09 & .70 & -2.14 & 67 & $.036^{*}$ \\
\hline 14. Change Text/Materials & 3.45 & .87 & 4.17 & .75 & -1.88 & 33 & .069 \\
\hline 15. Student Conference & 3.08 & .96 & 3.27 & .79 & -.64 & 62 & .525 \\
\hline 16. Call/Note Parents & 3.13 & 1.01 & 3.50 & .93 & -.99 & 69 & .324 \\
\hline 17. Parent Conference & 3.30 & .94 & 3.58 & .67 & -.98 & 79 & .330 \\
\hline 18. Consult Specialists & 3.38 & 1.03 & 3.69 & .75 & -1.05 & 75 & .296 \\
\hline 19. Behavior Management & 3.52 & .89 & 4.14 & .69 & -1.74 & 36 & .090 \\
\hline
\end{tabular}

or CASTRF form as expressed by the percentage of teachers choosing the intervention. Results suggest that "One-to-One Instruction" (82.2\%) was most frequently chosen for use with an academic problem by referring teachers followed by "Parent Conference" $(61.8 \%)$ and "Change in Seating" (60.2\%). Least frequently chosen interventions include: "Other" (9.3\%), "After School HeIp" (5.8\%), "Oral versus Written Tests/Reports" (18.5\%), and "Change in Text/Materials" (23.2\%).

Teachers rated the effectiveness of authentic interventions selected for use with a student with an academic problem as somewhat less effective than results reported for analogue data. 
The overall mean effectiveness score $(\underline{\mathrm{M}}=2.55)$ is somewhat lower than the median choice point on the 1-5 point Likert-type Scale. The mean intervention effectiveness ratings for

Table 8

Comparison of Analogue Behavioral Referral Effectiveness Ratings For Special and General Educators

\begin{tabular}{|c|c|c|c|c|c|c|c|}
\hline \multirow[t]{2}{*}{ Intervention } & \multicolumn{2}{|c|}{ General } & \multicolumn{2}{|c|}{ Special } & \multirow[t]{2}{*}{$\underline{t}$} & \multirow[t]{2}{*}{$\underline{\underline{\mathrm{df}}}$} & \multirow[t]{2}{*}{$\underline{p}$} \\
\hline & $\mathrm{M}$ & $\mathrm{SD}$ & $\mathrm{M}$ & $\mathrm{SD}$ & & & \\
\hline 1. Change in seating & 2.97 & 1.02 & 2.93 & 1.00 & .15 & 86 & .881 \\
\hline 2. Change in groups & 2.80 & .81 & 2.67 & 1.22 & .42 & 48 & .677 \\
\hline 3. Restate directions & 2.73 & .94 & 3.50 & .58 & -1.58 & 24 & .127 \\
\hline 4. Oral vs. written & 2.25 & 1.28 & 3.50 & .71 & -1.29 & 8 & .233 \\
\hline 5. One-To-One instruction & 2.78 & 1.35 & 4.67 & .58 & -2.34 & 19 & $.030^{*}$ \\
\hline 6. After school help & 2.46 & 1.06 & 3.00 & .00 & -.50 & 23 & .622 \\
\hline 7. Tutoring & 2.09 & 1.04 & 3.00 & .00 & -.83 & 10 & .424 \\
\hline 8. Use of charts & 3.18 & .93 & 3.83 & .75 & -1.65 & 44 & .106 \\
\hline 9. Reduction of work & 3.00 & .94 & 3.75 & .96 & -1.44 & 19 & .167 \\
\hline 10. Modify assignments & 3.00 & .82 & 3.50 & .71 & -.83 & 19 & .417 \\
\hline 11. Keep After School & 2.82 & .90 & 2.67 & .58 & .30 & 35 & .771 \\
\hline 12. Reward System & 3.28 & .97 & 4.54 & .52 & -4.54 & 78 & $.001 *$ \\
\hline 13. Modify presentation & 3.06 & 1.25 & 4.00 & .00 & -1.04 & 17 & .313 \\
\hline 14. Change Text/Materials & 2.56 & .88 & 3.00 & .00 & -.488 & 8 & .645 \\
\hline 15. Student Conference & 2.94 & .90 & 3.58 & 1.00 & -2.25 & 80 & $.028 *$ \\
\hline 16. Call/Note Parents & 3.16 & .93 & 3.36 & .92 & -.67 & 71 & .507 \\
\hline 17. Parent Conference & 3.35 & 1.15 & 3.69 & 1.03 & -1.20 & 85 & .233 \\
\hline 18. Consult Specialists & 3.26 & 1.00 & 3.67 & .89 & -1.14 & 63 & .259 \\
\hline 19. Behavior Management & 3.73 & & 4.36 & .74 & -2.24 & 86 & $.028 *$ \\
\hline
\end{tabular}

${ }^{*} \mathrm{p}<.05$

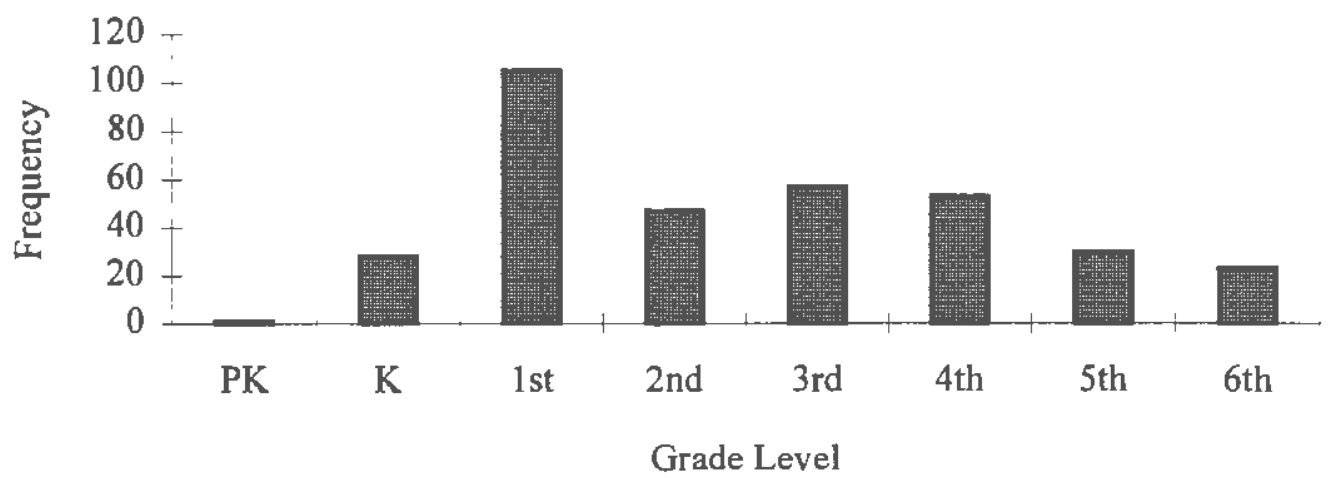

Figure 5. Grade level of referred students 
academic referrals is reported in Table 9. The most effective interventions include: "Other" $(\underline{M}=3.00, \underline{\mathrm{SD}}=1.35)$, "Change Text/Materials" $(\underline{\mathrm{M}}=2.97, \underline{\mathrm{SD}}=1.3)$, "One-to-One Instruction," $(\underline{M}=2.95, \underline{S D}=1.27)$, "Oral versus Written Tests/Reports" $(\underline{M}=2.93, \underline{S D}=1.30)$, and "Modify Worksheets/Assignments" $(\underline{M}=2.92, \underline{S D}=1.31)$. The interventions chosen for academic referrals and rated as least effective include: "Change in Groups" $(\underline{M}=1.88, \underline{\mathrm{SD}}=1.20)$, "Change in Seating" $(\underline{M}=2.06, \underline{S D}=1.31)$, and "Consult with Specialist" $(\underline{M}=2.16, \underline{S D}=1.34)$. It should be noted that although "Change Text/Materials," "Other," and "Oral vs. Written Tests/Reports" are the most effectively rated interventions for academic referrals, they are the least frequently chosen. Also, although teachers use "Change in Seat" it is not considered to be among the most effective of the interventions. In general there appears to be a discrepancy between the frequency of intervention selection and the ratings of effectiveness. Teachers do not always choose interventions which they rate as most effective. Those participants indicating that they chose "Other" indicated the following types of interventions: "Truancy Petition," "Homework," "Principal's Observation," "Literacy/Chapter Reading," "Medication," "Teach Organizational Skills," "Consult with Teachers," "Whole Language Instruction," "Peer Helper" and "Resource."

\section{Behavior Problem}

Table 10 contains the frequency data for authentic intervention selection for teachers referring a student primarily for a behavior problem. The frequency data are also reported as a percentage of the number of teachers choosing the intervention. Results, which are very similar to the results obtained for authentic academic data, show that "One-To-One Instruction" $(83.7 \%)$, "Change in Seating" (76.7\%) and "Parent Conference" (69.8\%) constitute the most frequently chosen interventions when a teacher refers a student for a behavior problem. Again, less frequently chosen interventions tend to mirror directly the findings for academic problems, 
and include: "After School Help" (9.3\%), "Oral versus written tests/Reports" (12.8\%), and "Change Text/Materials" (16.3\%).

Table 9

Authentic Frequency and Effectiveness Ratings for Academic Interventions $(\mathrm{N}=258)$

\begin{tabular}{|c|c|c|c|}
\hline & Frequency of Use & Effectiveness ${ }^{2}$ & \\
\hline & & M & $\underline{\mathrm{SD}}$ \\
\hline 1. Change in Seating & 60.2 & 2.06 & $\overline{1.31}$ \\
\hline 2. Change in Groups & 39.0 & 1.88 & 1.2 \\
\hline 3. Student Restate Direction & 59.1 & 2.42 & 1.24 \\
\hline 4. Oral vs. Written Test & 18.5 & 2.93 & 1.3 \\
\hline 5. One-To-One Instruction & 82.2 & 2.95 & 1.27 \\
\hline 6. After School Help & 5.8 & 2.33 & 1.58 \\
\hline 7. Tutoring & 34.4 & 2.83 & 1.23 \\
\hline 8. Organizational Charts & 26.3 & 2.65 & 1.32 \\
\hline 9. Reduce Work Assign. & 42.5 & 2.80 & 1.33 \\
\hline 10. Modify sheets/Assign. & 37.8 & 2.92 & 1.31 \\
\hline 11. Keep After School & 29.0 & 2.41 & 1.26 \\
\hline 12. Reward System & 38.6 & 2.74 & 1.34 \\
\hline 13. Modify Mat/Presentation & 48.3 & 2.46 & 1.32 \\
\hline 14. Change Text/Materials. & 23.2 & 2.97 & 1.30 \\
\hline 15. Student Conference & 42.9 & 2.18 & 1.18 \\
\hline 16. Call/Note Parent & 56.4 & 2.29 & 1.32 \\
\hline 17. Parent Conference & 61.8 & 2.35 & 1.39 \\
\hline 18. Consult Specialists & 47.5 & 2.16 & 1.34 \\
\hline 19. Behavior Management & 28.2 & 2.85 & 1.38 \\
\hline 20. Other & 9.3 & 3.00 & 1.35 \\
\hline
\end{tabular}

${ }^{1}$ Percentage of Teachers who chose this intervention

${ }^{2}$ Mean/Standard Deviation

Effectiveness ratings for interventions selected for use with students referred for behavior problems reported in Table 10 indicate that teachers feel that interventions selected are not very effective. Mean ratings range from $1.44(\underline{S D}=.92)$ to $2.77(\underline{S D}=1.17)$. The most effective interventions include: "Tutoring" $(\underline{\mathrm{M}}=2.77, \underline{\mathrm{SD}}=1.17)$, "One-to-One Instructions" $(\underline{\mathrm{M}}=2.56$, $\underline{\mathrm{SD}}=1.47)$, and "Oral versus Written Tests/Reports" $(\underline{\mathrm{M}}=2.71, \underline{\mathrm{S}}=1.60)$. The least effective interventions which were selected for use with a behavior problem are: "Keep after School" $\underline{M}=1.44, \underline{\mathrm{S}}=.92)$, "After School Help" $(\underline{\mathrm{M}}=1.50, \underline{\mathrm{S}}=1.00)$, and "Change in 
Groups" $(\underline{M}=1.87, \underline{S D}=1.18)$. When effectiveness ratings are compared with intervention selection frequencies, it is noted that "Oral vs. Written Tests/Reports" is rated as one of the most effective interventions in the case of an authentic behavioral referral but it is among the least likely to be chosen intervention.

\section{Academic versus Behavior Problems}

Frequency. The frequency of intervention selection is graphically represented by Figure 6 . The following interventions were chosen much more frequently when the referral was for behavioral problems than for academic problems: "Reward System," $\chi^{2}(1, \underline{n}=344)=23.11$, $\underline{\underline{p}}<.05$; "Behavioral Management Techniques" $\chi{ }^{2}(1, \underline{\mathbf{n}}=344)=9.33, \underline{\mathrm{p}}<.05$; "Student

Table 10

Authentic Frequency and Effectiveness Ratings for Behavioral Interventions $(\mathrm{N}=87$ )

\begin{tabular}{lrrr}
\hline Intervention & Frequency of Use & \multicolumn{2}{c}{ Effectiveness $^{2}$} \\
\hline 1. Change in Seating & 76.7 & 2.14 & 1.3 \\
2. Change in Groups & 50.0 & 1.87 & 1.18 \\
3. Student Restate Directions & 64.0 & 1.97 & 1.16 \\
4. Oral vs. Written Tests/Reports & 12.8 & 2.71 & 1.6 \\
5. One-to-One Instructions & 83.7 & 2.56 & 1.47 \\
6. After School Help & 9.3 & 1.50 & 1.00 \\
7. Tutoring & 31.4 & 2.77 & 1.17 \\
8. Use of Organizational Charts & 36.0 & 1.78 & 1.04 \\
9. Reduce Work Assignments & 44.2 & 1.88 & 1.21 \\
10. Modify Worksheet/Assign. & 32.6 & 2.21 & 1.13 \\
11. Keep After School & 52.3 & 1.44 & .92 \\
12. Reward System & 68.6 & 2.28 & 1.23 \\
13. Modify Materials/Presentation & 43.0 & 2.13 & 1.15 \\
14. Change Text/Materials & 16.3 & 1.86 & .90 \\
15. Student Conference & 61.6 & 2.00 & 1.13 \\
16. Call/Note Parent & 68.6 & 2.32 & 1.25 \\
17. Parent Conference & 69.8 & 2.33 & 1.34 \\
18. Consult Specialists & 53.5 & 2.38 & 1.51 \\
19. BehaviorManagement & 53.5 & 2.29 & 1.16 \\
\hline
\end{tabular}

'Percentage of Teachers who chose this intervention

${ }^{2}$ Mean and Standard Deviation for Effectiveness Ratings 
Conference," $\chi^{2} \quad(1, \underline{n}=344)=4.11, \underline{p}<.05$; "Call/Note to Parents," $\chi^{2}(1, \underline{n}=344)=7.47, \underline{p}<.05$;

"Change of Seat," $\chi^{2}(1, \underline{n}=344)=15.36, \underline{p}<.05$; and "Keep After School," $\chi^{2}(1$,

$\underline{N}=344)=18.09, \underline{p}<.05$. Although not statistically significant, teachers tended to select interventions such as "Modification of Materials/Presentation" and "Change of Text/Materials" more frequently when the presenting referral problem was primarily academic.

Effectiveness. In general, the effectiveness ratings for interventions chosen for Academic referrals are somewhat greater than for interventions chosen for Behavioral referrals as shown in Figure 7. Student's t-tests to examine the differences between mean scores were conducted but only five (Numbers $8,9,10,11,14$ ) of the nineteen comparisons between authentic academic and authentic behavior mean effectiveness ratings indicate that significant differences appear to exist. For instance, the mean effectiveness rating for intervention \#8, "Use of Organizational Charts" with an acadernic referral $(\underline{M}=2.65, \underline{S D}=1.32)$ was significantly greater than for a behavior referral $(\underline{M}=1.78, \underline{\mathrm{S}}=1.04), \underline{\mathrm{t}}(67)=2.76, \underline{\mathrm{p}}<.05$. The mean effectiveness rating for intervention \#9, "Reduce Work Assignments" for an academic referral $(\underline{M}=2.80$,

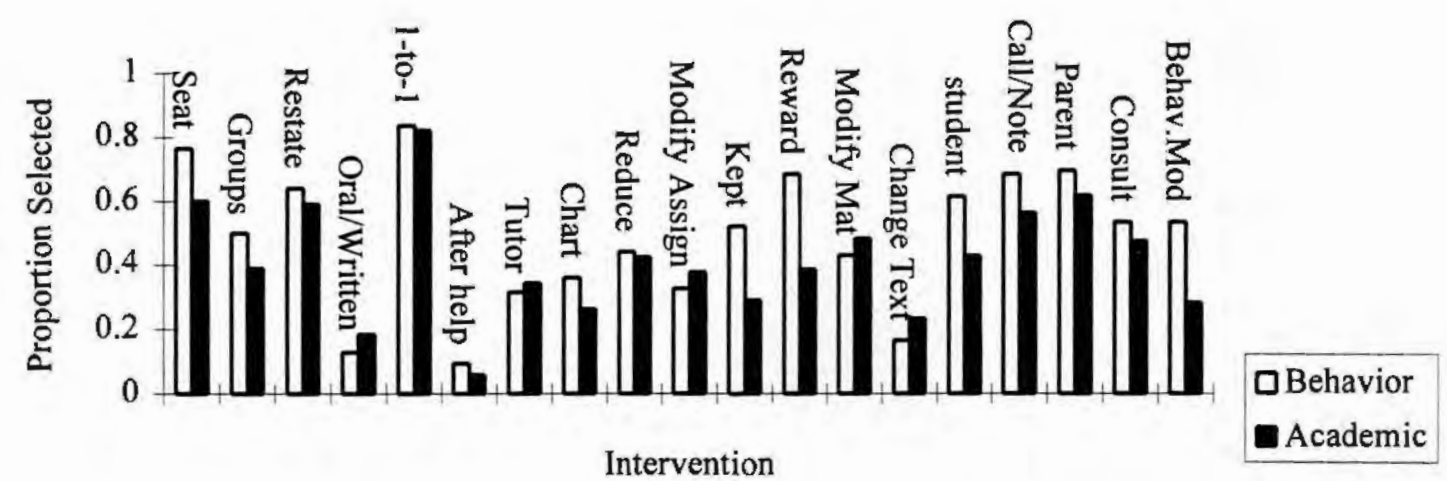

Figure 6. Frequency of intervention selection-authentic data 
$\underline{\mathrm{SD}}=1.33)$ was significantly greater than for a behavior referral $(\underline{\mathrm{M}}=1.88, \underline{\mathrm{SD}}=1.21), \underline{\mathrm{t}}(80)=3.00$, $\mathrm{p}<.05$. The mean effectiveness rating for intervention \#10, "Modify Worksheets/assignments" for an academic referral $(\underline{M}=2.92, \underline{\mathrm{SD}}=1.31)$ was significantly greater than for a behavior referral $(\underline{M}=2.21, \underline{S D}=1.13), \underline{t}(69)=2.10, \underline{p}<.05$. The mean effectiveness rating for intervention $\# 11$, "Keep After School" for an academic referral $(\underline{M}=2.41, \underline{\mathrm{SD}}=1.26)$ was significantly greater than for a behavior referral $(\underline{\mathrm{M}}=1.44, \underline{\mathrm{SD}}=.92), \underline{\mathrm{t}}(67)=3.36, \underline{\mathrm{p}}<.05$. Finally, the mean effectiveness rating for intervention \# 14, "Change Text/Materials" for an academic referral $(\underline{M}=2.97, \underline{\mathrm{SD}}=1.30)$ was significantly greater than for a behavior referral $(\underline{\mathrm{M}}=1.86, \underline{\mathrm{SD}}=.90)$, $\underline{t}(35)=2.13, \mathrm{~g}<.05$. In no comparison was mean effectiveness for an intervention significantly greater for a behavior referral than for an academic referral.

Academic versus Behavioral Problem-Collapsed Data

Data were collapsed for number of interventions for both academic and behavior matched data sets. For each subject, a total number of authentic interventions selected was calculated. A Pearson Product Moment Correlation coefficient indicates a positive significant relationship $(r=.71, \mathrm{p}<.01)$ between the number of interventions selected for an authentic academic referral and the number of interventions chosen for an authentic behavioral referral. The more interventions chosen for an academic referral, the more interventions chosen for behavioral referrals. Teachers who tend not to choose many interventions for academic referrals also tend not to choose many interventions for behavioral referrals.

\section{Analogue Versus Authentic Data}

WHAT IS THE RELATIONSHIP BETWEEN ANALOGUE AND AUTHENTIC DATA? ARE SELECTED INTERVENTIONS RATED SIMILARLY EFFECTIVE FOR ANALOGUE AND AUTHENTIC DATA? WILL REAL LIFE MIRROR THE HYPOTHETICAL?

In order to examine the relationship between Authentic and Analogue data, data sets were matched by individual according to teacher identification code. The resulting match yielded 
$\underline{n}=73$ for academic referrals and $\underline{n}=26$ for behavior referrals. In order to increase the power associated with this analysis, it was decided that subjects would be further matched by grade level.

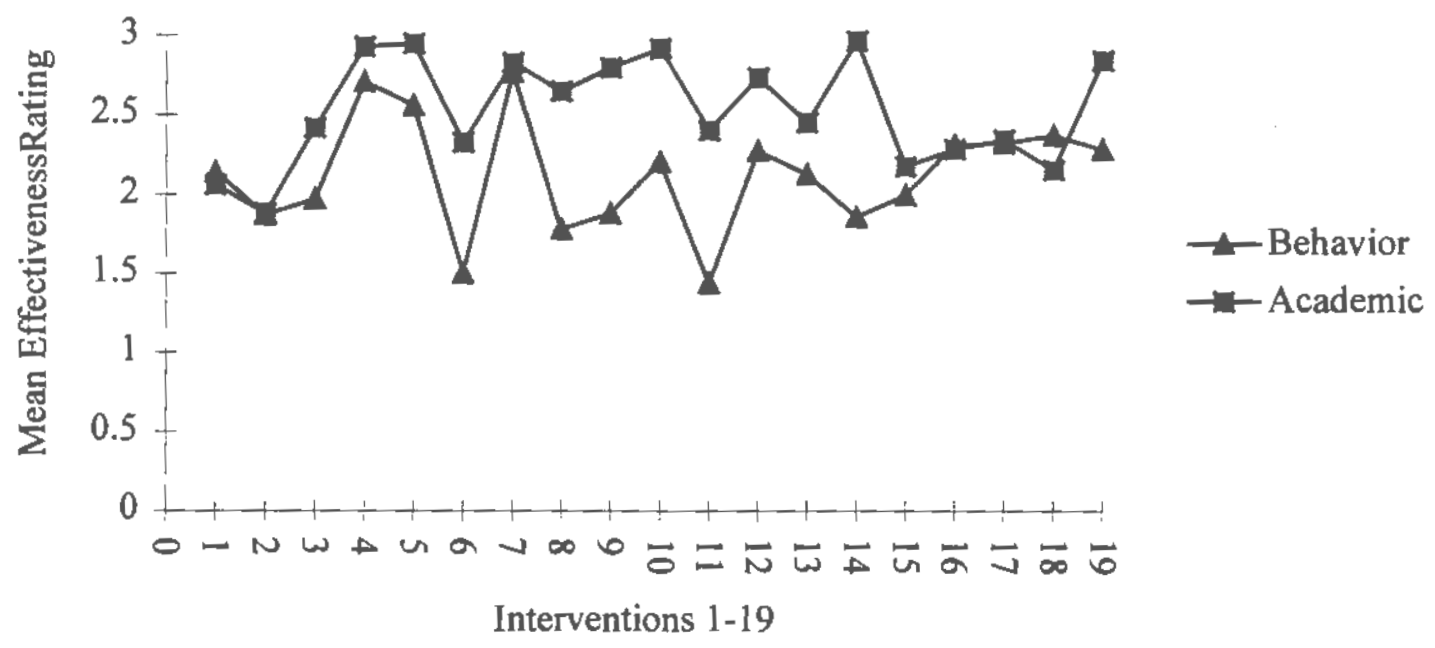

Figure 7. Effectiveness of interventions-authentic data

Further rationale for this decision involved the importance of the concordance in understanding between Analogue participants and Authentic referring teachers for the developmental and contextual issues of importance in the treatment of the student via the selection of prereferral intervention strategies. The subsequent match of survey to CASTRF form by grade level resulted in $\underline{N}=95$ for academic referral and $\underline{N}=72$ for behavioral referral. Unless otherwise specified, the subsequent analyses are based upon these matched samples.

\section{Intervention Selection}

\section{Academic Problem}

Chi-Square analyses were conducted to examine the relationship between the frequency of prereferral intervention selection for academic Authentic and Analogue data sets. Table 11 presents the Chi-Square statistics for all 19 comparisons between authentic and Analogue 
choices for this matched sample. Significant differences were noted only for 2 interventions. In both of these cases, teachers were more likely to select "Have Student Restate Directions" and "Parent Conference" when completing surveys than when actually referring a student for an evaluation. For all other comparisons, no significant differences were noted between Authentic and Analogue data for academic referral.

\section{Behavior Problem}

Table 11 also summarizes the Chi-Square analyses for behavior referrals. Results suggest no difference between the frequencies of intervention selection between Authentic and Analogue data for behavior referrals. In the case of the frequency of intervention selection for behavior referrals, it would appear that the real world mirrors the Analogue world.

\section{Table 11}

$\chi^{2}$ Comparisons of Authentic and Analogue Intervention Frequency Selection for Academic and Behavioral Referrals

1. Change in Seating

2. Change in Groups

3. Have Student Restate Direction

4. Oral vs. Written Tests/Reports

5. One-to-One Instruction

6. After School Help

7. Tutoring

8. Use of Organizational Charts

9. Reduction of Work Assignment

10. Modify Worksheet/Assign.

11. Keep After School

12. Reward System

13. Modify Material/Presentation

14. Change in Text/Materials

15. Student Conference

16. Call/Note to Parents

17. Parent Conference

18. Consult with Specialists

19. Behavior Management

Authentic ys. Analogue
Academic $(\mathrm{n}=95)$
.05
.12

$6.13 *$

.45

3.05

3.61

.00

.31

.26

2.74

.13

.30

3.72

.49

.45

.78

$7.01 *$

1.00

.33

\begin{tabular}{c} 
Authentic vs. Analogue \\
\hline Behavior ( $=72$ ) \\
.05 \\
1.36 \\
.05 \\
1.83 \\
.17 \\
2.30 \\
1.38 \\
.00 \\
.02 \\
1.62 \\
.00 \\
.04 \\
3.24 \\
1.08 \\
.03 \\
.01 \\
2.86 \\
.32 \\
1.06
\end{tabular}




\section{Intervention Effectiveness}

\section{Academic Problem}

In order to examine the strength of relationship between intervention effectiveness ratings between Analogue and Authentic data, Pearson Product Correlation Coefficients were calculated. Significant correlations would be expected if Authentic and Analogue ratings are comparable. Table 12 indicates, however, only 2 correlations were significant at the $\mathrm{p}<.05$ level. That is, for "After School Help" and "Student Conference," the ratings of the effectiveness of the intervention indicate a significant relationship between authentic and analogue data. In general, however, it would appear that the real world does not mirror the hypothetical when the ratings of academic intervention effectiveness are considered.

\section{Behavior Problem}

Ratings of intervention effectiveness for behavior referrals as reported in Table 13 show a similar pattern of findings as for Academic referrals. Only one significant negative correlation is noted between Analogue and Authentic ratings of effectiveness. As ratings of the effectiveness of "Behavior Management Techniques" increase for Analogue reports, the more likely the rating will decrease for report of the actual effectiveness of the intervention. The remaining correlations were not significant and are suggestive of a lack of concordance in the ratings of effectiveness for Analogue and Authentic data sets for this matched sample. Again, it would appear that there is little relationship between ratings of effectiveness across analogue and authentic methods.

Intervention Clustering

DO TEACHERS TEND TO USE INTERVENTIONS WHICH ARE SIMILAR TO EACH OTHER ALONG VARIOUS DIMENSIONS?

Authentic data intervention effectiveness ratings were factor analyzed in order to determine if interventions cluster together in a particular way. In order to examine if there exists a latent structure underlying these interventions, a number of procedures were attempted. 


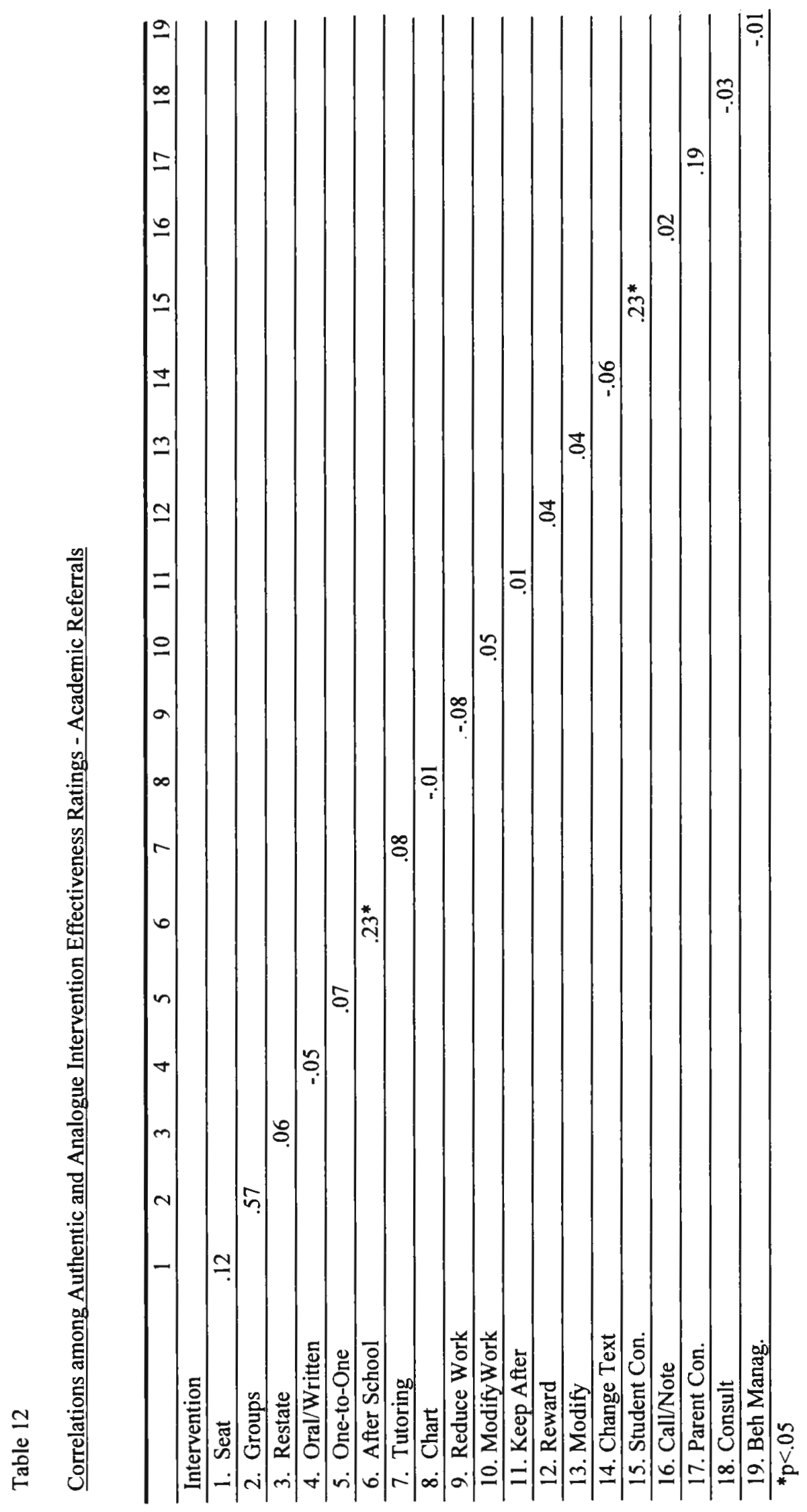




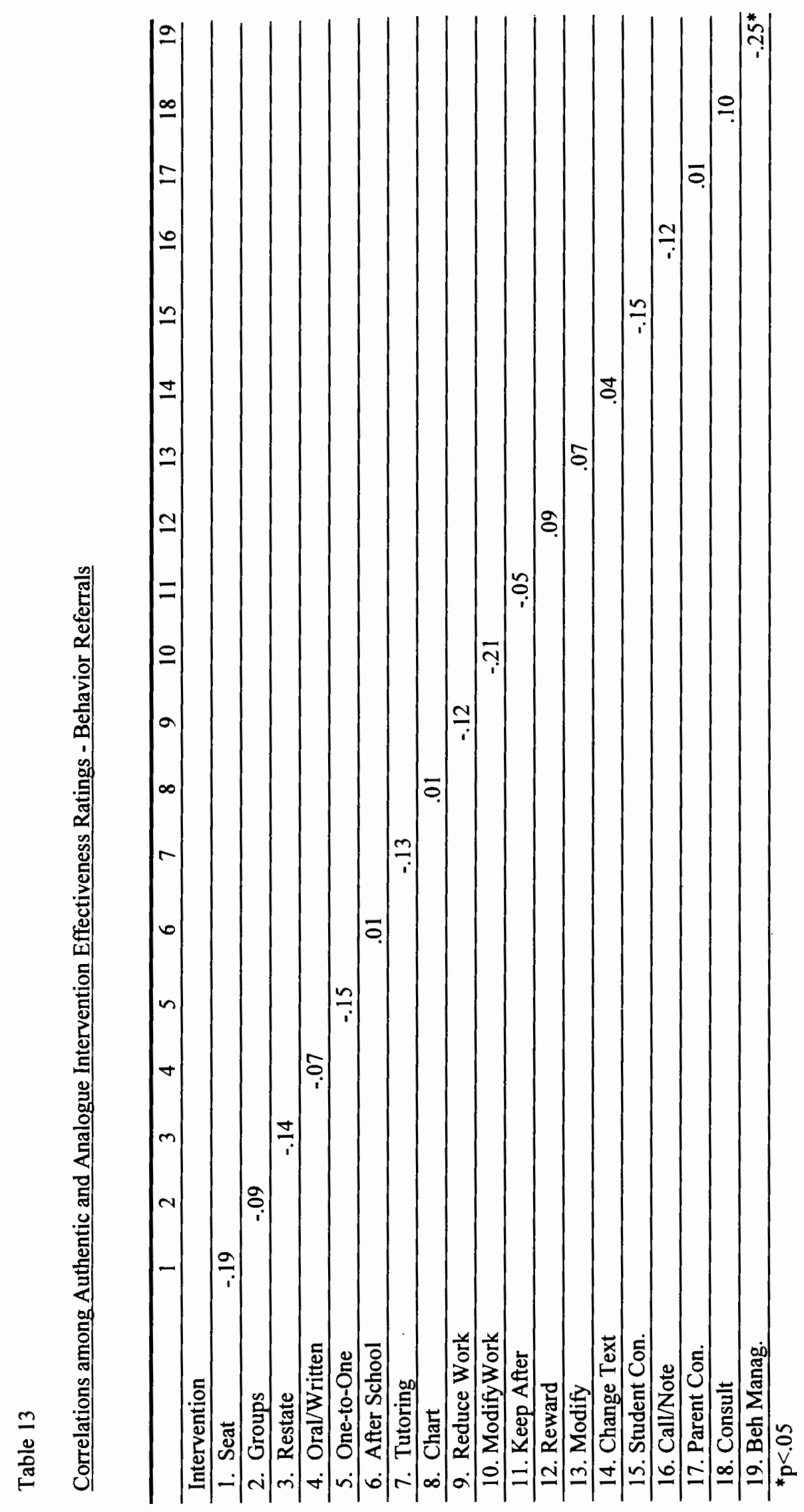


A Principal Components Analysis with Varimax rotation, a Principal Axis Factoring with

Varimax rotation and a Maximum Likelihood Analysis with Varimax rotation were conducted.

The Maximum Likelihood Analysis with Varimax rotation performed on the 20 interventions for the full data set of CASTRF forms $(\underline{N}=345)$ was selected for maximum interpretability.

The solution, which accounted for $56 \%$ of the total variance, resulted in 5 factors (referred to for the purposes of reporting as Clusters). Results of these analyses for teachers' effectiveness ratings are reported in Table 14.

Table 14

Factor Loadings, Communalities $\left(\mathrm{h}^{2}\right)$, Percents of Variance for Maximum Likelihood Extraction and Varimax Rotation for Teachers' Ratings of Intervention Effectiveness for Authentic Data $(N=345)$

\begin{tabular}{|c|c|c|c|c|c|c|}
\hline & $\mathrm{F} 1$ & $\mathrm{~F} 2$ & $\underline{F}$ & $\mathrm{~F} 4$ & $\underline{\mathrm{F} 5}$ & $\underline{h^{2}}$ \\
\hline Modify Worksheet (10) & .827 & .006 & .130 & .244 & .119 & .775 \\
\hline Reduction of Work (9) & .740 & .149 & .189 & .115 & .032 & .621 \\
\hline Modify Materials (13) & .504 & .082 & 134 & .271 & .355 & .478 \\
\hline Change Text/Mater.(14)s & .403 & .154 & .128 & .053 & .141 & .225 \\
\hline Oral vs. Written tests (4) & .383 & .193 & .369 & -.024 & -.013 & .321 \\
\hline Call/Note to Parents (16) & .145 & .778 & .121 & .083 & .291 & .732 \\
\hline Parent Conference (17) & .089 & .713 & .198 & .105 & .028 & .568 \\
\hline Student Conference (15) & .248 & .440 & .285 & .307 & .146 & .452 \\
\hline Student Restate Direct. (3) & .306 & .383 & .327 & .273 & .188 & .467 \\
\hline Change Seat (1) & .163 & .078 & .573 & .182 & .137 & .413 \\
\hline Use Chart (8) & .095 & .124 & .456 & .184 & .199 & .306 \\
\hline One-One Instruction (5) & .279 & .112 & .404 & .156 & .146 & .300 \\
\hline Change in Groups (2) & .176 & .282 & .332 & .173 & .069 & .255 \\
\hline Keep After School (11) & .089 & .162 & .352 & .506 & .067 & .418 \\
\hline Consult Specialist (18) & .073 & .457 & -.033 & .483 & .325 & .555 \\
\hline After School Help (6) & .144 & .002 & .079 & 463 & -.013 & .242 \\
\hline Tutoring (7) & .200 & .166 & .309 & .375 & .041 & .306 \\
\hline Other $(20)$ & .032 & .166 & .156 & .269 & .110 & .137 \\
\hline Reward (12) & .147 & .144 & .310 & .025 & .688 & .613 \\
\hline Behavior Manag (19) & .172 & .305 & .095 & .106 & 439 & .336 \\
\hline Percent of variance: & 27.4 & 6.1 & 3.3 & $3 . \overline{3}$ & 2.6 & \\
\hline \multicolumn{7}{|c|}{$\mathrm{F} 1=$ Individualized Curricular Changes } \\
\hline \multicolumn{7}{|c|}{$\mathrm{F} 2=$ Communication } \\
\hline \multicolumn{7}{|c|}{ F3=Process Instructional Adaptations } \\
\hline \multicolumn{7}{|c|}{$\mathrm{F} 4=$ Extracurricular Interventions } \\
\hline \multicolumn{7}{|c|}{ F5=Behavioral Conditioning Interventions } \\
\hline
\end{tabular}


Loadings of .40 and above were used as the criterion for including an item in a factor.

Five variables $(4,3,2,7,20)$ did not meet the criterion for inclusion and were eliminated. With 15 remaining variables, the five factors were identified as: Individualized Curricular Changes (ICC), Communication (COM), Process Instructional Adaptations (PIA), Extracurricular Interventions (EXI) and Behavioral Conditioning Interventions (BCI). Factors appear to be internally consistent with the lowest Squared Multiple Correlation (SMC) reported at .572 . However, communality values for some of the variables were quite low and may indicate that the variables are not exceptionally well defined for the factor solution.

\section{Analogue Data Factor Scores}

The five factor solution was tested on analogue data. For each survey participant, a total factor score was calculated for each factor based upon a weighted sum of effectiveness ratings (to account for differences in numbers of items on the factors) for each variable included in each factor. Separate scores were calculated for Academic and Behavior referrals. Results show significant positive correlations between Factor Scores for Academic Referrals and Behavior Referrals as presented in Table 15. Therefore, it would appear that there is a significant relationship between the effectiveness ratings of factor scores for Academic and Behavior Problems with the exception of the use of Behavioral Conditioning Interventions. For academic referral, Process Instructional Adaptations were rated as most effective among factor scores. Behavioral Conditioning Interventions were least effective. On the other hand, for behavioral referrals, Behavioral Conditioning Interventions were rated the most effective among factor scores. Instructional Curricular Changes are among the least effective for behavior referrals. The more effective a teacher finds a set of factor interventions for an academic referral, the more effective those interventions would be for a behavioral referral. No relationship exists between the effectiveness ratings for the use of Behavioral Conditioning Interventions between academic and behavioral referrals. 
Each analogue participant was assigned an intervention type based on the largest of their Factor Scores. The following frequencies in Table 16 are reported for Intervention Type for Academic and Behavior Referrals. Results show that, for behavior referrals, no teachers were classified as using a primarily Individualized Curricular Change (ICC) approach to intervention selection and rating. For behavior referrals, most teachers can be classified as using Behavioral Conditioning Interventions (BCI) or Communication (COM) as their primary intervention. The same teachers, considering an academic referral, on the other hand, switch hats and become

Table 15

Factor Scores ${ }^{\mathrm{a}}$ and Correlations-Analogue Data Effectiveness Ratings

\begin{tabular}{|c|c|c|c|c|c|}
\hline Factor $^{\mathrm{a}}$ & \multicolumn{2}{|c|}{ Academic Referral } & \multicolumn{3}{|c|}{ Behavior Referral } \\
\hline $\mathrm{ICC}$ & 8.23 & 5.31 & 2.23 & 3.77 & $.488^{* *}$ \\
\hline COM & 9.53 & 4.72 & 10.67 & 4.44 & $.591 * *$ \\
\hline PLA & 10.89 & 4.40 & 6.51 & 3.93 & $.420^{* *}$ \\
\hline EXI & 5.98 & 4.09 & 5.25 & 4.26 & $.549^{* *}$ \\
\hline$\underline{\mathrm{BCI}}$ & 5.38 & 5.99 & 14.64 & 3.84 & .221 \\
\hline $\begin{array}{l}{ }^{\mathrm{p}}<.01 \\
{ }^{\mathrm{a}} \text { Facto } \\
\text { ICC (S } \\
\text { COM } \\
\text { PIA (S } \\
\text { EXI (S } \\
\text { BCI (S }\end{array}$ & $\begin{array}{l}\text { calcula } \\
\text { Effectiv } \\
\text { f Effect } \\
\text { Effectiv } \\
\text { Effectiv } \\
\text { Effectiv }\end{array}$ & $\begin{array}{l}\text { ess: Ratings } \\
\text { eness Ratin } \\
\text { less Ratings } \\
\text { ess Ratings } \\
\text { ess Rating }\end{array}$ & $\begin{array}{l}\text { rventio } \\
\text { tervent } \\
\text { rventio } \\
\text { rventio } \\
\text { rventio }\end{array}$ & $\begin{array}{l}9,10, \\
\text { s } 15, \\
1,5,8 \\
6,11, \\
2,19)\end{array}$ & $\begin{array}{l}1.33 \\
33\end{array}$ \\
\hline
\end{tabular}

Table 16

Frequencies of Analogue Intervention Type

\begin{tabular}{lcc}
\hline & Academic Referral & Behavior Referral \\
\hline TEACHER NTERVENTION TYPE & $\frac{\mathrm{N}}{21}$ & $\underline{\mathrm{N}}$ \\
Individualized Curricular Changes & 22 & 0 \\
Communication & 39 & 22 \\
Process Instructional Adaptations & 3 & 6 \\
Extracurricular Interventions & 10 & 3 \\
Behavioral Conditioning Interventions & 95 & 64 \\
Total & 95 \\
\hline
\end{tabular}


primarily Process Instructional Adaptors (PIA) or Communicators (COM). Results suggest possible intraindividual flexibility to intervention selection and rating.

\section{Authentic Data Factor Scores}

Each CASTRF participant was also assigned an intervention type based on the largest of their Factor Scores. The following frequencies in Table 17 are reported for Intervention Type for Academic and Behavior Referrals. Eighteen percent (18\%) of classifiable teachers making academic referral and $16 \%$ of teachers making behavioral referral would be considered to be individualized curricular changers. Results show no differences between observed and expected frequencies for referral and intervention type, $\chi^{2}(5, \underline{n}=345)=3.84, \underline{p}=.572$. Interestingly, for the authentic data, teachers were classified as using and rating "Process Instructional Changes" most frequently for both academic and behavioral referrals. Forty-one percent ( $41 \%)$ of classifiable teachers making academic referrals were considered Process Instructional Adaptors and $33 \%$ of classifiable teachers making behavioral referrals were considered Process Instructional Adaptors. Also, teachers are least likely to be classified as relying primarily on Extracurricular Interventions (academic $=5.5 \%$, behavior $=3.1 \%$ ). Additionally, no significant differences were noted between mean effectiveness ratings for authentic academic versus behavioral referrals or any factor, as can be seen in Table 18.

Table 17

Frequencies of Authentic Intervention Type

\begin{tabular}{lcc}
\hline & Academic Referral & Behavior Referral \\
\hline TEACHER INTERVENTION TYPE & $\underline{N}$ & $\underline{N}$ \\
Individualized Curricular Changes & 34 & 10 \\
Communication & 22 & 10 \\
Process Instructional Adaptations & 74 & 21 \\
Extracurricular Interventions & 10 & 2 \\
Behavioral Conditioning Interventions & 41 & 20 \\
Unclassifiable & 77 & 24 \\
Total & 258 & 87 \\
\hline
\end{tabular}


Table 18

Factor Scores for Authentic Effectiveness Ratings

\begin{tabular}{lllllll}
\hline & \multicolumn{2}{l}{ Academic } & $(\mathrm{N}=258)$ & \multicolumn{2}{l}{ Behavior $(\mathrm{N}=87)$} & $\mathrm{d}$ \\
& $\mathrm{M}$ & $\mathrm{SD}$ & $\mathrm{M}$ & $\mathrm{SD}$ & $\mathrm{t}$ & $\mathrm{df}$ \\
\hline BCI & 2.31 & 4.31 & 3.35 & 4.31 & -1.94 & 342 \\
COM & 1.98 & 3.70 & 2.68 & 3.88 & -1.48 & 342 \\
EXI & 1.07 & 2.52 & .94 & 1.58 & .43 & 342 \\
ICC & 2.18 & 3.88 & 1.60 & 2.78 & 1.28 & 342 \\
PLA & 3.54 & 4.14 & 3.57 & 3.76 & -.06 & 342 \\
\hline
\end{tabular}

No significant differences noted

Efficacy and Prereferral Interventions

IS THE TEACHER EFFICACY SCALE RELIABLE AND VALID? WHAT IS THE RELATIONSHIP BETWEEN PERCEIVED EFFICACY PERCEPTIONS AND TEACHER VARIABLES?

\section{The Teacher Efficacy Scale}

In order to verify the existence of the two factor solution that was found by Guskey and Passaro (1994), a Factor Analysis of the type conducted in their study was conducted on this sample. Results confirm the factor solution found. A Generalized Least Squares extraction with Varimax rotation was selected for a two factor solution. Table 19 outlines the factor loadings on this scale and generally confirms the internal versus external distinction found in their study. It should be noted, however, that weaker factor loadings were apparent for items 5 , 6,15 , and 21 as compared with results from Guskey and Passaro (1994). All items were used for subsequent analyses.

Each of the 97 teacher subjects completed the 21 item Teacher Self-Efficacy Scale. Table 20 suggests greater variability among mean scores on the External Efficacy Scale as compared with the Internal Efficacy Scale. The items which make up the Internal Efficacy Scale are Items $\# 1,7,8,11,12,14,15,16,18$, and 19 . The items which make up the External Efficacy Scale are Items $\# 2,3,4,5,6,9,10,13,17,20$, and 21 . Item means were examined for Skewness and Kurtosis and results suggest that all iterns were normally distributed except for 
the Skewness of item \#6 (1.66). No transformation of this variable was done as, in this case, it would significantly impede interpretability (Tabachnick \& Fidell, 1989). The scale was subject

Table 19

Factor Loadings for the Teacher Efficacy Scale: Current Findings Compared with Guskey and Passaro (1994)

\begin{tabular}{|c|c|c|c|c|c|}
\hline & \multicolumn{2}{|c|}{ Guskey \& Passaro (1994) } & \multicolumn{2}{|c|}{ Tillotson (1998) } & \\
\hline Item No. & Factor 1 & Factor 2 & $\underline{F} 1$ & $\underline{\mathrm{F} 2}$ & Communality \\
\hline 1 & -.030 & .546 & -.011 & .442 & .364 \\
\hline 2 & .563 & -.180 & .476 & .072 & .426 \\
\hline 3 & .572 & .114 & .494 & -.103 & .434 \\
\hline 4 & .610 & .082 & .453 & .166 & .330 \\
\hline 5 & .448 & -.163 & .128 & -.102 & .362 \\
\hline 6 & .421 & -.114 & .011 & -.406 & .364 \\
\hline 7 & -.017 & .601 & .029 & .572 & .510 \\
\hline 8 & -.333 & .534 & -.373 & .645 & .608 \\
\hline 9 & .778 & -.010 & .853 & -.104 & .672 \\
\hline 10 & .664 & -.259 & .580 & -.125 & .442 \\
\hline 11 & -.226 & .700 & -.079 & .616 & .556 \\
\hline 12 & .020 & .619 & -.040 & .552 & .384 \\
\hline 13 & .411 & .168 & .398 & .148 & .357 \\
\hline 14 & -.047 & .592 & .120 & .215 & .362 \\
\hline 15 & -.254 & .423 & -.342 & .158 & .367 \\
\hline 16 & -.133 & .441 & -.103 & .406 & .374 \\
\hline 17 & .344 & -.053 & .254 & -.008 & .291 \\
\hline 18 & .056 & .343 & .021 & .313 & .222 \\
\hline 19 & -.359 & .503 & -.574 & .592 & .680 \\
\hline 20 & .682 & -.152 & .820 & -.134 & .657 \\
\hline 21 & .289 & -.027 & .017 & -.256 & .303 \\
\hline
\end{tabular}

to a reliability analysis to determine internal reliability of items. Cronbach's alpha coefficient was found to be .708 for the Internal Efficacy Scale and .663 for the External Efficacy Scale.

For each respondent, two composite scores were calculated entitled the External Efficacy Score (EES) and the Internal Efficacy Score (IES). The EES score was calculated as an average of item responses for the items which make up the external scale, and the IES score was calculated as an average of item responses for the items which make up the internal scale.

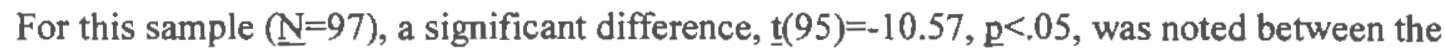


EES $(\underline{M}=3.10, \underline{S D}=.62)$ and the IES $(\underline{M}=4.15, \underline{S D}=.54)$ scores. In essence, the sample appears to be more internal than external with a significant negative correlation $(\mathrm{r}=-.38)$. It should be noted that the total EES (Kurtosis=.22, Skewness=.122). and IES (Kurtosis=-.51, Skewness $=$ .22) scores were both normally distributed.

\section{Efficacy and Referrals to Special Education}

The relationship between referring and nonreferring teachers on the Teacher Efficacy Scale was examined with Independent Sample t-tests. No significant differences were found between teachers who have referred a Student A-type child (referring teachers) and teachers who have not referred a Student A-type child (nonreferring teachers) on measures of External Efficacy $\underline{t}(93)=.13, \underline{p}>, 05$. Also, no significant differences were found between referring and nonreferring teachers on the Intemal Efficacy Scale $t(94)=-.39, p>.05$. Similarly, no significant differences were found for behavioral referrals between referring teachers and nonreferring on the measure of External Efficacy, $\mathrm{t}(92)=.77, \mathrm{p}>, 05$ or the Internal Efficacy Scale, $\mathrm{t}(93)=.23$, $\mathrm{p}>.05$.

\section{Efficacy and Experience}

In order to examine the relationship between years of experience and efficacy scores, Pearson Product Moment correlations were conducted. No significant relationship was found between years of experience and either the EES ( $r=-07)$ or IES ( $r=.009)$. Additionally, no significant relationship was demonstrated between age and either the EES $(\underline{r}=.08)$ or IES $(\underline{r}=-$ .04). A significant difference, however, was noted between males $(\underline{\mathrm{M}}=4.58, \underline{\mathrm{SD}}=.47)$ and females $(\underline{\mathrm{M}}=4.12, \underline{\mathrm{SD}}=.54)$ on the IES scale, $\underline{\mathrm{t}}(94)=2.34, \mathrm{p}<.05$. Men in this sample were more internally oriented than women.

\section{Efficacy and Teacher Type}

The self-efficacy scores of general education teachers and special education teachers were examined. No significant differences were found between general education teachers $(\underline{M}=3.11$, 
$\underline{\mathrm{SD}}=.62)$ and special education teachers $(\underline{M}=3.05, \underline{\mathrm{S}}=.67)$ on external efficacy scores, $\underline{t}(94)=.39, \underline{p}<.05$. Additionally, no significant differences were found between general education teachers $(\underline{M}=4.12, \underline{\mathrm{SD}}=.55)$ and special education teachers $(\underline{\mathrm{M}}=4.31, \underline{\mathrm{SD}}=.52)$ on internal efficacy scores, $\mathrm{t}(95)=-1.32, \mathrm{p}<.05$.

A Pearson Product Moment Correlation was conducted to examine the relationship between self-efficacy and teacher's length of participation in a prereferral intervention program. No relationship was evidenced between external or internal self-efficacy scores of teachers and their length of CAP/CAST participation ( $[=.10$ and $[=.077$, respectively).

Efficacy and Intervention Use and Effectiveness

WHAT IS THE RELATIONSHIP BETWEEN TEACHERS' EXTERNAL AND INTERNAL EFFICACY PERCEPTIONS AND THEIR SELECTION OF INTERVENTIONS AND EFFECTIVENESS RATINGS?

\section{Prediction \#1}

The degree of internal self-efficacy will be positively related to the number of interventions chosen and ratings of intervention effectiveness.

\section{Analogue Data}

Efficacy and Frequency of Intervention Selection. Partial Correlations controlling for years of teaching experience were conducted to examine the relationship between internal and external self-efficacy scores and the frequency of interventions chosen for both academic and behavioral referrals. No relationship was found between scores on the external efficacy scale and the number of interventions selected for Student $A, p r=.06, \underline{n}=95, \underline{p}>.57$. Similarly, no relationship was demonstrated between scores on the internal efficacy scale and the number of interventions for Student $A, p F=19, \underline{n}=93, \underline{p}=.065$. Additionally, no relationship was 
Table 20

\section{Descriptive Statistics for Teacher Self-Efficacy Scale}

\begin{tabular}{llllll}
\hline & \multicolumn{2}{c}{ Internal Scale } & \multicolumn{3}{c}{ External Scale } \\
Item \# & $\mathrm{M}$ & $\mathrm{SD}$ & Item \# & $\mathrm{M}$ & $\mathrm{SD}$ \\
\hline 1 & 4.06 & .97 & 2 & 3.48 & 1.31 \\
7 & 4.07 & .93 & 3 & 3.00 & 1.19 \\
8 & 4.39 & 1.06 & 4 & 4.06 & 1.50 \\
11 & 4.09 & .95 & 5 & 2.91 & 1.63 \\
12 & 4.13 & .93 & 6 & 1.77 & 1.01 \\
14 & 4.03 & 1.17 & 9 & 3.07 & 1.12 \\
15 & 3.48 & 1.15 & 10 & 2.18 & 1.11 \\
16 & 4.79 & .97 & 13 & 4.75 & 1.15 \\
18 & 4.34 & 1.10 & 17 & 3.55 & 1.46 \\
19 & 4.13 & 1.12 & 20 & 2.68 & 1.07 \\
& & & 21 & 2.59 & 1.55 \\
\hline
\end{tabular}

demonstrated between the number of interventions selected for Student B and external self efficacy scores $\underline{p}=.06, \underline{n}=92, \underline{p}=.575$ or internal efficacy scores $\underline{p}=.04, \underline{n}=93, \underline{p}=.69$.

\section{Efficacy and Effectiveness of Interventions. Pearson Product Moment Correlation}

coefficients were examined in order to explore the relationship between self-efficacy and intervention effectiveness ratings for analogue data. No significant correlations were found between either internal or external self-efficacy scores and the effectiveness ratings of interventions chosen for an academic referral. For behavioral referrals, however, a number of significant correlations were noted. Table 21 indicates the correlation coefficients for behavioral referral interventions and scores on measure of internal and external efficacy. Results suggest that teachers who are external in their perceptions of efficacy, tend to rate particular interventions as less effective than teachers who are less external. Internally oriented individuals, on the other hand, tend to rate several interventions as more effective than less internally oriented individuals.

In particular, the more externally efficacious the teacher, the less likely that "Change in Groups" will be rated to be an effective intervention but the more likely that "After School 
Help," "Use of Organizational Chart," "Reduction of Work Assignments," "Modification of Materials," and "Behavioral Management Techniques" will be rated as effective. The more internally efficacious the teacher, the more likely that "Change in Group," "One-to-One Instruction," "Reduction of Work Assignments," "Reward System," and "Behavior Management Techniques" will be effective. Interestingly, teachers who are highly external and highly internal are likely to rate "Behavior Management," "Reduction of Work Assignments" to be effective interventions.

For each individual, a mean effectiveness rating score was generated for both academic referrals and for the behavior referrals. Partial correlations controlling for years of teaching experience were conducted to examine the relationship between internal and external selfefficacy scores and the mean effectiveness ratings of interventions chosen for both academic and behavioral referrals and are reported in Table 22. Interestingly, although no significant relationships were noted between internal or external efficacy scores for the effectiveness of interventions chosen for an academic referral, significant relationships were again noted between both internal and external efficacy scores and the effectiveness of interventions chosen for behavioral referrals. Specifically, a positive relationship is found between internal selfefficacy scores and the total effectiveness score for academic referrals. Therefore, the more internally efficacious the teacher, the more likely that this individual will report that interventions selected for behavioral referrals are effective. On the other hand and, as would follow logically from the aforementioned finding, the more External the efficacy score of the individual, the less likely they are to report that behavioral interventions are effective.

Efficacy and Intervention Types. Given the literature that suggests that consideration should be given to the relationship between the presumably independent variables of efficacy such as Teaching vs. Personal or Internal vs. External (Woolfolk \& Hoy, 1990), the analogue 
sample was divided according to efficacy type. For each individual, a split was made based on the mean for internal efficacy $(\underline{M}=3.10, \underline{S D}=.62)$ and external efficacy $(\underline{M}=4.15, \underline{S D}=.54)$.

Table 21

Correlations between Self-Efficacy Scores and Ratings of Effectiveness of Interventions for Behavioral Referrals

\begin{tabular}{llc} 
& External Efficacy & Internal Efficacy \\
\hline Intervention & $\underline{\mathrm{r}}$ & .169 \\
Change in Seating & -.118 & $.344^{*}$ \\
Change in Groups & $-.318^{*}$ & .170 \\
Have Student Restate Directions & -.062 & .553 \\
Oral vs. Written Tests/Reports & -.517 & $.462^{*}$ \\
One-To-One Instruction & .347 & .211 \\
After School Help & $.595^{* *}$ & .377 \\
Tutoring & .167 & .132 \\
Use of Organizational Charts & $.411^{* *}$ & $.529^{*}$ \\
Reduction of Work Assignments & $.559^{*}$ & -.029 \\
Modify Worksheet/Assignments & .414 & .151 \\
Keep After School & .268 & $.267^{*}$ \\
Reward System & .200 & .333 \\
Modify Material/Presentation & $.579^{* *}$ & .092 \\
Change in Text/Materials & .148 & .190 \\
Student Conference & -.154 & .173 \\
Call/Note to Parents & .206 & .121 \\
Parent Conference & .025 & .197 \\
Consult with Specialists & .221 & $.215^{*}$ \\
Behavior Management & $.273^{*}$ & \\
\hline
\end{tabular}

Table 22

Partial Correlations Controlling for Years of Teaching Experience for Academic versus Behavioral Referrals and Internal and External Efficacy Scores

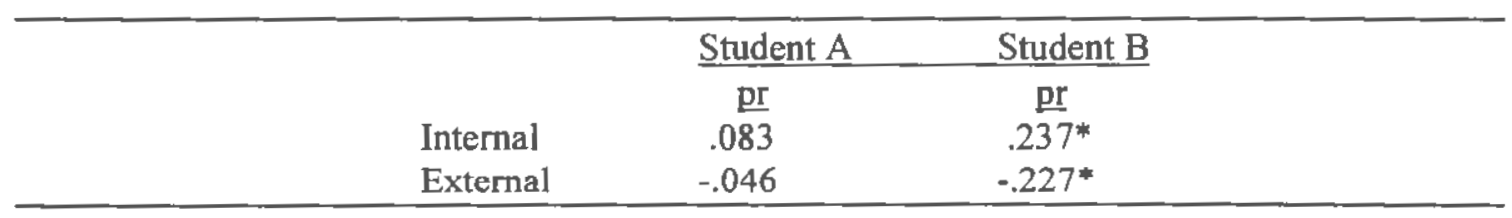


Table 23 presents the means and standard deviations for the new split scores. As is noted, most of the sample present with high levels of perceived internal efficacy and low levels of perceived external efficacy. Each individual was classified then as either high (score $\geq 3.10$ ) or low (score $<3.10$ ) on internal efficacy and also as either high (score $\geq 4.15$ ) or low (score $<4.15$ ) on external efficacy. Four possible typologies were created to account for the possible interaction of internal and external efficacy. Individuals were classified as either High External/High Internal (16.5\%), Low External/High Internal (69.1\%), High External/Low Internal $(7.2 \%)$, or Low External/Low Internal $(6.2 \%)$. The majority of individuals were classified as Low External/High Internal.

A Crosstabs procedure to examine the relationship between intervention types and efficacy types was conducted. Results indicate that the greatest number of individuals responding to the

Table 23

Efficacy Split Scores

\begin{tabular}{|c|c|c|c|c|c|c|}
\hline & \multicolumn{3}{|c|}{ High } & \multicolumn{3}{|c|}{ Low } \\
\hline & $\underline{\mathrm{n}}$ & $M$ & SD & $\underline{\mathbf{n}}$ & $\mathbf{M}$ & SD \\
\hline External & 23 & 3.93 & .32 & 73 & 2.84 & .44 \\
\hline Internal & 84 & 4.29 & .44 & 13 & 3.25 & .18 \\
\hline
\end{tabular}

analogue academic referral were considered to prefer Process Instructional Adaptations (PIA) whereas the greatest number of individuals responding to the analogue behavioral referral were considered to prefer Behavioral Conditioning Interventions $(\mathrm{BCI})$. Table 24 presents the numbers of individuals by intervention type and efficacy type. A 5x4 Chi Square analysis indicates no significant differences between observed and expected frequencies for academic referrals $\chi^{2}(12, \underline{n}=94)=4.33, \underline{p}=.98$. Significant differences, however, were discovered for behavior referrals $\chi^{2}(9, \underline{n}=94)=18.40, \underline{p}=.03$. Those classified as Low External/ High Internal were more likely to prefer behavioral conditioning interventions (BCI). 
Table 24

Crosstabs of Intervention Type by Efficacy Type

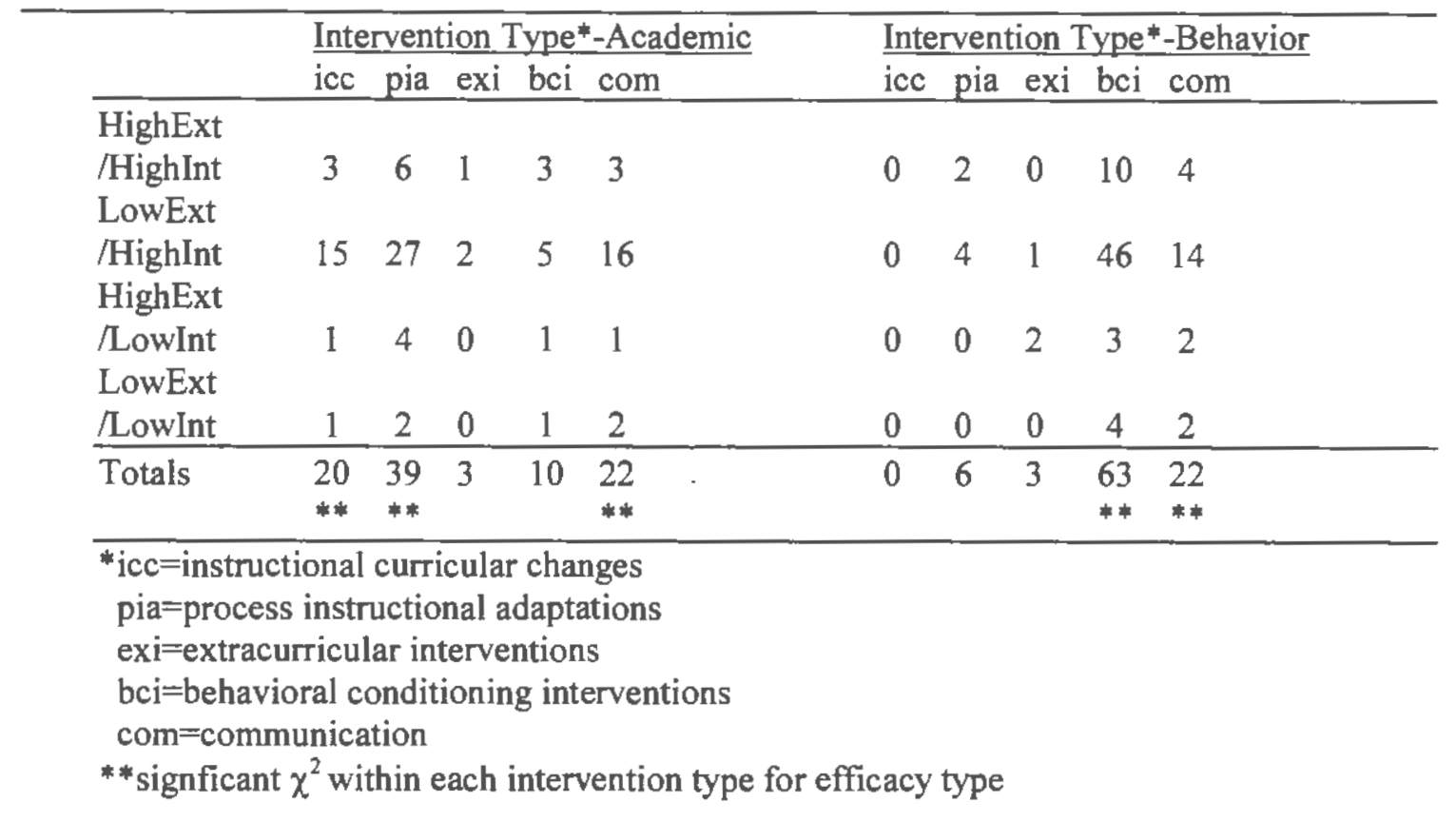

Figure 8 graphically represents the percentages of individuals by intervention type and efficacy type for academic referrals. Figure 9 graphically represents the percentages of individuals by intervention type and efficacy type for behavioral referrals. No individual was classified as preferring instructional curricular changes for behavioral referrals.

\section{Authentic Data}

Efficacy and Frequency of Intervention Selection. Partial Correlations controlling for years of teaching experience were conducted to examine the relationship between internal and external self-efficacy scores and the frequency of interventions chosen for both authentic academic and behavioral referrals. No relationship was found between scores on the external efficacy scale and the number of interventions selected for academic referrals, $\underline{r}=-.-161, \underline{n}=71$, $\mathrm{p}=.173$, or for behavioral referrals, $\underline{\mathrm{r}}=-.038, \underline{\mathrm{n}}=50, \mathrm{p}=.787$. Similarly, no relationship was demonstrated between scores on the internal efficacy scale and the number of interventions 


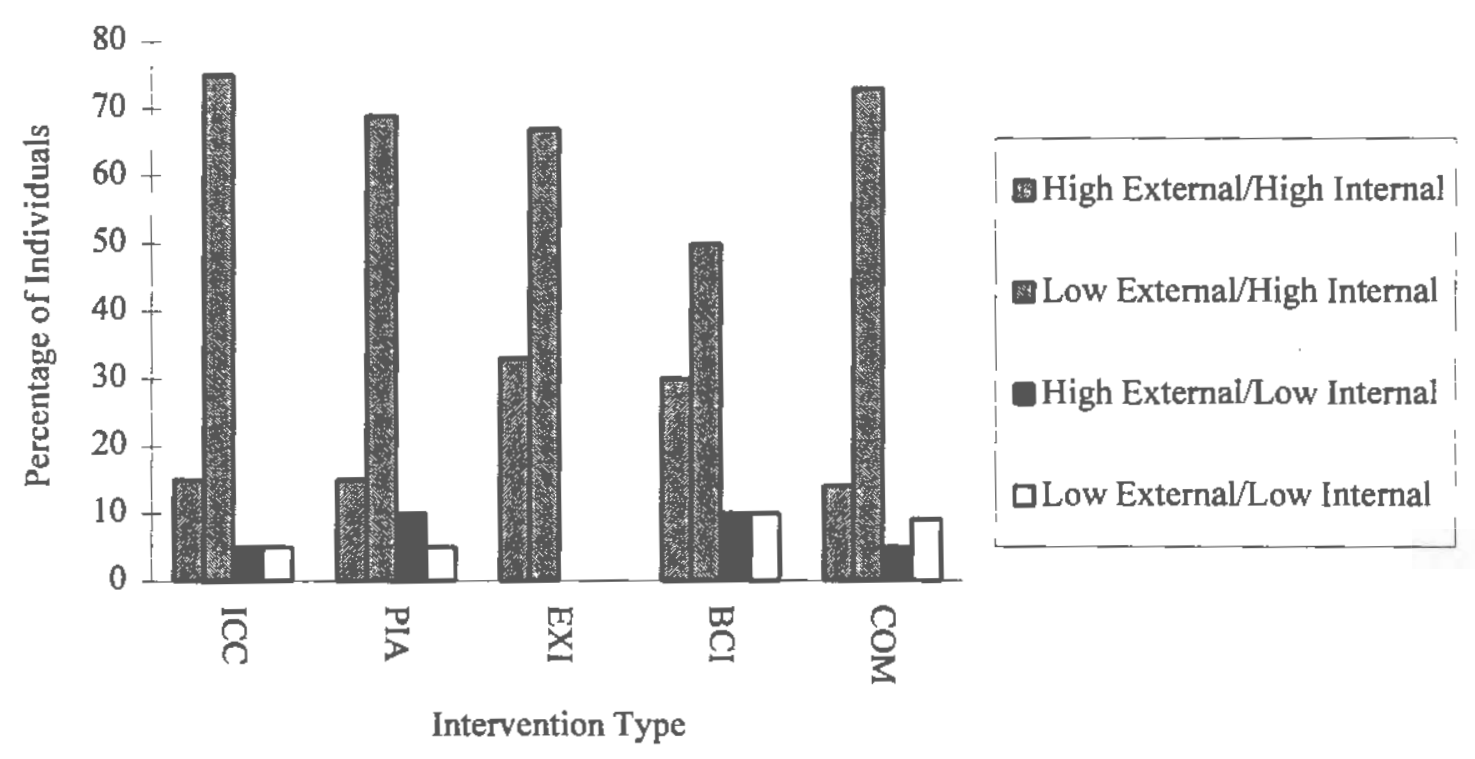

Figure 8. Efficacy type and intervention preference-academic referrals

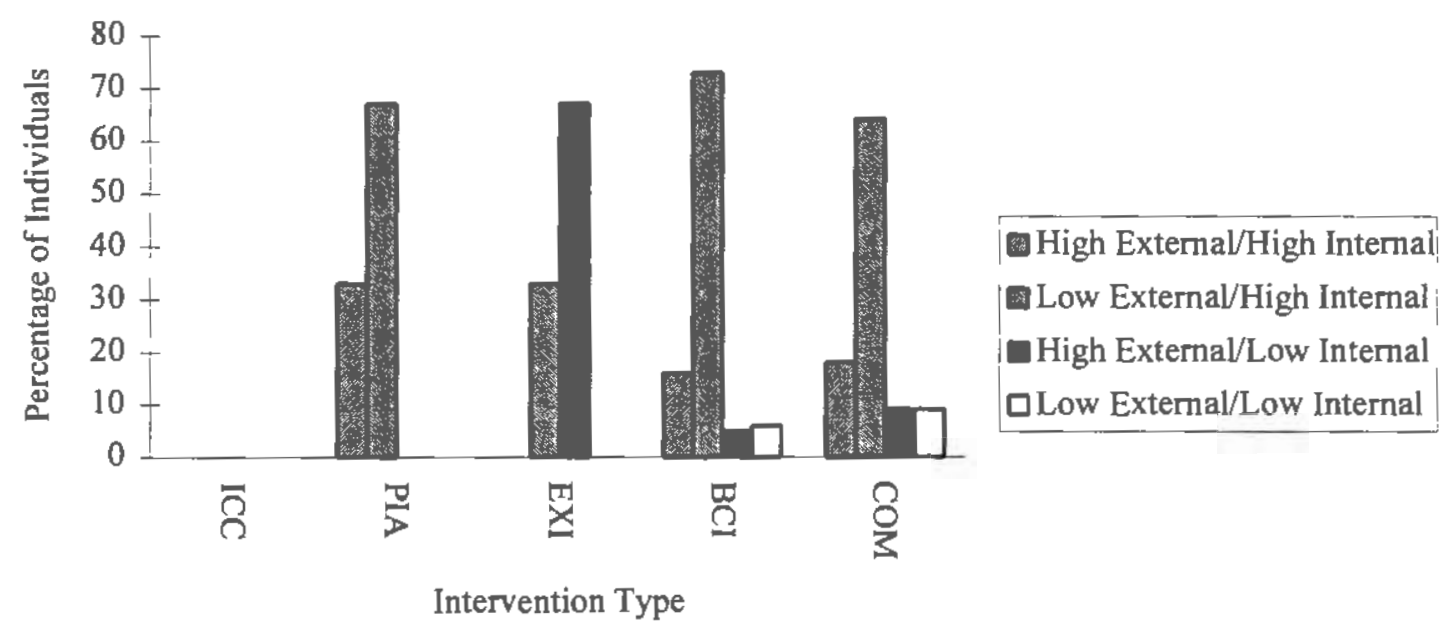

Figure 9. Efficacy type and intervention preference-behavioral referrals 
chosen for academic referrals, $\underline{\underline{y}}=-.059, \underline{\mathrm{n}}=71, \underline{\mathrm{p}}=.619$ or for behavioral referrals, $\underline{\underline{y}}=-.12, \underline{\mathrm{n}}=50$, $\mathrm{p}=.401$

Efficacy and Effectiveness of Interventions. Partial Correlations controlling for years of teaching experience were also conducted to examine the relationship between internal and external self-efficacy scores and the effectiveness of authentic intervention chosen for both academic and behavioral referrals. No significant relationships were noted between external self-efficacy scores and the effectiveness of academic interventions, $\underline{\underline{y}}=.057, \underline{\underline{n}}=71, \underline{p}=.634$, or behavioral interventions, $\underline{r}=.028, \underline{n}=50, \underline{p}=.846$ on the matched sample data set (matched for individual and grade). Similarly, no significant relationships were noted between internal selfefficacy scores and the effectiveness of interventions chosen for academic referrals $\underline{r}=.104$, $\underline{n}=71, \mathrm{p}=382$, or behavioral referrals $\underline{\underline{r}}=.016, \underline{\mathrm{n}}=50, \mathrm{p}=.906$. However, when the unaltered data set for individually matched data for behavior referrals $(\underline{n}=32)$ was examined, a significant negative relationship was found between the number of authentic interventions utilized for the behavioral referral and scores on the external efficacy scale. In this case, the more external the individual's sense of self-efficacy, the fewer interventions are chosen for authentic behavioral referrals.

\section{Prediction \#2}

The degree of external self-efficacy will be positively related to factored interventions.

A discriminant function analysis was performed using 5 predictors (age, years of teaching experience, internal and external self-efficacy scores and number of interventions selected) to predict group membership in 5 groups of intervention type. Intervention type groups were: Individualized Curricular Changes (ICC), Communication (COM), Process Instructional Adaptations (PIA), Extracurricular Interventions (EXI) and Behavioral Conditioning 
Interventions (BCI). Four canonical functions were calculated, with a combined $\chi^{2}(20)=22.34$, $\mathrm{p}=.32$. No variables qualified for further analysis as no significant differences had been

Table 25

Descriptive Statistics for Teacher Variables by Intervention Type

\begin{tabular}{|c|c|c|c|c|c|c|c|c|c|c|c|c|}
\hline & \multicolumn{3}{|c|}{$\begin{array}{l}\text { Years of } \\
\text { Experience }\end{array}$} & \multicolumn{3}{|c|}{$\mathrm{Age}^{\mathrm{b}}$} & \multicolumn{3}{|c|}{ External Efficacy ${ }^{c}$} & \multicolumn{3}{|c|}{ Internal Efficacy } \\
\hline & $\underline{\mathrm{n}}$ & $\underline{M}$ & $\underline{S D}$ & $\underline{\mathrm{n}}$ & $\underline{\mathbf{M}}$ & $\underline{\mathrm{SD}}$ & $\underline{\mathbf{n}}$ & $\underline{\mathrm{M}}$ & $\underline{\mathrm{SD}}$ & $\underline{\mathbf{n}}$ & $\underline{M}$ & $\underline{\mathrm{SD}}$ \\
\hline $\mathrm{ICC}$ & $\overline{2} 1$ & 17.6 & $\overline{7.6}$ & 21 & $\overline{46.6}$ & $\overline{5.1}$ & 20 & 3.0 & .73 & 21 & $\overline{4.4}$ & .55 \\
\hline PIA & 39 & 14.3 & 7.9 & 39 & 41.8 & 9.7 & 39 & 3.2 & .56 & 39 & 4.0 & .53 \\
\hline EXI & 3 & 6.0 & 2.7 & 3 & 37.7 & 20.3 & 3 & 3.5 & .83 & 3 & 4.1 & .55 \\
\hline $\mathrm{BCI}$ & 10 & 10.6 & 9.0 & 10 & 37.2 & 9.4 & 10 & 3.2 & .60 & 10 & 4.2 & .57 \\
\hline $\mathrm{COM}$ & 22 & 15.2 & 9.6 & 22 & 41.4 & 9.6 & 22 & 3.2 & .55 & 22 & 4.1 & .47 \\
\hline
\end{tabular}

ANOVA RESULTS:

${ }^{\mathrm{a}} \mathrm{F}(4,90)=2.12, \mathrm{p}=.085$

${ }^{b} F(4,90)=2.22, p=.074$

${ }^{\mathrm{c}} \mathrm{F}(4,89)=.62, \mathrm{p}=.651$

${ }^{d} \mathrm{~F}(4,89)=1.67, \mathrm{D}=.165$

revealed between any predictor variables and group membership. Overall, results are not suggestive of any association between groups and predictors. Additionally, an ANOVA using intervention type as an independent variable and dependent variables of: Internal Efficacy Score, Extemal Efficacy Score, Age and Years of Teaching Experience confirmed a lack of relationship among variables. Table 25 reports means and standard deviations for these Intervention Types and the results of the 4 ANOVAs that were performed. 


\section{DISCUSSION}

\section{Analogue Versus Authentic Findings}

Results of the current investigation raise some important considerations in terms of the use analogue methodology in the examination of teacher's use and perceptions of the effectiveness of interventions. One of the primary purposes of this investigation was to examine the differences between how teachers say they will respond in a given (analogue) situation and how they respond in a corresponding authentic situation. If analogue methodology creates the same answers as does an authentic method, results provide empirical support for the validity of the former.

In terms of the comparability of authentic and analogue findings, teachers tend to use many interventions with the same relative frequencies but rate the effectiveness of these interventions quite differently. Thus to answer the question of comparability between authentic and analogue methods, it would appear that the hypothetical mirrors the real world in the former but not in the latter cases. This finding, in part, supports research in clinical behavioral research that has demonstrated comparability between an analogue sample and a clinical sample (Emmelkamp, Mersch, \& Vissia, 1985). In essence, while teachers may make choices about the types of interventions they would use at the same relative frequencies, they find the actual implementation of these interventions much less effective than they might report in the relatively dispassionate survey method.

\section{Academic versus Behavioral Interventions}

For survey respondents, teachers are likely to use and find behavior management techniques, reward systems, parent involvement, and consultation with specialists as effective for prereferral intervention for children with behavioral problems. Of these, behavioral 
management techniques and parent involvement are most likely to be chosen and rated as effective. Also, least likely chosen interventions for those with behavior problems are also rated as least effective. For children with academic problems, teachers may not use interventions which they find most effective. For example, while they find one-to-one instruction, modification of worksheets/assignments, and materials/presentation highly effective, they are less likely to use these interventions compared with others such as parent conference, have students restate directions, change seat, and consult with specialists. It may be that the use of these more effective interventions is hampered by the more individualized and therefore more time consuming nature of the interventions. The finding that teachers may not use interventions which they find to be effective is supported by authentic data, as well.

The current investigation revealed many fewer referrals for behavior problems than for academic-type problems. While the current study elicited a $25 \%$ behavioral referral rate, a $10 \%$ figure is reported elsewhere (Gottlieb, Gottlieb, \& Trongone, 1991). Soodak and Podell (1993) also found a lower referral rate for students with behavior problems as compared with students with combined learning and behavior problems. Also, the evidence seems to suggest that teachers who have previously made a referral for a child with behavioral problems may be more likely to refer this type of child than teachers who have not made previous referrals and may be less likely to believe that a referral is appropriate. Combined with finding s of decreased referral rates for children with behavioral problems, it is hypothesized that perhaps teachers feel that they should handle behavioral issues on their own or that a referral may not hold great promise for remediation.

Many interventions selected for children with primarily academic issues are rated as more effective than interventions for students for whom a behavioral referral is made except, perhaps, in the case of the use of reward as a method of management for behavioral problems. Despite this exception, the relatively greater effectiveness of interventions in the case of an 
academic problem is a relatively strong finding as it tended to be confirmed in the case of both analogue and authentic referrals. Differences in the effectiveness ratings between academic and behavioral interventions suggest that behavioral referrals may be perceived as less amenable to accommodation or treatment in the general education classroom whereas academic interventions are perceived as more successfully implemented. As Ashton (1984) suggests, teachers may feel quite confident about their ability to motivate certain behaviors in some students while feeling less competent with others. This is interesting given the finding of a study of instructional practices by Baker and Zigmond (1990) that explored the issue of the types of accommodations needed by students with mild disabilities in the general education setting. The observations from the Baker and Zigmond (1990) single setting, naturalistic study suggested that staff, while spending much time on classroom management and routines, geared their efforts at undifferentiated large group instruction. The authors comment that fundamental changes in instruction, in fact, would be necessary to adequately accommodate children with learning disabilities in the classroom. In fact, the current study shows that interventions for students with academic problems are chosen among interventions which are geared at changes made in the classroom and which encourage additional, intensive work outside the classroom.

\section{Intervention Use}

The current study indicates that teachers who tend to use many interventions for academic referrals also generally use many interventions for behavioral referrals. Findings also suggest that teachers do use interventions which are similar to each other. The current investigation found five dimensions of interventions which included: Individualized Curricular Changes, Communication, Process Instructional Changes, Extracurricular changes and Behavioral Conditioning Interventions. These are clusters of interventions which teachers tend to use for either academic or behavioral problems and are similar to those identified by Algozzine et al. 
(1983). In the real world, teachers tend to use instructional modifications for students with academic-type problems and behavioral conditioning and communication strategies with students with behavioral problems. Teachers use one cluster of effective interventions for an academic problem but may change and utilize other clusters of interventions for behavioral refertals.

\section{General versus Special Educators}

In the case of special educators, who were somewhat less experienced than their general education colleagues in this sample, ratings of effectiveness were greater for many academic and behavioral interventions. Given the difference in the preservice training programs between the general education teacher and the special education teacher, this finding is intuitively appealing. The core principles in special education center around the individualized approach to the student with a disability in order that the student benefit maximally from education. Although the field has certainly seen conflicting views and disagreements about instructional strategies (Friend, 1996), these results are interesting in consideration of the differences in training received by general and special educators and in their unique roles in the school system. The general teacher training education emphasis on curriculum and the special education teacher training emphasis on adapting to the more individual differences may account for the greater perceived effectiveness of interventions across problems of interventions directed to individual adaptation.

\section{Teacher Efficacy}

The current findings replicated the findings of a two factor solution of an internal versus external efficacy dimension. This dichotomy may be more in line with Bandura's original conceptualization of the construct than the Teacher Efficacy and Personal Efficacy constructs 
purported by others (Woolfolk \& Hoy, 1990, Ashton \& Webb, 1982; Gibson \& Dembo, 1984) One problem with consistency in findings may have to do with the use of variations in Teacher Efficacy Scale across studies.

Results also show that the Teacher Efficacy Scale is a useful and reliable measure of teacher efficacy as has been called for by researchers (Gibson \& Dembo, 1984). Internal reliability for this sample was good. The samples used for this investigation were largely more internally and less externally oriented although males in this sample were more internal than females. No relationship was evidenced, however, between self-efficacy and age, referral status, years of teaching experience or special versus general education teachers.

Unlike the findings by Soodak and Podell (1993), no significant differences were found in the current study regarding the decision to refer a student for a special education evaluation. No differences were noted between referring and nonreferring teachers on measures of efficacy or effectiveness of interventions. It should be noted that in a study by Jordan, Kircasli-Iftar and Diamond (1993) a significant positive correlation between self-efficacy and a belief that teachers should assume responsibility for at-risk and exceptional leamers was noted. Soodak and Podell (1993) assert that teacher efficacy is a critical belief underlying teachers' decision making. In particular, they found that regular education teachers' greater perceived efficacy predicted their perception that student with problems could be served in the regular education setting.

Teachers who are more internally efficacious, however, are more likely to find interventions for use with students with behavioral problems to be effective a finding which is supported by previous research (Brownell \& Pajares, 1996). This finding lends further support for construct validity with the Teacher Efficacy Scale. Construct validation, as Bandura (1997a) states, "is an ongoing process in which both the validity of the postulated causal structure in the conceptual scheme and the self-efficacy measures are being assessed" (p.5). 
Unlike findings of Chester and Beaudin (1996) teachers with greater experience with professional collaboration (in the current case, with CAP/CAST) did not show relationship to self-efficacy beliefs as might have been expected.

Another interesting finding of the current study is that for authentic data, individuals who were more externally efficacious, attempted fewer interventions for students with behavioral problems. This finding seems to suggest that externally oriented individuals may not believe in their own capacity to deal with behavioral problems effectively.

As Schunk (1983) suggests, efficacy appraisals are influenced by, not only one's past performance as judged by the weighting of the relative contribution of personal and situational factors, but by the perceived difficulty of the task, the amount of effort expended, the type of extemal aid received, situational circumstances under which the performance occurred and temporal patterns of success and failure. While the current study did not evaluate the relative contributions of each of these factors, it may be the case that since teachers rated behavioral interventions to be less effective, in general, that they found the situation of a child with behavior problems to be more difficult and had to exert more effort in prereferral intervention. Therefore those teachers with high levels of internal efficacy are more confident about their ability to control or their expectations of achieving satisfactory outcome for students.

Is self-efficacy a stable personality trait or a state-dependent characteristic? Bandura (1997a) holds that self-efficacy does not share the major properties usually associated with personality traits. For example, unlike personality traits, "efficacy beliefs do not necessarily remain immutable over time" (p. 45). One might, however, develop an efficacy scale which is more genuinely trait-like by assessing perceived capabilities across a range of clearly specified activities within that trait. The problems, however with a trait-like approach to study is the price which is paid in terms of "explanatory and predictive power" (p. 41). 


\section{Research Methodology}

The results of the current investigation provide a useful critique of the research methodology currently in use in the field of intervention research and design. The methodological implications of these notable differences between authentic and analogue design findings suggests the inadequacy of the analogue approach to study alone and the difficulties inherent with such an approach. If we want to know what types of interventions teachers use and how effective they believe those interventions to be, we must look at these questions across multiple methods as the removed quality of the analog approach alone surely does not capture all of the variables or qualities which impact upon these decisions. For this study, the issue of external validity is shored by inclusion of authentic data and the issue of internal reliability is addressed by the matched sample used to study the analogue/authentic comparison. The direct comparability of subject analogue/authentic responses may be somewhat unusual in a study of prereferral intervention strategies as no precedent could be found in the literature.

Although advantages such as control over variables, random assignment and convenience contribute to the use of laboratory studies, they also tend to result in lower realism, suspicion and bias of subjects and have possibly low external validity (Taylor, Peplau, \& Sears, 1997). In the case of an increasing literature base that has utilized analogue approaches with vigor (Witt et al., 1984) the same types of issues may apply. For example, teachers or teachers in training programs responding to survey questionnaires perhaps as a part of a course requirement may bring into question biases or issues of social desirability. According to Borkovec and Rachman (1979) it should be noted that practitioners tend to discount analogue situations whereas researchers in universities tend to insist upon their importance-a statement which certainly may speak to the external and face validity of the analogue approach. On the other hand, it may be that as long as relevant behavior is studied, methodological differences are not important. 
When an analogue situation is conceived, its full implications for the respondent may not be immediate. After all, reading about a student with behavioral problems in a vignette or even a more powerful video analogue may not correspond with the same attitudes, actions, and problem solving strategies utilized in the same way as when the teacher has worked with the student for days, weeks or months in the classroom. The actions and beliefs about the effectiveness of interventions in this case may not correspond with the survey responses. Additionally, we either assume that the teacher will demonstrate concomitant understanding of the vignette situation as the researcher does or we fail to consider the correspondence in meaning between the analogue and the authentic situations. The question of the predictability or reliability of responses may be hampered by a lack of concordance of meaning. This lack of consensus may affect the ways to which this analogue is responded. Unfortunately, as the literature base builds upon this type of analogue methodology, we may be missing one or more crucially confounding variables.

Berkowitz and Donnerstein (1982) in their discussion of external validity and critique of laboratory experimental in psychology state that "whether laboratory results are generalizable to other situations is an empirical question (p. 245)." Kazdin (1978) also reported that whether or not findings from analogue therapy research generalizes to the clinical situation is an empirical question. External validity in a study, or the ability to generalize results to the real world, is not necessarily govemed by physical representativeness as Berkowitz and Donnerstein (1982) surmise. Rather, it is the meaning of the situation, stimuli or question which is crucial to extemal validity. The current study attempted to simulate the circumstance of referral for the teacher with certain grounding questionnaire items which would perhaps link with subsequent authentic analyses. In the majority of analog studies, however, this bridge is never built. The research, then, may stand as an island in which the meaningfulness of the results might never be fully appreciated on the mainland. 
On the other hand, as quoted by Berkowitz and Donnerstein (1982), "there are limits on the generalizability of all findings which can be recurred only through systematic testing with different subjects, setting, and responses" (Flanagen \& Dipboye, 1980, p. 465). As they point out, one cannot fault every experiment only because it would seem to lack ecological validity. They also quote Carlsmith et al. (1976) who said "One cannot guarantee generalizability simply by providing an experiment that has a high degree of mundane realism. This does not increase out confidence in our ability to generalize from the results, for in the final analysis the question is an empirical one"'(p. 86).

As Borkovec and Rachman (1979) state, "describing an experiment as an analogue is a description and not a criticism (p. 260)." It is not just the generalizability of findings from analogue to authentic, then, which is sought after but rather the confirmation or refutation of theoretical predictions with research findings whether analogue or authentic (Rakover, 1980; Kazdin, 1980).

By its very nature, analogue research involves the linear deconstruction of variables of study in order to control for Independent Variables or treatment effects on the Dependent Variable. How much, though, does this deconstruction distort the nature of the phenomenon? Martens and Witt (1984) state that "the common practice of assessing only (a) target response may result in a fractionalized representation of the larger behavioral ecology" (p. 205).

In his commentary regarding the use of analogue research in the family therapy literature, Gurman (1984) suggests that the principles of wholeness and nonsummativity in systems theory are relevant to a discussion involving the analysis of isolation of variables in research design. He points out that general systems theory purports that "no system can be adequately understood or totally explained once it have been broken down into its component parts" ( $\mathrm{p}$. 342). It is, rather, a focus on the interconnectedness of variables, the organization and dynamical rather than the linear relationships which help us to understand behavior. He 
concludes that "once removed from its originating context, a given 'bit" of behavior, or experimentally manipulated its next occurrence arises in an entirely new context" (p. 343). He utilizes an "analogous" example of a researcher's attempt to construct a human being from a series of organ systems from a number of human subjects and arguing that the resultant creature is no different than humans of more natural origination. This is a question of validity which is a consideration whenever deconstructivistic research is undertaken.

\section{The Changing Educational Environment}

A recent study by Brownell and Pajares (1996) suggests that variables which may be impacting on the success of mainstreamed students with learning and behavior problems in the general education environment include: perceived efficacy, collegiality with special education teachers, preservice preparation, quality of in-services and principal support. Specifically, they found that teacher's efficacy beliefs had the strongest direct effect on reported success in mainstreaming students with learning and behavior problems. They also reported that, interestingly, general education teachers who experienced better collegial relationships with other general education teachers and with students from higher socioeconomic backgrounds were less likely to report success in instructing students with learning and behavior problems.

The call for greater emphasis on prereferral intervention strategies to be utilized prior to referral to special education has been intimately linked to the inclusion or mainstreaming movement. In fact, according to Schloss (1992), the emphasis on placement in a least restrictive environment has become an irrefutable social and legislative mandate. The educational system has witnessed a major change in the roles of teachers within what was formerly the domain of special education. With this change in role comes a shift in skills which must be developed and implemented in the regular classroom. Thus, teachers must acquire new skills, for example, in working with academically and socially disadvantaged 
youth, participate in multidisciplinary planning meetings and modify traditional views and approaches to disciplining student with handicaps.

This call and mandate for an increasingly inclusive model of education is not without its critics. Taylor and Justen (1996) suggest that if general teachers can effectively manage all students without the aid of the direct intervention of specialists, inclusion is justifiable. However, they point out that there is considerable opposition to full inclusion. Although many of the intervention studies that have been done have found positive results, they question whether the same interventions, without the money and full resources of a full initial initiative would be as effective. They question the generalizability of findings in these studies. They argue that in order to support full inclusion, inclusion should be shown to be more effective than special pullout programs and the effectiveness of collaboration should be shown clearly.

Taylor and Justin (1996) recommend that inclusion be considered to be just one option on a continuum of services. Even harsher critics state that "general education settings produce achievement outcomes for students with learning disabilities that are neither desirable nor acceptable" (Zigmond, et al., 1995, p. 540). Despite the amount of money, time and other resources expended for implementation of full inclusion their review of special education in restructured schools, the authors find reason to question the overall effectiveness of restructured schools.

\section{Limitations of the Study}

Much of the literature which has been built regarding effective interventions has considered the actual effectiveness of interventions chosen but have failed to consider the opinion of teachers regarding their likely use of these interventions. Effectiveness, in the current study, was measured by teachers' subjective ratings of the perceived effectiveness of interventions which they had used and presumed effectiveness of analogue interventions. No 
attempt was made here to evaluate the actual effectiveness of interventions chosen and therefore, it is not possible that ratings of effectiveness are measurable in terms of student or classroom objectives or goals.

Another limitation of the current study may be considered in terms of the concordance of meaning between analogue and authentic case histories. A teacher making a referral after weeks or perhaps months of intervention work and the teacher hypothesizing about the referral may represent qualitatively different perspectives. Knowledge regarding the variables which impact upon decisions to refer would aid in our construction of analogue surveys which would then take into consideration the full decision making process.

Teachers may not always feel free to refer all students they believe will benefit from special education (Soodak \& Podell, 1993). As has been found elsewhere, systemic and administrative factors in schools may discourage teachers from referring students for whom they believe regular education to be inappropriate (Christenson, Ysseldyke, \& Algozzine, 1982). The presumed comparability between analogue and authentic cases may, however, be lacking if complex, dynamical factors indeed influence intervention use in the case of actual referrals that are not reproducible in an analogue format.

The equivalence of stimuli intensity, reaction and availability of resources may also differentially impact upon decisions about intervention selection and effectiveness. On the other hand, it was the case, that some degree of concordance was demonstrated in terms of the types of interventions selected for authentic and analogue methodologies which may provide some evidence for the concordance of situations.

The sample of teachers completing the questionnaires and Teacher Efficacy Scale were a largely internally efficacious group. It is perhaps the case that findings were confounded by a self-selected sample of survey respondents who were largely more sure of their abilities to deal with students with problems in their classrooms. Therefore, their ratings of effectiveness may 
have been influenced by their relatively greater perceived ability to influence learning outcomes in their students. This may also explain the relatively surprising lack of findings with respect to the number of years of experience and efficacy.

The list of interventions available for selection, which had been preselected by the State Department of Education in their attempt to ensure the gathering of prereferral intervention data, is limited to 19 interventions. The actual interventions which are utilized by teachers may be significantly wider in scope than the CASTRF form acknowledges. Although there is a place for "other" interventions which could be used, in reality, few teachers formally indicated that they had used other than the prescribed interventions. Despite this limitation, however, evidence was found for the clustering of interventions based upon effectiveness ratings suggesting that there may be some consistency within subjects for the types of interventions chosen.

Finally, the lack of a large authentic-analogue matched sample by individual may have contributed to muddied findings. Perhaps results would have been different with a pure match of person to person rather than the choice to match on grade level.

\section{Directions for Future Research}

Replication of the current findings should be pursued with another sample in other areas of the country which have been_differentially impacted by the mainstreaming movement and the call for prereferral interventions. Given the finding of greater effectiveness of many interventions by special educators, variables which influence this perceived effectiveness might be further explored. It may be that training differences or experiential differences account to these differences. In particular, special educators may find behavioral problems to be adequately handled by a range of behavioral management techniques. More specific information regarding the types of behavioral management techniques might be useful to share 
with general educators given the increasingly inclusive nature of the regular education classroom.

While some discussion in the family therapy literature is reported with respect to analogue versus clinical findings, more information about the validity of analogue versus authentic research could be conducted across disciplines.

Future research might focus on the development and implementation of programs designed to increase the efficacy of teachers particularly given the changes necessitated by school reform. Programs should foster personal teaching efficacy through staff development and classroom activities. Fritz, Miller-Hyl, Kreutzer, and MacPhee (1995) have developed a program entitled "Dare to Be You" for these purposes to increase efficacy and address issues of confidence and involvement in professional roles. The authors state that, "when compared with teachers who did not participate in the DTBY training or implement its curriculum, the participating teachers demonstrated increased feelings of personal competence in meeting the needs of their students and perceived fewer external constraints on student learning, greater satisfaction with their professional roles as teachers and increased integration of their professional roles with other roles" (p. 207).

Rather than limiting the study of efficacy to individual teacher variables, the relationship between collective educational efficacy and prereferral intervention effectiveness is another area that might be explored in a future research design. Bandura (1997a) describes two approaches to the study of perceived collective efficacy. The first is the measurement and evaluation of the total of members appraisals of their own personal capabilities. In this method, the congregation of individual self-efficacy ratings would pool together to tell us something about the efficacy of the group as a whole. The second method would be to gather information about member's appraisals of the group or school capability as a whole in meeting educational goals or solving problems. He goes on to explain that even if a group of highly efficacious 
individuals (collective individual efficacy) were to work poorly together as a whole (collective group efficacy), measure of the former only would overestimate their productivity. On the other hand, if a group of less efficacious individuals containing a few highly efficacious individuals were sampled, the results may tend to underestimate group efficacy. The relationship between these two approaches is summarized in the following statement:

Beliefs of personal efficacy are not detached from the larger social system in which members function. In appraising their personal efficacies, individuals inevitably consider group processes that enhance or hinder their efforts....an assessment focus at the individual level is steeped in processes operating within the group. Nor does a focus at the group level remove all thought about the individuals who contribute to the collective effort. Not surprisingly, the two indices of collective efficacy are at least moderately correlated (p. 478-479).

There may be many variables which impact upon intervention use, effectiveness and efficacy. However, it has been the case that analysis has been limited to linear, deconstructionistic methods of inquiry. The utilization, for example, of path analysis or computer simulation programs to consider multiple, dynamical variables to study these interconnections and feedback loops may be the important next step in characterizing the nature of relationships among variables.

The comparison of authentic and analogue designs may have something to offer in a consideration of training for school psychologists in the scientist-practitioner model. We must attempt, as scientist practitioners to keep in mind the importance of balance in the pursuit of synthesis. Perhaps when we become engulfed by the laboratory, the analogue or the abstract and are drawn away from naturally occurring complexity we may sterilize the meaning out of some of our research questions. Ours should not be the pursuit of "mundane realism" but a respect for the complex, perhaps nonlinear nature of the relationships among variables. 


\section{REFERENCES}

Algozzine, B., Christenson, S., \& Ysseldyke, J. E. (1982). Probabilities associated with the referral to placement process. Teacher Education and Special Education, 5, 19-23.

Algozzine, B., \& Korinck, L. (1985). Where is special education for students with high prevalence handicaps going? Exceptional Children, 51, 388-394.

Algozzine, B., Ysseldyke, J. E., Christenson, S., \& Thurlow, M. L. (1983). A factor analysis of teachers' intervention choices for dealing with students' behavior and learning problems. The Elementary School Journal, 84, 189-197.

Ashton, P. (1984). Teacher efficacy: A motivational paradigm for effective teacher education. Journal of Teacher Education, 35, 28-32.

Ashton, P. T., \& Webb, R. (1982, March). Teachers' sense of efficacy: Toward an ecological model. Paper presented at the Annual Meeting of the American Educational Research Association: New York.

Bahr, M. W. (1994). The status and impact of prereferral intervention: "We need a better way to determine success." Psychology in the Schools, 31, 309-318.

Baker, J., \& Zigmond, N. (1990). Are regular education classes equipped to accommodate students with 1 earning disabilities? Exceptional Children, 56, 515-526.

Bandura, A. (1977). Social learning theory. Englewood Cliffs, NJ: Prentice Hall.

Bandura, A. (1982). Self efficacy mechanism in human agency. American Psychologist, 37, $122-147$.

Bandura, A. (1986). Social foundations of thought and action: A social cognitive theory. Englewood Cliffs, NJ: Prentice-Hall.

Bandura, A. (1997a). Self-efficacy: the exercise of control. New York: Freeman.

Bandura, A. (1997b). Guide for constructing self-efficacy scales. Unpublished manuscript, Stanford University, Palo Alto, CA.

Benz, C. R., Bradley, L., Alderman, M. K., \& Flowers, M. A. (1992). Personal teaching efficacy: Developmental relationships in education. Journal of Educational Research, 85, 274286.

Berkowitz, L., \& Donnerstein, E. (1982). External validity is more than skin deep: Some answers to criticisms of laboratory experiments. American Psychologist, 37, 245-257.

Berman, P., \& McLaughlin, M. W., Bass, G., Pauly, E., \& Zellman, G. (1977). Federal Programs supporting educational change, Vol. VII: Factors affecting implementation and continuation. Santa Monica, CA: The Rand Corporation 
Borkovec, T., \& Rachman, S. (1978). The utility of analogue research. Behavioral Research and Therapy, 17, 253-261.

Broussard, B. A., Book, C., \& Byers. (1988). Teacher beliefs and the cultures of teaching. Journal of Teacher Education, 35, 28-32.

Brownell, M. T., \& Pajares, F. M. (1996). The influence of teachers' efficacy beliefs on perceived success in mainstreaming students with learning and behavior problems: A path analysis. Research Bulletin, 27, 1-23.

Carlsmith, J. M., Ellsworth, P. C., \& Aaronson, E. Methods of research in social psychology. Reading, MA: Addison-Wesley, 1976.

Chester, M. D., \& Beaudin, B. Q. (1996). Efficacy beliefs of newly hired teachers in urban schools. American Educational Research Journal, 33, 233-257.

Christenson, S., Ysseldyke, J. E., \& Algozzine, B. (1982). Institutional and external pressures influencing referral decisions. Psychology in the Schools, 19, 341-345.

Chwalisz, K. D., Altmaier, E. M., \& Russell, D. W. (1992). Causal attributions, selfefficacy, cognitions, and coping with stress. Journal of Social and Clinical Psychology, 11. $377-400$.

Cohen, J. (1960). A coefficient of agreement for nominal scales. Educational and Psychological Measurement, 20, 37-46

Cone, J. D., \& Foster, S. L. (1993). Dissertations and theses from start to finish: Psychology and related fields. Washington, D. C: American Psychological Association.

Conoley, J. C., \& Gutkin, T. B. (1986). School psychology: A reconceptualization of service delivery realities. In S. N. Elliott \& J. C. Witt (Eds.), The Delivery of Psychological services in Schools: Concepts, Processes and Issues (pp. 393-424). Hillsdale, N. J: Lawrence Erlbaum.

Council for Exceptional Children. (1992). Providing an appropriate education to children with attention deficit disorder (Report in ERIC Digest, \#E512). Restin, VA: ERIC Clearinghouse on Handicapped and Gifted Children.

Dembo, M. H., \& Gibson, S. (1985). Teachers' sense of efficacy: An important factor in school improvement. The Elementary School Journal, 86, 173-184.

de Mesquita, P. B., \& Drake, J. C. (1994). Educational reform and the self-efficacy beliefs of teachers implementing nongraded primary school programs. Teaching and Teacher Education, 10, 291-302.

Education for All Handicapped Children Act of 1975 (PL 94-142), 20 U. S. C. $§ 401$ (supp. 1975).

Elliott, S. N. (1988a). Acceptability of behavioral treatments: Review of variables that influence treatment selection. Professional Psychology Research and Practice, 19, 68-80. 
Elliott, S. N. (1988b). Acceptability of behavioral treatments in educational settings. In J. C. Witt, S. N. Elliott, \& F. M. Gresham (Eds.), Handbook of Behavior Therapy in Education (pp. 121-150). New York: Plenum.

Elliott, S. N., Turco, T. L., \& Gresham, F. M. (1987). Consumers' and clients' pretreatment acceptability ratings of classroom group contingencies. Journal of School Psychology, 25, 145-153.

Elliott, S. N., Witt, J. C., Galvin, G., \& Peterson, R. (1984). Acceptability of positive and reductive interventions: Factors that influence teachers' decisions. Journal of School Psychology, 22, 353-360.

Enochs, L. G., Schamann, L. C., \& Riggs, I. M. (1995). The relationship of pupil control to preservice elementary science teacher self-efficacy and outcome expectancy. Science Education, 79, 63-75.

Emmelkamp, P. M. G., Mersch, P. P., \& Vissia, E. (1985). The external validity of analogue outcome research: Evaluation of cognitive and behavioral interventions. Behavior Research and Therapy, 23, 83-86.

Flanagan, M. F., \& Dipboye, R. L. (1980). Representativeness does have implications for the generalizability of laboratory and field research findings. American Psychologist, 35, 464467.

Foster, G. G., Schmidt, C., \& Sabotino, D. (1976). Teacher expectancies and the label "learning disabilities." Journal of Learning Disabilities, 22, 330-333.

Friend, M. (1996). Response to reflections on special education teacher preparation. Teacher Education and Special Education, 19, 220.

Fritz, J. J., Miller-Hyls, J. M., Kreutzer, J. C., \& MacPhee, D. (1995). Fostering personal teaching efficacy through staff development and classroom activities. The Journal of Educational Research, 88, 200-208.

Fuchs, D., Fuchs, L. S., \& Bahr, M. W. (1990). Mainstream assistance teams: A scientific basis for the art of consultation. Exceptional Children, 57, 128-139.

Fuchs, L. S., Fuchs, D., \& Bishop, N. (1992). Instructional adaptation for students at risk. Journal of Educational Research, 86, 70-84.

Gettinger, M. (1988). Analogue assessment: Evaluating academic abilities. In E. S. Shapiro \& T. Kratochwill (Eds.), Behavioral assessment in schools: Conceptual foundations and practical applications (pp. 247-289). New York: Guilford.

Gibson, S., \& Dembo, M. H. (1984). Teacher efficacy: A construct validation. Journal of Educational Psychology, 76, 569-582.

Gottlieb, J., Gottlieb, B. W., \& Trongone, S. (1991). Parent and teacher referrals for psychoeducational evaluation. Journal of Special Education, 25, 155-167. 
Gresham, F. M., \& Lopez, M. F. (1996). Social validation: A unifying concept for school-based consultation research and practice. School Psychology Quarterly, 11, 204-227.

Gurman, A. S. (1984). Commentary: Analogue research and the family therapist. Family Process, 23, 341-345.

Guskey, T. R. (1988). Teacher efficacy, self-concept, and attitudes toward the implementation of instructional innovation. Teaching and Teacher Education, 4, 63-69.

Guskey, T. R., \& Passaro, P. D. (1994). Teacher efficacy: A study of construct dimensions. American Educational Research Journal, 31, 627-643.

Gutkin, T. B., \& Curtis, M. J. (1990). School-based consultation: Theory, techniques and research. In T. B. Gutkin \& C. R. Reynolds (Eds.), The handbook of school psychology (2nd ed., pp. 577-611). New York: Wiley.

Gutkin, T. B., Henning-Stout, M. \& Piersel, W. C. (1988). Impact of a district-wide behavioral consultation prereferral intervention service on patterns of school psychological service delivery. Professional School Psychology, 3, 301-308.

Harrison, A. W., Rainer, R. K., Hochwarter, W. A., \& Thompson, K. R. (1997). Testing the self-efficacy performance linkage of social-cognitive theory. The Journal of Social Psychology, 137, 79-88.

Henning-Stout, M., Lucas, D. A., \& McCary, V. L. (1993). Alternative instruction in the regular classroom: A case illustration and evaluation. School Psychology Review, 22, 81-97.

Heron, T. E., \& Harris, K. D. (1987). The educational consultant: Helping professional, parents, and mainstreamed students (2nd ed.). Boston: Allyn \& Bacon.

Hughes, J. N., Grossman, P., \& Barker, D. (1990). Teachers' expectancies, participation in consultation, and perception of consultant helpfulness. School Psychology Quarterly, 5, 176-179.

Hyman, I. A., \& Kaplinski, K. (1994). Will the real school psychologist please stand up?: Is the past a prologue for the future of school psychology? School Psychology Review, 23, 564-583.

Johnson, T. C., Stoner, G., \& Green, S. K. (1996). Demonstrating the experimenting society model with classroom behavior management interventions. School Psychology Review, $\underline{25,199-124 .}$

Jordan, A., Kircaali-Iftar, G, \& Patrick-Diamond, C.T. (1993). Who has a problem, the student or the teacher? Differences in teachers' beliefs about their work with at-risk and integrated exceptional students. International Journal of Disability, Development and Education, 40, 45-62.

Kazdin, A. E., (1978). Evaluating the generality of findings in analogue therapy research. Journal of Consulting and Clinical Psychology, 46, 673-686. 
Kazdin, A. E. (1980). Investigating generality of findings from analogue research: A rejoinder. Journal of Consulting and Clinical Psychology, 48, 772-773.

Kingery, P. M., Holcomb, D., Jibaja-Rusth, M., Pruitt, B. E., \& Buckner, W. P. (1994). Journal of Health Education, 25, 68-76.

Knoff, H. M. (1985). Attitudes toward mainstreaming: A status report and comparison of regular and special educators in New York and Massachusetts. Psychology in the Schools, 22. 410-418.

Lambert, N. M. (1976). Children's problems and classroom interventions from the perspective of classroom teachers. Professional Psychology, 1, 507-517.

Margolis, H., Fish, M., \& Wepner, S. B. (1990). Overcoming resistance to prereferral classroom interventions. Special Services in the Schools, 6, 167-187.

Martens, B. K., Peterson, R. L., Witt, J. C., \& Cirone, S. (1986). Teacher perceptions of school-based interventions. Exceptional Children, 53, 213-223.

Martens, B. K., \& Witt, J. C. (1984). Assessment and prediction in an ecological system: Application of the general linear model to the response-class concept. Journal of Behavioral Assessment, 6, 197-206.

Martens, B. K., \& Witt, J. C. (1988). Expanding the scope of behavioral consultation: A systems approach to classroom behavior change. Professional School Psychology, 3, 271-281.

Martens, B. K., Witt, J. C., Elliott, S. N., \& Darveaux, D. (1985). Teacher judgments concerning the acceptability of school-based interventions. Professional Psychology: Research and Practice, 16, 191-198.

McKee, W. T., Witt, J. C., Elliott, S. N., Pardue, M., \& Judycki, A. (1987). Practice informing research: A survey of research dissemination and knowledge utilization. School Psychology Review, 16, 338-347.

Melby, L. C. (1995). Teacher efficacy and classroom management: A strategy of teacher cognition, emotion and strategy usage associated with externalizing student behavior. Ph.D. diss., University of California, Los Angeles.

Murphy, C. A., Coover, D., \& Owen, S. (1989). Development and validation of the computer self-efficacy scale. Educational and Psychological Measurement, 49, 893-899.

O'Reilly, C., Northcraft, G. B., \& Sabers, D. (1989). The confirmation bias in special education eligibility decisions. School Psychology Review, 1, 126-135.

Rakover, S. S. (1980). Generalization from analogue therapy to the clinical situation: The paradox and the dilemma of generality. Journal of Consulting and Clinical Psychology, 48. $770-771$. 
Reschly, D. J. (1988). Special education reform: School psychology revolution. School Psychology Review, 17, 459-475.

Rotter, J. B. (1966). Generalized expectancies for internal versus external control of reinforcement. Psychological Monographs: General and Applied, 80, 1-28.

Safran, S. P. (1985). Correlates of special educators' self-efficacy beliefs. British Columbia Journal of Special Education, 9, 61-67.

Saklofske, D. H., Michayluk, J. O., \& Randhawa, B. S. (1988). Teachers' efficacy and teaching behaviors. Psychological Reports, 63, 407-414.

Schloss, P. J. (1992) Mainstreaming revisited. The Elementary School Journal, 92, 233244.

Schrag, J. A., \& Henderson, K. (1996). School-based intervention assistance teams and their impact on special education (Final Report Year 3 Deliverable \#5-3-4). Alexandria, VA: National Association of State Directors of Special Education. (ERIC Document Reproduction Service No. ED 392 196)

Schunk, D. H. (1983). Reward contingencies and the development of children's skills and self-efficacy. Journal of Educational Psychology, 75, 511-518.

Schunk, D. H. (1985). Self-efficacy and classroom learning. Psychology in the Schools, $\underline{22}, 208-223$.

Schunk, D. H., Hanson, A. R., \& Cox, P. D. (1987). Peer-model attributes and children's achievement behaviors. Journal of Educational Psychology, 79, 54-61.

Sevick, B. M., \& Ysseldyke, J. E. (1986). An analysis of teachers' prereferral interventions for students exhibiting behavioral problems. Behavioral Disorders, 11, 109-117.

Sindelar, P. T., Griffin, C. C., Smith, S. W., \& Watanabe, A. K. (1992). Prereferral intervention: Encouraging notes on preliminary findings. The Elementary School Joumal, 92, 245-259.

Smith, D. K. (1984). Practicing school psychologists: Their characteristics, activities, and populations served. Professional Psychology: Research and Practice, 15, 798-810.

Smith, D. K., \& Lyon, M. A. (1985). Consultation in school psychology: Changes from 1981 to 1984. Psychology in the Schools, 22, 404-409.

Soodak, L. C., \& Podell, D. M. (1993). Teacher efficacy and student problems as factors in special education referrals. The Journal of Special Education, 27, 66-81.

State of Rhode Island \& Providence Plantations Department of Elementary and Secondary Education. (1992). Prereferral procedures, classroom altematives process (CAP) Regulations of the Board of Regents for Elementary and Secondary Education governing the special education of students with disabilities (Section One, V., 3). 
Tabachnick, B. G., \& Fidell, L. S. (1989). Using Multivariate Statistics (2nd ed.). Northridge, C. A.: Harper Collins.

Taylor, R., \& Justen, J. E. (1996). Full inclusion of students with mild disabilities: a question of external validity. The Clearing House, 70, 108-110.

Taylor, S. E., Peplau, L. A., \& Sears, D. O. (1997). Social Psychology (9th ed.). Uppersaddle River, N. J.: Prentice-Hall.

U. S. Department of Education. (1992). Fourteenth Annual Report to Congress on the Implementation of the Individuals with Disabilities Act. Washington, D. C.; U. S. Government Printing Office.

Waguespeck, A. M., \& Moore, L. A. (1993). Teacher preferences for service delivery: A look at attribution research. School Psychology Quarterly, 8, 153-158.

Will, M. (1988). Educating students with learning problems and the changing role of the school psychologist. School Psychology Review, 17, 476-478.

Witt, J. C. (1986). Teachers' resistance to the use of school-based interventions. Journal of School Psychology, 24, 37-44.

Witt, J. C., Elliott, S. N., \& Martens, B. K. (1984). Acceptability of behavioral interventions used in classrooms: The influence of teacher time, severity of behavior problem, and type of intervention. Behavioral Disorders, 10, 95-104.

Witt, J. C., \& Martens, B. K. (1983). Assessing the acceptability of behavioral interventions used in classrooms. Psychology in the Schools, 20, 510-517.

Witt, J. C., Martens, B. K., \& Elliott, S. N. (1984). Factors affecting teachers' judgment of the acceptability of behavioral interventions: Time involvement, behavior problem severity, and type of intervention. Behavior Therapy, 15, 204-209.

Woolfolk, A. E., \& Hoy, W. K. (1990). Prospective teachers' sense of efficacy and beliefs about control. Journal of Educational Psychology, 82, 81-91.

Ysseidyke, J. E., Pianta, B., Christenson, S., Wang, J. J., \& Algozzine, B. (1983). An analysis of prereferral interventions. Psychology in the Schools, 20, 184-190.

Ysseldyke, J. E., Thurlow, M., Graden, J., Wesson, C., Algozzine, B., \& Deno, S. (1983). Generalizations from five years of research on assessment and decision making. Exceptional Education Quarterly, 4, 75-93.

Zigmond, N., Jenkins, J., Fuchs, L. S., Deno, S., Fuchs, D., Baker, J. N., Jenkins, L., \& Couthino, M. (1995). Special education in restructured schools: findings from three multi-year studies. Phi Delta Kappan, 76, 531-541.

Zins, J., Kratochwill, T., \& Elliott, S. (Eds.) (1993). Handbook of consultation services for children. SanFrancisco: Jossey-Bass 
APPENDIX A

Teacher Questionnaire 


\section{Teacher Questionnaire}

Plense answer the following questions:

Today's dite:

1. How many years of tesching experience have you had since you were certified?

2. Your gender Male

3. Your age: years old

4. Which do you teach? Reguler Edncation ? or Specinl Education

CASE A: \#1) Please read the following hypothetical case exmple and answer the following questions

Stadeat A is studeat who is having dimenity managing specific aspeets of your currieulum. You notice that the stodeat $t$ struggling on an almost daily basts and you are concerned about the pocsibility of a learning disability. You notice that the studeat is having dificulty decoding words when asked to read aloed and bas trouble maintaining attention in the classroom. You notice that the atudeat's lapace in attention are not diaruptive to fellow students bat seev to hiterfere with the aequiattion of new anterial. Subile learning dificulties are aoted which inclade disorgantzation and dificalty retaining hiornatioa over the.

Questions:

Have you ever referred a student like STUDENT A for a evaluation for these types of problems? yes no

Which type of refernal appears to be most appropriete for Sardent A: no evaluation referral for behuviond problems referral for academic problems speech/language evalurtion Occupational therapy evaluation

FOR STUDENT A: Which of the following interventions would you find appropriate to address this student's problems? Next to each intervention you would recommend, please indicate on a scale of 1-5 your guess as to the effectiveness of this intervention: In other words, now keeping in mind this student, First please make a X mark for each intervontion you would use prior to referring this student for a special ectucation ovaluation. Second, circle one number from 1-5 describing how effective you feel this intervention would be only for the interventions you choose.

\begin{tabular}{|c|c|c|c|c|c|}
\hline \multirow{2}{*}{$\begin{array}{l}\text { Pleace Check (X) } \\
\text { I would select this intervention: } \\
\text { Change in seating }\end{array}$} & \multicolumn{5}{|c|}{$\begin{array}{l}\text { (Please eircie a number for only the laterventions you choose) } \\
\text { Not effective } \\
\text { Very Rifective }\end{array}$} \\
\hline & i & 3 & 3 & 4 & 5 \\
\hline Chenge in proups & t & 2 & 3 & 4 & 5 \\
\hline Hive student restute directions & T & 2 & 3 & 4 & 3 \\
\hline OCnel vs. wrincen testsireports & 1 & 2 & 3 & 4 & 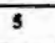 \\
\hline One-to-One instruction & 1 & 2 & 3 & 4 & 5 \\
\hline After school help & i & $\overline{2}$ & 3 & 4 & 3 \\
\hline Tutoring & 1 & 2 & 3 & 4 & 5 \\
\hline Use of orgmizationed charts & 1 & 2 & 3 & 4 & 5 \\
\hline Reduction of work mesignments & 1 & 2 & 3 & 4 & 5 \\
\hline Modify workshocts/acignmentes & 1 & 2 & 3 & 4 & 5 \\
\hline Keep after school & 1 & 2 & 3 & 4 & 5 \\
\hline Reward System & $T$ & 3 & 3 & 4 & 5 \\
\hline Modify maxeriuls and presentation & $\mathrm{T}$ & 2 & 3 & 4 & 5 \\
\hline Change in text/mmerials & 1 & 2 & 3 & 4 & 3 \\
\hline Suident Conference & $\mathrm{T}$ & 2 & 3 & 4 & 5 \\
\hline CallNots to parents & 1 & 2 & 3 & 4 & 3 \\
\hline Parent conference & 1 & 2 & 3 & 4 & 5 \\
\hline C_Consult with specielists & 1 & 2 & 3 & 4 & $\mathbf{s}$ \\
\hline Behavior Manapement Techniques & 1 & 2 & 3 & 4 & 3 \\
\hline Other & 1 & 2 & 3 & 4 & 5 \\
\hline
\end{tabular}


CASE B: \#2) Please read the following hypothetical cuse eximple and answer the following questions

Student $\mathbf{B}$ has not handed in assigned bomework in 3 weeks. The studeat bas dimeulty with follow-through and b divruptive to others itedenth. The stadeat ofien blarts out answers asd irrelevant comments with equal frequeacy.

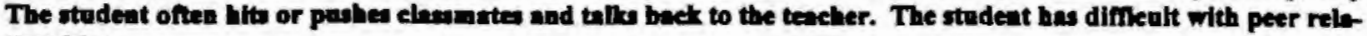
tonshipe.

Questions:

Hive you over referred a student like STUDENT B for an evaluntion for these types of problems? yes no

Which type of referral appears to be most approprinte for Student B:

no evahuation

referral for behavioral problems

referral for academic problems

speech/lenguage evaluation

Occupatioas therapy evaluation

FOR STUDENT B:: Which of the following interventions would you find appropriate to address this student's problems? Next to each intervention you would recommend, please indicate on a scale of 1-5 your guess as to the effectiveness of this intervention: In other words, now keeping in mind this student, First please make a X mank for each intervention you would use prior to refesring this student for a special education evaluntion. Second, circle one number from 1-5 describing how effective you feel this intervention would be only for the interventions you choose.

\begin{tabular}{|c|c|c|c|c|c|}
\hline $\begin{array}{l}\text { Please Check (X) } \\
\text { I would select tht intervention: }\end{array}$ & \multicolumn{5}{|c|}{$\begin{array}{l}\text { (Please circle a nomber for only the haterventions you choose) } \\
\text { Not effective Very Effective }\end{array}$} \\
\hline Chenge in senting & 1 & 3 & 3 & 4 & 3 \\
\hline Change in groupt & 1 & 2 & 3 & 4 & 3 \\
\hline Heve student restute directions & 1 & 3 & 3 & 4 & 5 \\
\hline Ond v. written tests/reports & 1 & 2 & 3 & 4 & 3 \\
\hline One-to-One instruction & $\mathbf{I}$ & 2 & 3 & 4 & 5 \\
\hline After sehool help & $\mathbf{I}$ & 2 & 3 & 4 & $\mathbf{s}$ \\
\hline - Tutoring & 1 & 2 & 3 & 4 & 5 \\
\hline Use of organizational churts & 1 & 2 & 3 & 4 & 5 \\
\hline Reduction of work assignments & $\overline{1}$ & 2 & 3 & 4 & 5 \\
\hline Modily worksheets/sssignments & $\mathbf{T}$ & 2 & 3 & 4 & 5 \\
\hline Keep after school & $\mathbf{1}$ & 2 & 3 & 4 & s \\
\hline Rewerd System & $\mathbf{I}$ & 2 & $\mathbf{3}$ & 4 & 5 \\
\hline Modify materials and presentation & 1 & 2 & 3 & 4 & 5 \\
\hline Change in text/miteriels & 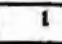 & 2 & 3 & 4 & 5 \\
\hline Student Conference & 1 & 2 & 3 & 4 & s \\
\hline Celinote to perents & $t$ & 2 & 3 & 4 & 5 \\
\hline Perent conference & $T$ & 2 & $\sqrt{3}$ & 4 & $\overline{3}$ \\
\hline Consult with specieltats & 1 & 2 & 3 & 4 & 5 \\
\hline Behavior Mmagement Techniques & 1 & 2 & 3 & 4 & 5 \\
\hline Other & $T$ & 3 & 3 & 4 & 5 \\
\hline
\end{tabular}

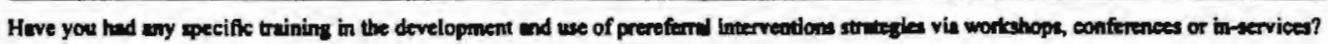

If so, plesse explain:

Do you currently perticipate in a CAP/CAST Prereferral service? YES No

If yes, since whe dene eppoximuty?

If so, is it helptul? If 20 , in what way? Plesse explein: 
APPENDIX B

Teacher Efficacy Scale 


\section{T.E.S}

PLEASE ANSWER THE FOLLOWING QUESTIONS BASED UPON YOUR OWN, PERSONAL OPINTON:

\begin{tabular}{|c|c|c|c|c|c|c|}
\hline & Strongly DI & gree & & & & ongly Agree \\
\hline & 1 & 2 & 3 & 4 & 5 & 6 \\
\hline $\begin{array}{l}\text { 1. When a student does berter than usually, many times it is } \\
\text { because the teacher exerts a litcle extra effor. }\end{array}$ & 1 & 2 & 3 & 4 & 5 & 6 \\
\hline $\begin{array}{l}\text { 2. The hours in my class have little influence on students } \\
\text { compared to the influence of their home environment. }\end{array}$ & 1 & 2 & 3 & 4 & 5 & 6 \\
\hline $\begin{array}{l}\text { 3. The amount a student can learn is primarlly related to fam- } \\
\text { ily background. }\end{array}$ & 1 & 2 & 3 & 4 & 5 & 6 \\
\hline $\begin{array}{l}\text { 4. If students aren't disciplined at home, they aren't likely to } \\
\text { accept any discipline. }\end{array}$ & 1 & 2 & 3 & 4 & 5 & 6 \\
\hline $\begin{array}{l}\text { 5. I have not been trained to deal with many of the learning } \\
\text { problems my studenis have. }\end{array}$ & 1 & 2 & 3 & 4 & 5 & 6 \\
\hline $\begin{array}{l}\text { 6. When a student is having difficulty with an ascignment, I } \\
\text { often have trouble adfusting it to his/her level. }\end{array}$ & 1 & 2 & 3 & 4 & 5 & 6 \\
\hline $\begin{array}{l}\text { 7. When a student gets a berter grade than he/ahe usually } \\
\text { gets, it is usually because I found better way of teaching that } \\
\text { student. }\end{array}$ & 1 & 2 & 3 & 4 & 5 & 6 \\
\hline $\begin{array}{l}\text { 8. When I really try, I cen get through to most difficult stur } \\
\text { dents. }\end{array}$ & 1 & 2 & 3 & 4 & $\mathbf{s}$ & 6 \\
\hline $\begin{array}{l}\text { 9. I am very limited in what I can achieve because a student's } \\
\text { home environment is a large influence on his/her achieve- } \\
\text { ment. }\end{array}$ & 1 & 2 & 3 & 4 & 5 & 6 \\
\hline $\begin{array}{l}\text { 10. Teachers are not a very powerful influence on student } \\
\text { achievement when all factors are considered. }\end{array}$ & 1 & 2 & 3 & 4 & 5 & 6 \\
\hline $\begin{array}{l}\text { 11. When the grades of students improve, it is usually because } \\
\text { their teachers found more effective teaching approaches. }\end{array}$ & 1 & 2 & 3 & 4 & $s$ & 6 \\
\hline $\begin{array}{l}\text { 12. If a student masters a new concept quilckly, this might be } \\
\text { because the teacher knew the necessary steps in teaching that } \\
\text { concept. }\end{array}$ & 1 & 2 & 3 & 4 & 5 & 6 \\
\hline $\begin{array}{l}\text { 13. If parents would do more for their chlldren, teachers could } \\
\text { do more. }\end{array}$ & 1 & 2 & 3 & 4 & 5 & 6 \\
\hline $\begin{array}{l}\text { 14. If a student did not remember information I gave in a pre- } \\
\text { vous lesson, I wousd know how to increase his/her retention } \\
\text { in the next lesson. }\end{array}$ & 1 & 2 & 3 & 4 & 5 & 6 \\
\hline $\begin{array}{l}\text { 15. The influences of a student's home experiences can be } \\
\text { overcome by good teaching. }\end{array}$ & 1 & 2 & 3 & 4 & 5 & 6 \\
\hline $\begin{array}{l}\text { 16. If a student in my class becomes disruptive and noisy, I } \\
\text { feel assured that I know some techniques to redirect him/her } \\
\text { quickly. }\end{array}$ & 1 & 2 & 3 & 4 & 5 & 6 \\
\hline $\begin{array}{l}\text { 17. Even a teacher with good teaching abilities may not reach } \\
\text { many students. }\end{array}$ & 1 & 2 & 3 & 4 & 5 & 6 \\
\hline $\begin{array}{l}\text { 18. If a student couidn't do a class assignment, most teachers } \\
\text { would be able to accurately assess whether the assignment was } \\
\text { at the correct level }\end{array}$ & 1 & 2 & 3 & 4 & 5 & 6 \\
\hline $\begin{array}{l}\text { 19. If I really try hard, I can get through to even the most dif- } \\
\text { flcult unmotivated students. }\end{array}$ & 1 & 2 & 3 & 4 & 5 & 6 \\
\hline $\begin{array}{l}\text { 20. When it comes right down to it, a teacher really can't do } \\
\text { much because most of a student's motivation and perfor- } \\
\text { mance depends on his/her environment. }\end{array}$ & 1 & 2 & 3 & 4 & 5 & 6 \\
\hline $\begin{array}{l}\text { 21. My teacher training program and/or experlence did not } \\
\text { give me the necessary skills to be an effective teacher. }\end{array}$ & 1 & 2 & 3 & 4 & 5 & 6 \\
\hline
\end{tabular}




\section{APPENDIX C}

Classroom Alternatives Support Team Request Form-Elementary 
HARMIC PUBLIC SCEOOLS

E CÁP/CASTI

ELSSROOK ALTERRATIVES SUPPORT TEAM REQUEST, FORM

EDERTARI

Page.

Date

$(12 / 91)$

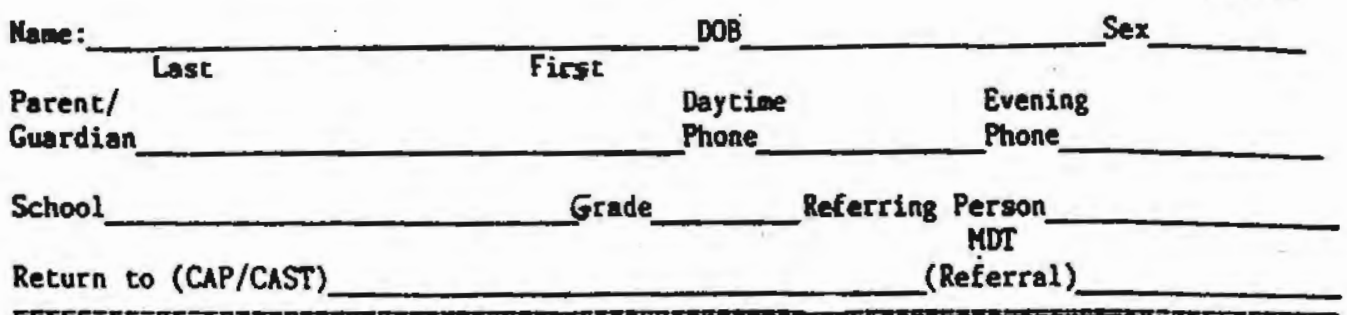

Reason for referral (describe the frasent problea(s) and ATTACH WORK SAMPLES):

What would you like the student to be able to do that he does not do now?

What do you see as this student's strengths?

What interventions have been atteroted?

Interventions

Change in seating

Change in groups

Student restates directions

Oral vs witten reports/tests

One-to-one instructions

After school help

Tutoring (teacher/parent/peer)

Use of organizational charts

Reduction of work assignments

Hodification of worksheets

Kept after school/during recess

Reward system

Modification of materials and presentation

Change in text/materials

Scudent conference-

Note/call to parents

Parent conference

Consultation with specialists

Behavior management techniọues

Orher

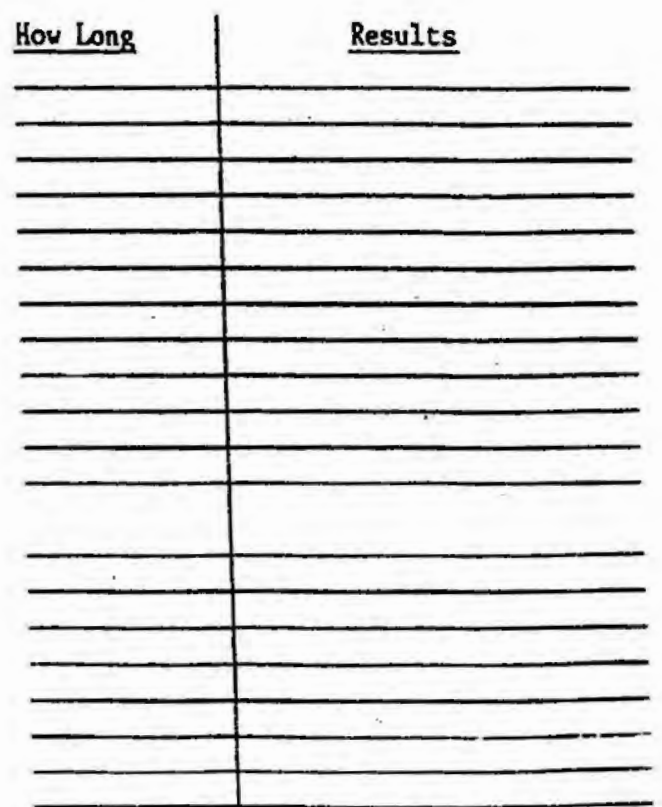


APPENDIX D

Letter Granting Permission to Access Archival Records 


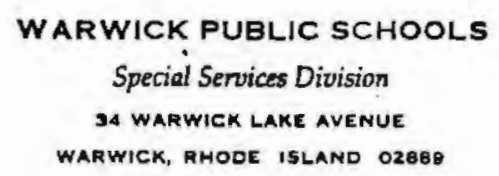

JOHN F. SHARKEY

TEL (4O1) $737-3300$ FAX (401) 739.6765

November 13,1996

Dear Mrs. Tillotson:

This letter is to inform you that permission is granted for you to collect data through the Warwick Public Schools for your dissertation project entitled "Authentic versus Analog Data: A Study of Prereferral Intervention Strategy Utilization, Effectiveness and Self-Efficacy Beliefs." The archival data will be available to you for collection via the Special Services Office. I understand you will additionally be collecting data in the form of a teacher questionnaire from elementary school teachers in this system.

This approval is, of course, contingent upon the specified assurances of confidentiality of teacher and student records as outlined in your proposal and the assumed approval of the Institutional Research Board at the University of Rhode Island. It is assumed that you will utilize the highest degree of care to maintain the confidentiality of the information you collect and shall not disclose any confidential information for any other purpose other than the furtherance of formal education, training, and/or research. You may publish your findings in an educational dissertation, professional journal or conference with permission from this office provided that no confidential information individually identifies any Warwick Public School students or employees.

Good luck as you work through this project. I look forward to reviewing the results of your project when you have completed your dissertation.

$J F S / s m h$

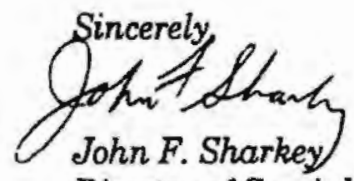

Director of Special Services 
APPENDIX E

Interrater Reliability Coding Scheme 


\title{
INTER-RATER RELLABILITY TRAINING
}

\author{
Coding Schema
}

Dear Rater:

In this task, you will be asked to translate qualitative statements made by teachers on an archival CAP/CAST forms into quantitative ratings on a 1-5 point Likert Scale. These qualitative statements have to do with the effectiveness of interventions chosen to be implemented with the referred student.

\section{STEPS:}

1. Note you will be rating $48 \mathrm{CAP} / \mathrm{CAST}$ forms which have been randomly selected from a larger data base. Each CAP/CAST form is numbered from 1 to 48 in the bottom left hand comer of the form. On your coding sheet, the farthest left hand column indicates the CAP/Cast form being rated.

2. Note that each of 20 intervention is numbered 1 through 20 across the top of the coding sheet. Along with the number of the intervention is a one or two word synopsis of the intervention title to aid in your matching the correct column.

3. Each intervention column contains 2 subcolumns. The left hand column will contain a checkmark or will remain blank. The right hand column will contain the evaluative rating (15).

3. For each CAP/CAST form, please first make a check mark $(\checkmark)$ in the 1st column underneath the selected intervention.

4. Next, please select the appropriate rating from the following chart to correspond with the qualitative statement offered on the CAP/CAST form. Place your numerical rating in the right hand column underneath the chosen intervention. The following descriptions provide the basis for the translation into a numerical rating on your coding sheet.

\begin{tabular}{|c|c|c|c|c|c|}
\hline${ }^{4} 0 "$ & “1" & $" 2 "$ & "3" & 464" & $45 \%$ \\
\hline & Not Effective & $\Rightarrow$ & Somewhat Effective & 9 & $\overline{V e r y}$ Effective \\
\hline No Report & No Effect & Limited Improvement & Some improvement & Good & Very Good \\
\hline Left Blank & No Result & Very Temporay & OK“ & Helpfu] & Excellent \\
\hline Unrelated Comment & Not Helpful & Minimal Improvement & Sometimes Helps & Better & very heipful \\
\hline not related to & No Improvement & Negligible & Varies & Positive & \\
\hline outcome or measure- & Nothing Helps & Mild Improvement & A Bit Better & & \\
\hline able result & Poor & & & & \\
\hline frequency/description & No change & & & & \\
\hline of current or & & & & & \\
\hline $\begin{array}{l}\text { pre-intervention } \\
\text { perfomance }\end{array}$ & & & & & \\
\hline
\end{tabular}

Please note: In order to rate 1-5, the statement must be directly related to improvement in student behavior or performance 
APPENDIX F

Letter of Introduction 


\begin{tabular}{llr} 
& \\
\hline DEPARTMENT OF PSYCHOLOGY & UNIVERSITY OF & Phone: 401-874-2193 \\
10 Chafee Rd, Suite 8 & RHODE ISLAND & Fax: 401-874-2157 \\
Kugston, Rhode Island 02881-0808 &
\end{tabular}

\section{Dear Teacher,}

I am in the process of completing my doctoral dissertation at the University of Rhode Island and I would be very grateful if you could help me out by providing your opinions and experience regarding use of pre-referral intervention strategies. As we know, recent changes in instructional goals and educational policy have resulted in greater mainstreaming of special education students, and the State has mandated CAP/CAST interventions before referral for multidisciplinary team evaluations. It is my hope to survey teachers regarding their use of interventions based upon our current pre-referral system.

This enclosed form should take approximately 20 minutes to complete. This survey is completely confidential and voluntary. None of the information collected will identify you by name. If you participate, you will be assigned a code that is printed on your survey form which will help me to identify your responses only for data analyses. The results, which will be analyzed and incorporated into the findings of my dissertation, will be completely free from any identifying information of you by name or location.

If you have any questions about this study or if you are not satisfied by the way this study is executed, you may contact me (phone: $401-737-3300$, ext. 4372), or my major professor Dr. Janet Kulberg (phone: 401-874-4228), anonymously if you choose. In addition, you may contact the Office of the Vice Provost for Graduate Studies, Research and Outreach at 70 Lower College Road, University of Rhode Island, Kingston, Rhode Island, (Phone: 401-874-2635). I would be happy to share the results of my study with you upon completion of my project.

Yours Truly,

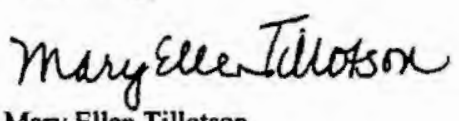

Mary Ellen Tillotson

School Psychologist

AFTER YOU COMPLETE THE SURVEY, PLEASE MAIL IT BACK TO ME IN THE STAMPED, SELF-ADDRESSED ENVELOPE I HAVE PROVIDED FOR YOUR USE...THANK YOU!!!! 
APPENDIX G

Informed Consent 


\author{
PARTICIPANT COPY \\ The University of Rhode Island \\ Department of Psychology \\ 10 Chafee Road, Suite 8 \\ Kingston, RI 02881-0808
}

\title{
ANALOGUE VERSUS AUTHENTIC DATA: PREREFERRAL INTERVENTION STRATEGY UTILIZATION, EFFECTIVENESS AND SELF-EFFICACY BELIEFS
}

\section{CONSENT FORM FOR RESEARCH}

I have been asked to take part in a research project involving my opinions and experiences regarding the use of pre-referral intervention strategies. The study involves my completion of the enclosed survey. I should feel free to ask questions now, or if I have more questions later, Mary Ellen Tillotson (401-737-300, ext. 4372), the person mainly responsible for this study, will discuss them with me.

There are no foreseeable risks or discomforts to me in participating in this study. Although there will be no direct benefit to me for taking part in this study, the researcher may learn more about pre-referral intervention strategy utilization, effectiveness and self-efficacy beliefs in public schools.

My part in this study is confidential. None of the information will identify me by name. If I participate, I will be assigned a code that is printed on the survey form which will help the researcher to identify my responses only for data analyses. The code-names list will be shredded immediately following data collection in order that my responses will remain confidential. This informed consent form will be separated immediately upon collection in order to further assure confidentiality. The results, which will be analyzed and incorporated into this dissertation, will be completely free from any identifying information of me by name or location. All records will be maintained in a confidential, locked file cabinet by the researcher.

The decision whether or not to take part in this study is up to me. I do not have to participate. If I decide to take part in the study, I may quit at any time. Whatever I decide will in no way be detrimental to me. If I wish to quit, I simply inform Mary Ellen Tillotson (401-737-3300, ext. 4372) of my decision. If I am not satisfied with the way this study is performed I may discuss my complaints with Mary Ellen Tillotson (phone: 401- 737-3300, ext. 4372), or her major professor Dr. Janet Kulberg (phone: 401-874-4228), anonymously if I so choose. In addition, I may contact the Office of the Vice Provost for Graduate Studies, Research and Outreach at 70 Lower College Road, University of Rhode Island, Kingston, Rhode Island, (Phone: 401-874-2635).

I have read the Consent Form. My questions have been answered. My signature on this form means that I understand the information and I agree to participate in this study. 
APPENDIX H

Approval from the Institutional Research Board on Human Subjects 


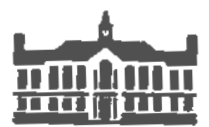

UNVVERSTY OF

RHODE ISLAND

DATE: $\quad 11 / 21 / 97$

TO: $\quad$ Student Pl: Mary Ellen Tillotson

Faculty Pl: Janet Kulberg

FROM: $\quad$ Professor Barbara S. Brown, Director of Compliance

AE:

\author{
H9798-014 Analogue versus Authentic Data: Prereferral \\ Intervention Strategy Utilization, Effectiveness \\ and Selt-Efficacy Beliefs
}

Your project was reviewed by the Institutional Review Board (IRB) and approved on the above date. The IRB approved the use of human subjects in this project as described in your proposal. This approval is valid for: 1 year

Under applicable regulations, no changes to procedures involving human subjects may be made without prior IRB review and approval. The regulations also require that you promptly notify the IRB of any problems involving human subjects that arise during the course of your work. Problems include unanticipated adverse events from participation in the project and, of course, any injuries.

Enclosed is the IRB Action Report certifying approval of your project.

If you have any question about the IRB process, or if you need assistance at any time, please feel free to contact me at the Research Office at (401)874-4328. 


\section{The University of Rhode Island \\ INSTITUTIONAL REVIEW BÖARD ON HUMAN SUBJECTS (IRB) \\ IRB ACTION REPORT}

The activity indicaled below has been reviewed by the University of Rhode Island Institutional Review Board (IRB) in accordance with the requirements of Title 45, Part 46 of the Code of Federal Regulations (Protection of Human Subjects), or other federal regulations as required such as 21CFR 50. The University hes an approved assurance of compliance on file with the Department of Health and Human Services which covers this activity. Our assurance number is MI457. Any changes which may alter the investigational situation must be reported promptly to the IRB. Any questions concerning this action can be directed to:

\section{Barbara S. Brown}

Director of Compliance

The Research Office

70 Lower College Road

University of Rhode Island

Kingston, RI 02881

Date: November 21, 1997

telephone: (401) 874-4328

IRB ID No. H9798-014

Project Tille: Analogue versus Authentic Data: Prereferral Intervention Strategy Utilization, Effectiveness and Self-Efficacy Beliefs

\begin{tabular}{|l|l|}
\hline Eaculo Investigator or Sponsor & Studeas Investipator (if applicables): \\
Janet Kulberg & Mary Ellen K. Tillotson \\
Psychology & 200 Post Road Unit 233 \\
Chafee & Warwick, RI 02888 \\
\hline
\end{tabular}

\begin{tabular}{|l|l|l|l|l|}
\hline Datc of Initial IRB Review: & Type of Review: & Date of Action: & Action: & $\begin{array}{l}\text { Monitoring } \\
\text { Intercali } \\
1 \text { year }\end{array}$ \\
August 14,1997 & Expedited & $8 / 25 / 97$ & Approved & . \\
\hline
\end{tabular}

Comments:

The change in your survey/data collection method was approved at the 11/20/97 full-board meeting, with the stipulation that the "Boiler Plate" Informed Consent form be followed more closely.

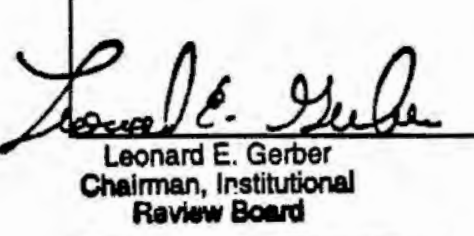

IRB Chair (or Designated Member)

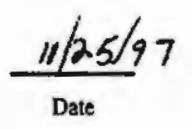

Date

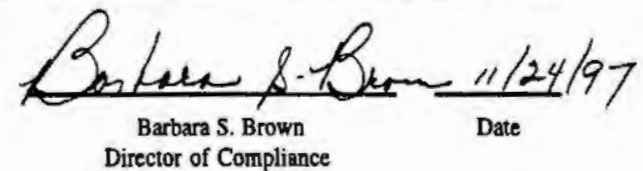




\section{APPENDIX I}

Study Information Form (Revised Consent) 


\title{
TEAR OFF AND KEEP THIS FORM FOR YOURSELF
}

\author{
STUDY INFORMATION FORM \\ The University of Rhode Island \\ Department of Psychology \\ 10 Chafee Road, Suite 8 \\ Kingston, RI 02881-0808
}

\section{ANALOGUE VERSUS AUTHENTIC DATA: PREREFERRAL INTERVENTION STRATEGY UTILIZATION, EFFECTIVENESS AND SELF-EFFICACY BELIEFS}

\section{INFORMATION ABOUT THIS RESEARCH}

I have been asked to take part in a research project involving my opinions and experiences regarding the use of pre-referral intervention strategies. The study involves my completion of the enclosed survey. 1 should feel free to ask questions now, or if I have more questions later, Mary Ellen Tillotson (401-737-300, ext. 4372), the person mainly responsible for this study, will discuss them with me.

There are no foreseeable risks or discomforts to me in participating in this study. Although there will be no direct benefit to me for taking part in this study, the researcher may learn more about pre-referral intervention strategy utilization, effectiveness and self-efficacy beliefs in public schools.

My part in this study is confidential. None of the information will identify me by name. If I participate, I will be assigned a code that is printed on the survey form which will help the researcher to identify my responses only for data analyses. The code-names list will be shredded immediately following data collection in order that my responses will remain confidential. The results, which will be analyzed and incorporated into this dissertation, will be completely free from any identifying information of me by name or location. All records will be maintained in a confidential, locked file cabinet, at the University of Rhode Island, by the researcher.

The decision whether or not to take part in this study is up to me. I do not have to participate. Whatever I decide will in no way be detrimental to me. My completion of the survey materials will serve as my consent to participate in this research study. If I wish to quit, I simply inform Mary Ellen Tillotson (401737-3300, ext. 4372) of my decision. If I am not satisfied with the way this study is performed I may discuss my complaints with Mary Ellen Tillotson (phone: 401-737-3300, ext. 4372), or her major professor Dr. Janet Kulberg (phone: 401-874-4228), anonymously if I so choose. In addition, I may contact the Office of the Vice Provost for Graduate Studies, Research and Outreach at 70 Lower College Road, University of Rhode Island, Kingston, Rhode Island, (Phone: 401-874-2635). 


\section{BIBLIOGRAPHY}

Abelson, R. P. (1988). Conviction. American Psychologist, 43, 267-275.

Adelman, H. S. (1992). LD: The next 25 years. Journal of Learning Disabilities, 25, 1722.

Albee, G. W. (1968). Conceptual models and manpower requirements in psychology. American Psychologist, 23, 317-320.

Aldrich, S. F., \& Martens, B. K. (1993). The effects of behavioral problems analysis versus instructional environment information on teachers' perceptions. School Psychology Quarterly, 8, 110-124.

Algozzine, B., Christenson, S., \& Ysseldyke, J. E. (1982). Probabilities associated with the referral to placement process. Teacher Education and Special Education, 5, 19-23.

Algozzine, B., \& Korinek, L. (1985), Where is special education for students with high prevalence handicaps going? Exceptional Children, 51, 388-394.

Algozzine, B., \& Maheady, L. (1986). When all else fails, teach! Exceptional Children, 52, 487-488.

Algozzine, B., Ysseldyke, J. E., Christenson, S., \& Thurlow, M. L. (1983). A factor analysis of teachers' intervention choices for dealing with students' behavior and learning problems. The Elementary School Journal, 84, 189-197.

Allinder, R. M. (1995). An examination of the relationship between teacher efficacy and curriculum-based measurement and student achievement. Remedial and Special Education, 16, 247-254.

Alpert, J. D. (1976). Conceptual bases of mental health consultation in the schools. Professional Psychology, 7, 619-626.

Alpert, J. L, \& Meyers, J. (1983). Training in consultation: Perspectives from mental health, behavioral and organizational consultation. Springfield, ill: CC Thomas.

Alpert, J. L., Weiner, L. B., \& Ludwig, L. M. (1979). Evaluation of outcome in school consultation. Journal of School Psychology, 17, 333-338.

Alpert, J. L., \& Yammer, M. D. (1983). Research in school consultation: A content analysis of selected journals. Professional Psychology: Research and Practice, 14, 604-612.

Ashton, P. (1984). Teacher efficacy: A motivational paradigm for effective teacher education. Journal of Teacher Education, 35, 28-32.

Ashton, P. T., \& Webb, R. (1982, March). Teachers' sense of efficacy: Toward an ecological model. Paper presented at the Annual Meeting of the American Educational Research Association: New York. 
Aubry, C. (1987). Training for the role of school consultant as a means of dealing effectively with behavior problems in schools. Educational and Child Psychology, 4, 14-29.

Bahr, M. W. (1994). The status and impact of prereferral intervention: "We need a better way to determine success". Psychology in the Schools, 31, 309-318.

Baker, J. \& Zigmond, N. (1990). Are regular education classes equipped to accommodate students with 1 earning disabilities? Exceptional Children, 56, 515-526.

Bandura, A. (1977). Social learning theory. Englewood Cliffs, NJ: Prentice Hall.

Bandura, A. (1982). Self efficacy mechanism in human agency. American Psychologist, 37. $122-147$.

Bandura, A. (1986). Social foundations of thought and action: A social cognitive theory. Englewood Cliffs, NJ: Prentice-Hall.

Bandura, A. (1997a). Self-efficacy: the exercise of control. New York: Freeman.

Bandura, A. (1997b). Guide for constructing self-efficacy scales. Unpublished manuscript, Stanford University, Palo Alto, CA.

Bandura, A. (1997c). Self-efficacy. Harvard Mental Health Letter, 13, 4-7.

Bardon, J. (1982). The psychology of school psychology. In C. R. Reynolds, \& T. B. Gutkin (Eds.). The Handbook of School Psychology (pp. 3-13). New York: Wiley.

Bardon, J. I. (1987). The translation of research into practice in school psychology. School Psychology Review, 16, 317-328.

Bateman, B. (1992). Learning disabilities: The changing landscape. Journal of Learning Disabilities, 25, 29-36.

Benz, C. R., Bradley, L., Alderman, M. K., \& Flowers, M. A. (1992). Personal teaching efficacy: Developmental relationships in education. Journal of Educational Research, 85, 274285 .

Bergan, J. R. (1990). Contributions of behavioral psychology to school psychology. In T. B. Gutkin \& C. R. Reynolds (Eds.), The handbook of school psychology (2nd ed., pp. 126-142). New York: John Wiley \& Sons.

Bergan, J. R., \& Kratochwill, T. R. (1990). Behavioral consultation and therapy. New York: Plenum Press.

Bergan, J., \& Neumann, A. J. (1980). The identification of resources and constraints influencing plan design in consultation. Journal of School Psychology, 18, 317-323.

Bergan, J. R., \& Tombari, M. L. (1975). The analysis of verbal interactions occurring during consultation. Journal of School Psychology, 13, 209-226. 
Bergan, J. \& Tombari, M. (1976). Consultant skill and efficiency and the implementation and outcomes of consultation. Joumal of School Psychology, 14, 3-13.

Berkowitz, L., \& Donnerstein, E. (1982). External validity is more than skin deep. American Psychologist, 37, 245-257.

Berman, P., \& McLaughlin, M. W., Bass, G., Pauly, E., \& Zellman, G. (1977). Federal Programs supporting educational change, Vol. VII: Factors affecting implementation and continuation. Santa Monica, CA: The Rand Corporation

Bickel, W. E., \& Bickel, D.D. (1986). Effective schools, classrooms, and instruction: Implications for special education. Exceptional Children, 52, 489-500.

Blase, J. J. (1990). Some negative effects of principals' controlling-oriented and protective political behavior. American Educational Research Journal, 27, 727-753.

Borkovec, T., \& Rachman, S. (1979). The utility of analogue research. Behavioral Research and Therapy, 17, 253-261.

Brantlinger, E. (1997). Using ideology: Cases of nonrecognition of the politics of research and practice in special education. Review of Educational Research, 67, 425-459.

Broussard, B. A., Book, C., \& Byers. (1988). Teacher beliefs and the cultures of teaching. Joumal of Teacher Education, 35, 28-32.

Brownell, M. T. \& Pajares, F. M. (1996). The influence of teachers' efficacy beliefs on perceived success in mainstreaming students with learning and behavior problems: A path analysis. Research Bulletin, 27, 1-23.

Burke, J. P., \& Demers, S. T. (1979). A paradigm for evaluating assessment interviewing techniques. Psychology in the Schools, 16, $51-60$.

Cannon, G. S., Idol, L, \& West, F. J. (1992). Educating students with mild handicaps in general classrooms: Essential teaching practices for general and special educators. Journal of Learning Disabilities, 25, 300-317.

Caplan, G. (1970). The theory and practice of mental health consultation. New York: Basic Books.

Carlson, C. I., \& Tombari, M. L. (1986). Multilevel school consultation training: Preliminary program evaluation. Professional School Psychology, 1, 89-104.

Carlson, R. (1984). What's social about social psychology? Where's the person in personality research? Journal of Personality and Social Psychology, 47, 1304-1309.

Carlsmith, J. M., Ellsworth, P. C., \& Aaronson, E. Methods of research in social psychology. Reading, MA: Addison-Wesley, 1976.

Carter, J., \& Sugai, G. (1989).; Survey on prereferral practices: Responses from state departments of education. Exceptional Children, 55, 298-302. 
Chesler, M. A., Bryant, B. I., \& Crowfoot, J. E. (1976). Consultation in school: Inevitable conflict, partisanship, and advocacy. Professional Psychology, 7, 637-645.

Chester, M. D., \& Beaudin, B. Q. (1996). Efficacy beliefs of newly hired teachers in urban schools. American Educational Research Journal, 33, 233-257.

Chin, R., \& Benne, K. D. (1976). General strategies for effecting changes in human systems. In W. G. Bennis, K. D. Benne, R. Chin, \& K. E. Corey (Eds.), The planning of change (3rd ed.). New York: Holt, Rinehart \& Winston.

Christenson, S., Ysseldyke, J. E., \& Algozzine, B. (1982). Institutional and external pressures influencing referral decisions. Psychology in the Schools, 19, 341-345.

Chwalisz, K. D., Altmaier, E. M., \& Russell, D. W. (1992). Causal attributions, selfefficacy, cognitions, and coping with stress. Journal of Social and Clinical Psychology, 11, $377-400$.

Cohen, J. (1960). A coefficient of agreement for nominal scales. Educational and Psychological Measurement, 20, 37-46

Cohen, J. (1992). A power primer. Psychological Bulletin, 112, 155-159.

Cone, J. D., \& Foster, S. L. (1993). Dissertations and theses from start to finish: Psychology and related fields. Washington, D. C: American Psychological Association.

Conoley, J. C. (1981). Consultation in schools: Theory, research and practice. New York: Academic Press.

Conoley, J. C., \& Conoley, C. W. (1982). School consultation: A guide to practice and training. New York: Pergamon.

Conoley, J. C., \& Conoley, C. W. (1988). Useful theories in school-based consultation. Remedial and Special Education, 9, 14-20.

Conoley, C. W., Conoley, J. C., Ivey, D. C., \& Scheel, M. J. (1991). Enhancing consultation by matching the consultee's perspectives. Journal of Counseling and Development, 69, 546-549.

Conoley, J. C., \& Gutkin, T. B. (1986). School psychology: A reconceptualization of service delivery realities. In S. N. Elliott \& J. C. Witt (Eds.), The Delivery of Psychological services in Schools: Concepts, Processes and Issues (pp. 393-424). Hillsdale, N. J: Lawrence Erlbaum.

Conoley, J., \& Gutkin, T. (1986). Educating school psychologists for real world. School Psychology Review, 15, 457-465.

Costenbader, V., Swartz, J., \& Petrix, L. (1992). Consultation in the schools: The relationship between preservice training, perception of consultative skills, and actual time spent in consultation. School Psychology Review, 21, 95-108. 
Council for Exceptional Children (1992). Providing an appropriate education to children with attention deficit disorder. ERIC Digest, \#E512, Restin, VA: ERIC Clearinghouse on Handicapped and Gifted Children.

Curtis, M. J., \& Anderson, T. (1976). Consulting in educational settings: A collaborative approach. Cincinnati: Faculty Resource Center, University of Cincinnati.

Curtis, M. J., \& Meyers, J. (1985). Best practices in school-based consultation. In A. Thomas \& J. Grimes (Eds.), Best practices in school psychology (pp. 79-94). Washington, DC: National Association of School Psychologists.

Dembo, M. H., \& Gibson, S. (1985). Teachers' sense of efficacy: An important factor in school improvement. The Elementary School Journal, 86, 173-184.

de Mesquita, P. B., \& Drake, J. C. (1994). Educational reform and the self-efficacy beliefs of teachers implementing nongraded primary school programs. Teaching and Teacher Education, 10, 291-302.

Deno, S. L. (1975). A consulting problem in which student behavior is the focus. In C. Parker (Ed.), Psychological consultation: Helping teachers meet special needs. Reston, VA: Council for Exceptional Children.

Education for All Handicapped Children Act of 1975 (PL 94-142), 20 U. S. C. § 401 (supp. 1975).

Elliott, S. N. (1986). Children's ratings of the acceptability of classroom interventions for misbehavior: Findings and methodological considerations. Journal of School Psychology, 24, 23-35.

Elliott, S. N. (1988a). Acceptability of behavioral treatments: Review of variables that influence treatment selection. Professional Psychology Research and Practice, 19, 68-80.

Elliott, S. N. (1988b). Acceptability of behavioral treatments in educational settings. In J. C. Witt, S. N. Elliott, \& F. M. Gresham (Eds.), Handbook of Behavior Therapy in Education (pp. 121-150). New York: Plenum.

Elliott, S. N., Turco, T. L., \& Gresham, F. M. (1987). Consumers' and clients' pretreatment acceptability ratings of classroom group contingencies. Joumal of School Psychology, 25, 145-153.

Elliott, S. N., \& Witt, J. C. (Eds.). (1986). The delivery of psychological services in schools: Concepts, processes, and issues. Hillside, NJ: Erlbaum.

Elliott, S. N., Witt, J. C., Galvin, G. A., \& Moe, G. L. (1986). Children's involvement in intervention selection: Acceptability of interventions for misbehaving peers. Professional Psychology: Research and Practice, 17, 235-241. 
Elliott, S. N., Witt, J. C., Galvin, G., Peterson, R. (1984). Acceptability of positive and reductive interventions: Factors that influence teachers' decisions. Journal of School Psychology, 22, 353-360.

Elliott, S. N., Witt, J. C., \& Kratochwill, T. R. (1984). Selecting, implementing, and evaluating classroom interventions. In C. R. Reynolds, T. B. Gutkin, S. N. Elliott, \& J. C. Witt (Eds.), School Psychology: Essentials of Theory and Practice. New York: Wiley.

Emmelkamp, P. M., Mersch, P. P., \& Vissia, E. (1985). The external validity of analogue outcome research: evaluation of cognitive and behavioral interventions. Behavioral Research and Therapy, 23, 83-86.

Enochs, L. G., Schamann, L. C., \& Riggs, I. M. (1995). The relationship of pupil control to preservice elementary science teacher self-efficacy and outcome expectancy. Science Education, 79, 63-75.

Erchul, W. P. (1987). A relational communication analysis of control in school consultation. Professional School Psychology, 2, 113-124.

Erchul, W. P., \& Chewning, T. G. (1990). Behavioral consultation from a requestcentered relational communication perspective. School Psychology Quarterly, 5, 1-20.

Erchul, W. P., \& Conoley, C. W. (1991). Helpful theories to guide counselors' practice of school-based consultation. Elementary School Guidance and Counseling, 25, 204-211.

Erchul, W. P., Covington, C. G., Hughes, J., \& Meyers, J. (1995). Further explorations of request-centered relational communication within school consultation. School Psychology Review, 24, 621-632.

Erchul, W. P., \& Schulte, A. C. (1990). The coding of consultation verbalizations: How much is enough? School Psychology Quarterly, 5, 256-264.

Fairchild, T. N. (1976). School psychological services: An empirical comparison of two models. Psychology in the School, 13, 156-162.

Farkas, G. M., \& Tharp, R. G. (1980). Observation procedure, observer gender, and behavior valence as determinants of sampling error in a behavior assessment analogue. Journal of Applied Behavior Analysis, 13, 529-536.

Ferguson, M. L. (1991). Collaborative/consultative service delivery: An introduction. Language, Speech and Hearing Services in Schools, 22, 147-155.

Fine, M. J., Graham, V. L., \& Wright, J. G. (1979). Personal variables that facilitate or impede consultation. Psychology in the Schools, 16, 533-539.

Flanagan, M. F., \& Dipboye, R. L. (1980). Representativeness does have implications for the generalizability of laboratory and field research findings. American Psychologist, 35, 464467. 
Flugum, K. R., \& Reschly, D. J. (1994). Prereferral interventions: Quality indices and outcomes. Journal of School Psychology, 32, 1-14.

Forness, S. R., \& Knitzer, J. (1992). A new proposed definition and terminology to replace "serious emotional disturbance" in individuals with disabilities act. School Psychology Review, 21, 12-20.

Foster, G. G., Schmidt, C., \& Sabotino, D. (1976). Teacher expectancies and the label "learning disabilities." Journal of Learning Disabilities, 22, 330-333.

Friend, M. (1988). Putting consultation into context: Historical and contemporary perspectives. Remedial and Special Education, 9, 7-13.

Friend, M. (1996). Response to reflections on special education teacher preparation. Teacher Education and Special Education, 19, 220.

Friend, M., \& Bauwens, J. (1988). Managing resistance: An essential consulting skill for learning disabilities teachers. Journal of Learning Disabilities, 21, 556-561.

Fritz, J. J., Miller-Heyl, J., Kreutzer, J. C., \& MacPhee, D. (1995). Foster personal teaching efficacy through staff development and classroom activities. Journal of Educational Research, 88, 200-208.

Fuchs, D., \& Fuchs, L. S. (1989). Exploring effective and efficient prereferral interventions: A component analysis of behavioral consultation. School Psychology Review, $18,260-283$.

Fuchs, D., \& Fuchs, L. S. (1994). Inclusive schools movement and the radicalization of special educaiton reform. Exceptional Children, 60, 294-309.

Fuchs, D., Fuchs, L. S., \& Bahr, M. W. (1990). Mainstream assistance teams: A scientific basis for the art of consultation. Exceptional Children, 57, 128-139.

Fuchs, L. S., Fuchs, D., \& Bishop, N. (1992). Instructional adaptation for students at risk. Journal of Educational Research, 86, 70-84.

Fuchs, D., Fuchs, L., Gilman, S., Reeder, P., Bahr, M., Fernstrom, P., \& Roberts, H. (1990). Prereferral intervention through teacher consultation: Mainstream assistance teams. Academic Therapy, 25, 263-276.

Ferguson, D. L., \& Ferguson, P. M. (1997). Debating inclusion in Synecdoche, New York: A response to Gresham and MacMillan. Review of Educational Research, 67, 416-420.

Gallesich, J. (1973). Organizational factors influencing consultation in schools. Journal of School Psychology, 11, 57-65.

Gallesich, J. (1985). Toward a meta-theory of consultation, The Counseling Psychologist, $13,336-354$. 
Gavrilidou, M., de Mesquita, P. B., \& Mason, E. J. (1994). Greek teachers' perceptions of school psychologists in solving classroom problems. Journal of School Psychology, 32, 293304.

Gerber, M. M. (1988). Tolerance and technology of instruction: Implications for special education reform. Exceptional Children, 54, 309-314.

Gettinger, M. (1988). Analogue assessment: Evaluating academic abilities. In M. Shapiro, E. S., \& Kratochwill, T. (Eds.), Behavioral assessment in Schools: Conceptual Foundations and Practical Applications. New York: Guilford.

Gibson, S., \& Dembo, M. H. (1984). Teacher efficacy: A construct validation. Journal of Educational Psychology, 76, 569-582.

Goldman, S. (1986). The school psychologist's role in regular education. Communiqué, $14,9-10$.

Gottlieb, J., Gottlieb, B. W., \& Trongone, S. (1991). Parent and teacher referrals for psychoeducational evaluation. Journal of Special Education, 25, 155-167.

Graden, J. L. (1989). Reactions to school consultation: Some considerations from a problem-solving perspective. Professional School Psychology, 4, 29-35.

Graden, J. L., Casey, A., \& Bonstrom, O. (1985). Implementing a prereferral intervention system: Part II. The data. Exceptional Children, 51, 487-496.

Graden, J. L., Zins, J. E., \& Curtis, M. J. (Eds.). (1988). Alternative educational delivery systems: Enhancing options for all students. Washington, DC: NASP.

Gresham, F. M. (1989). Assessment of treatment integrity in school consultation and prereferral intervention. School Psychology Review, 18, 37-50.

Gresham, F. M., Gansle, K.A., Noell, G.H., Cohen, S., \& Rosenblum, S. (1993). Treatment integrity of school based intervention studies: 1980-1990. School Psychology Review, 22, 254-272.

Gresham, F. M., \& Kendall, G. K. (1987). School consultation research: Methodological critique and future research directions. School Psychology Review, 16, 306-3I6.

Gresham, F. M., \& Lopez, M. F. (1996). Social validation: A unifying concept for schoolbased consultation research and practice. School Psychology Quarterly, 11, 204-227.

Gresham, F. M., \& MacMillan, D. L. (1997). What we have here is a failure to communicate: A rejoinder to Ferguson and Ferguson. Review of Educational Research, 67, 421-423.

Gurman, A. S. (1984). Commentary: Analogue research and the family therapist. Family Process, 23, 341-354. 
Guskey, T. R. (1988). Teacher efficacy, self-concept, and attitudes toward the implementation of instructional innovation. Teaching and Teacher Education, 4, 63-69.

Guskey, T. R., \& Passaro, P. D. (1994). Teacher efficacy: A study of construct dimensions. American Educational Research Journal, 31, 627-643.

Gutkin, T. B. (1980). Teacher perceptions of consultation services provided by school psychologists. Professional Psychology, 11, 637-642.

Gutkin, T. B. (1981). Relative frequency of consultee lack of knowledge, skills, confidence, and objectivity in school settings. Journal of School Psychology, 19, 57-61.

Gutkin, T. B. (1986). Consultees' perception of variables relating to the outcomes of school-based consultation interactions. School Psychology Review, 3, 375-382.

Gutkin, T. B., \& Ajchenbaum, M. (1984). Teachers' perceptions of control and preferences for consultative services. Professional Psychology: Research and Practice, 15. 565-570.

Gutkin, T. B., \& Bossard, M. D. (1984). Impact of consultant, consultee, and organizational variables on teacher attitudes toward consultation services. Journal of School Psychology, 22, 251-258.

Gutkin, T. B., Clark, J. H., \& Ajchenbaum, M. (1985). Impact of organizational variables on the delivery of school-based consultation services: A comparative case study approach. School Psychology Review, 14, 230-235.

Gutkin, T. B., \& Curtis, M. J. (1990). School-based consultation: Theory, techniques and research. In T. B. Gutkin \& C. R. Reynolds (Eds.), The handbook of school psychology (2nd ed., pp. 577-611). New York: Wiley.

Gutkin, T. B., Henning-Stout, M., \& Piersel, W. C. (1988). Impact of a district-wide behavioral consultation prereferral intervention service on patterns of school psychological service delivery. Professional School Psychology, 3, 301-308.

Gutkin, T. B., \& Hickman, J. A. (1988). Teachers' perceptions of control over presenting problems and resulting preferences for consultation versus referral services. Journal of School Psychology, 26, 395-398.

Gutkin, T. B., \& Hickman, J. A. (1990). The relationship of consultant, consultee and organizational characteristics to consultee resistance to school-based consultation: An empirical analysis. Journal of Educational and Psychological Consultation, 1, 111-122.

Gutkin, T. B., Singer, J. H., \& Brown, R. (1980). Teacher reactions to school based consultation services: A multivariate analysis. Journal of School Psychology, 18, 126-134.

Harrison, A. W., Rainer, R. K., Hochwarter, W. A., \& Thompson, K. R. (1997). Testing the self-efficacy-performance linkage of social-cognitive theory. The Journal of Social Psychology, 137, 79-88. 
Hattie, J. A., Sharpley, C. F., \& Rogers, H. J. (1984). Comparative effectiveness of professional and paraprofessional helpers. Psychological Bulletin, 95, 534-541.

Hawryluk, M. K., \& Smallwood, D. L. (1986). Assessing and addressing consultee variables in school-based behavioral consultation. School Psychology Review, 15, 519-528.

Henning-Stout, M., \& Conoley, J. C. (1987). Consultation and counseling as procedurally divergent: Analysis of verbal behavior. Professional Psychology: Research and Practice, 18, 124-127.

Henning-Stout, M., Lucas, D. A., \& McCary, V. L. (1993). Alternative instruction in the regular classroom: A case illustration and evaluation. School Psychology Review, 22, 81-97.

Heppner, P. P., \& Claiborn, C. D. (1989). Social influence research in counseling: A review and critique. Journal of Counseling Psychology, 36, 365-387.

Heron, T. E., \& Harris, K. D. (1987). The educational consultant: Helping professional, parents, and mainstreamed students (2nd ed.). Boston: Allyn \& Bacon.

Heron, T. E., \& Kimball, W. H. (1988). Gaining perspective with the educational consultation research base: Ecological considerations and further recommendations. Remedial and Special Education, 9, 21-47.

Hofmeister, A. M. (1990). Individual differences and the form and function of instruction. The Journal of Special Education, 24, 150-159.

Hoy, W. K. (1990). Organizational climate and culture: A conceptual analysis of the school workplace. Journal of Educational and Psychological Consultation, 1, 149-168.

Hughes, J. N. (1979). Consistency of administrators' and psychologists' actual and ideal perceptions of school psychologists' activities. Psychology in the Schools, 16, 234-239.

Hughes, J. N. (1983). The application of cognitive dissonance theory to consultation. Journal of School Psychology, 21, 349-357.

Hughes, J. N. (1986). Ethical issues in school consuitation. School Psychology Review, 15, 489-499.

Hughes, J. N., Grossman, P., \& Barker, D. (1990). Teachers' expectancies, participation in consultation, and perceptions of consultant helpfulness. School Psychology Quarterly, 5, 176179.

Hyman, I. A., \& Kaplinski, K. (1994). Will the real school psychologist please stand up?: is the past a prologue for the future of school psychology? School Psychology Review, 23, 564-583.

Hynd, G. W. (1988). Blowing on the sails: Yes, but... School Psychology Review, 17, 485-489. 
Idol, L. (1988). A rationale and guidelines for establishing special education consultation programs. Remedial and Special Education, 9, 48-58.

Idol, L. (1989). Reaction to Walter Pryzwansky's presidential address to the American psychological association on school consultation. Professional School Psychology, 4, 15-19.

Idol, L. (1989). The resource/consulting teacher: An integrated model of service delivery. Remedial and Special Education, 10, 38-48.

Idol-Maestas, L., \& Ritter, S. (1985). A follow-up study of resource/consulting teachers: Factors that facilitate and inhibit teacher consultation. Teacher Education and Special Education, 8, 121-131.

Iwata, B. A., Wong, S. E., Riordan, M. M., Dorsey, M. F., \& Lau, M. M. (1982). Assessment and training of clinical interviewing skills: Analogue analysis and field replication. Journal of Applied Behavior Analysis, 15, 191-203.

Jellinek, M. S. (1990). School consultation: Evolving issues. Journal of the American Academy of Child and Adolescent Psychiatry, 29, 311-314.

Johnson, L. J., Pugach, M. C., \& Hammitte, D. J. (1988). Barriers to effective special education consultation. Remedial and Special Education, 9, 41-47.

Johnson, T. C., Stoner, G., \& Green, S. K. (1996). Demonstrating the experimenting society model with classroom behavior management interventions. School Psychology Review, 25. 199-124.

Johnston, N. S. (1990). School consultation: The training needs of teachers and school psychologists. Psychology in the Schools, 27, 51-56.

Jordan, A., Kircaali-Iftar, G, \& Diamond, C.T. (1993). Who has a problem, the student or the teacher? Differences in teachers' beliefs about their work with at-risk and integrated exceptional students. International Journal of Disability, Development and Education, 40, 4562 . Wiley.

Katz, D., \& Kahn, R. L. (1978). The social psychology of organizations. New York:

Kazdin, A. E. (1978). Evaluating the generality of findings in analogue therapy research. Journal of Consulting and Clinical Psychology, 46, 673-686.

Kazdin, A. E. (1980). Investigating generality of findings from analogue research: A rejoinder. Journal of Consulting and Clinical Psychology, 48, 772-773.

Kiesler, D. J. (1983). The 1982 interpersonal circle: A taxonomy for complementarity in human transactions. Psychological Review, 90, 185-214.

Keith, T. Z. (1988). Research methods in school psychology: An overview. School Psychology Review, 17, 502-520. 
Kendrick, D. T. (1986). How strong is the case against contemporary social and personality psychology? A response to Carlson. Journal of Personality and Social Psychology, $\underline{50,839-844 .}$

Kendrick, D. T., \& Funder, D. C. (1988). Profiting from controversy: Lessons from the person-situation debate. American Psychologist, 43, 23-34.

Kingery, P. M., Holcomb, D., Jibaja-Rusth, M., Pruitt, B. E., \& Buckner, W. P. (1994). The health self-efficacy scale. Journal of Health Education, 25, 68-76.

Knoff, H. M. (1985). Attitudes toward mainstreaming: A status report and comparison of regular and special educators in New York and Massachusetts. Psychology in the Schools, 22. 410-418.

Kovaleski, J. F. (1988). Paradigmatic obstacles to reform in school psychology. School Psychology Review, 17, 479-484.

Kratochwill, T. R. (1990). Advances in behavioral assessment. In T. B. Gutkin \& C. R. Reynolds (Eds.), The handbook of school psychology (2nd ed., pp. 328-364). New York: Wiley.

Kratochwill, T. R., \& Bergan, J. R. (1978). Training school psychologists: Some perspectives on a competency-based behavioral consultation model. Professional Psychology, 9, 71-82.

Kratochwill, T. R., Sheridan, S. M., Rotto. P., \& Salmon, D. (1991). Preparation of school psychologists to serve as consultants for teachers of emotionally disturbed children. School Psychology Review, 20, 530-549.

Kratochwill, T. R., \& vanSomeren, K. R. (1985). Barriers to treatment success in behavioral consultation: Current limitations and future directions. Journal of School Psychology, 23, 225-24

Kratochwill, T. R., Van Someren, K. R., \& Sheridan, S. M. (1989). Training behavioral consultants: A competency-based model to teach interview skills. Professional School Psychology, 4, 41-58.

Lambert, N. M. (1976). Children's problems and classroom interventions from the perspective of classroom teachers. Professional Psychology, 1, 507-517.

Lambert, N. M. (1986a). Conceptual foundations for school psychology: Perspectives from the development of the school psychology program at Berkeley. Professional School Psychology, 1, 215-223.

Lambert, N. M. (1986b). Engineering new designs for school psychological service delivery: A commentary on school psychology: A blueprint for training and practice. Professional School Psychology, 1, 295-300. 
Lloyd, J. W., Singh, N. N., \& Repp, A. C. (Eds.). (1991). The regular education initiative: Alternative perspectives on concepts, issues and models. Sycamore, IL: Sycamore Publishing Co.

Macmillan, D. L., Forness, S. R., \& Trumbull, B. M. (1973). The role of punishment in the classroom. Exceptional Children, 40, 85-96.

Mann, P. (1973). Student consultants: Evaluation by consultees. American Journal of Community Psychology, 1, 182-193.

Mannino, F. V., \& Shore, M. F. (1975). The effects of consultation: A review of empirical studies. American Journal of Community Psychology, 17, 275-282.

Margolis, H., Fish, M., \& Wepner, S. B. (1990). Overcoming resistance to prereferral classroom interventions. Special Services in the Schools, 6, 167-187.

Martens, B. K., Erchul, W. P., \& Witt, J. C. (1992). Quantifying verbal interactions in school-based consultation: A comparison of four coding schemes. School Psychology Review, 21, 109-124.

Martens, B. K., \& Keller, H. R. (1987). Training school psychologists in the scientific tradition. School Psychology Review, 16, 329-337.

Martens, B. K., Lewandowski, L. J., \& Houk, J. L. (1989). Correlational analysis of verbal interactions during the consultative interview and consultee's subsequent perceptions. Professional Psychology: Research and Practice, 20, 334-339.

Martens, B. K., Lewandowski, L. J., \& Houk, J. L. (1989). The effects of entry information on the consultation process. School Psychology Review, 18, 225-234.

Martens, B. K., \& Meller, P. J. (1989). Influence of child and classroom characteristics on acceptability of interventions. Journal of School Psychology, 27, 237-245.

Martens, B. K., Peterson, R. L., Witt, J. C., \& Cirone, S. (1986). Teacher perceptions of school-based interventions. Exceptional Children, 53, 213-223.

Martens, B. K., \& Witt, J. C. (1984). Assessment and prediction in an ecological system: Application of the general linear model to the response-class concept. Journal of Behavioral Assessment, 6, 197-206.

Martens, B. K., \& Witt, J. C. (1988). Expanding the scope of behavioral consultation: A systems approach to classroom behavior change. Professional School Psychology, 3, 271-281.

Martens, B. K., Witt, J. C., Elliott, S. N., \& Darveaux, D. (1985). Teacher judgments concerning the acceptability of school-based interventions. Professional Psychology: Research and Practice, 16, 191-198.

Martin, R. P. (1983). Consultant, consultee, and client explanations of each others behavior in consultation. School Psychology Review, 12, 35-41. 
McDougall, L. M., Reschly, D. J., \& Corkery, J. M. (1988). Changes in referral interviews with teachers after behavioral consultation training. Journal of School Psychology, 26, $225-$ 232.

McKee, W. T., \& Witt, J. C. (1990). Effective teaching: A review of instructional, and environmental variables. In T. B. Gutkin \& C. R. Reynolds (Eds.), The Handbook of School Psychology, (2nd ed., pp. 821-846). New York: Wiley.

McKee, W. T., Witt, J. C., Elliott, S. N., Pardue, M., \& Judycki, A. (1987). Practice informing research: A survey of research dissemination and knowledge utilization. School Psychology Review, 16, 338-347.

Medway, F. J. (1979). How effective is school consultation: A review of recent research. Journal of School Psychology, 17, 275-282.

Medway, F. (1982). School consultation research: Past trends and future directions. Professional Psychology, 13, 275-282.

Medway, F. J. (1989). Further considerations on a cognitive problem-solving perspective on school consultation. Professional School Psychology, 4, 21-27.

Medway, F. J., \& Forman, S. (1980). Psychologists' and teachers' reaction to mental health and behavioral school consultation. Journal of School Psychology, 18, 338-348.

Medway, F. J., \& Updyke, J. F. (1985). Meta-analysis of consultation outcome studies. American Journal of Community Psychology, 13, 489-505.

Melby, L. C. (1995). Teacher efficacy and classroom management: A strategy of teacher cognition, emotion and strategy usage associated with externalizing student behavior. Ph.D. diss., University of California, Los Angeles.

Meyers, J. (1973). A consultation model for school psychological services. Journal of School Psychology, 11, 5-15.

Meyers, J. (1988). School psychology: The current state of practice and future practice of the specialty. Professional School Psychology, 3, 165-176.

Meyers, J., Parsons, R. D., \& Martin, R. (1979). Mental health consultation in the schools. San Francisco: Jossey-Bass.

Meyers, J. M., Wurtz, R., \& Flanagan, D. (1981). A national survey investigating consultation training occurring in school psychology programs. Psychology in the Schools, 18 , 297-302.

Morrison, G. M., Walker, D., Wakefield, P., \& Soldberg, S. (1994). Teacher preferences for collaborative relationship to efficacy for teaching in prevention-related domains.

Psychology in the Schools, 31, 221-231.

Murdick, N. L., Petch-Hogan, B. (1996). Inclusive classroom management: Using preintervention strategies. Intervention in School and Clinic, 31, 172-176. 
Murphy, C. A., Coover, D., \& Owen, S. (1989). Development and validation of the computer self-efficacy scale. Educational and Psychological Measurement, 49, 893-899.

Myrick, C. C. (1986). An emerging consensus on school psychology's future. Professional School Psychology, 1, 291-294.

National Joint Committee on Learning Disabilities (1992). School Reform: Opportunities for excellence and equity for individuals with learning disabilities (a special report). Journal of Learning Disabilities, 25, 276-280.

Neef, N. A., Shafer, M. S., Egel, A. L., Cataldo, M. F., \& Parrish, J. M. (1983). The class specific effects of compliance training with "do" and "don't" requests: Analogue analysis and classroom application. Journal of Applied Behavior Analysis, 16, 81-99.

Nelson, J. R., Smith, D. J., Taylor, L., Dodd, J. M., \& Reavis, K. (1991). Prereferral intervention: A review of the research. Education and Treatment of Children, 14, 243-253.

Nelson, J. R., Smith, D. J., Taylor, L., Dodd, J. M., \& Reavis, K. (1992). A statewide survey of special education administrators regarding mandated prereferral interventions. Remedial and Special Education, 13, 34-39.

Norris, D. A., Burke, J. P., \& Speer, A. L. (1990). Tri-level service delivery: An alternative consultation model. School Psychology Quarterly, 5, 89-110.

Oakland, T., \& Cunningham, J. L. (1990). Advocates for educational services for all children need improved research and conceptual bases. School Psychology Quarterly, 5, 66-77.

Oakland, T., Shermis, M.D., \& Coleman, M. (1990). Teacher perceptions of differences among elementary students with and without learning disabilities in referred samples. Journal of Learning Disabilities, 23, 499-520.

O'Reilly, C., Northcraft, G.B., \& Sabers, D. (1989). The confirmation bias in special education eligibility decisions. School Psychology Review, 1, 126-135.

Osterweil, S. O. (1987). A structured process of problem definition in school consultation. The School Counselor, 34, 345-352.

Ozer, E. M., \& Bandura, A. (1990). Mechanisms governing empowerment effects: A self efficacy analysis. Joumal of Personality and Social Psychology, 58, 472-486.

Parkay, F. W., Greenwood, G., Olejnik, S., \& Proller, N. (1988). A study of the relationship among teacher efficacy, locus of control, and stress. Journal of Research and Development in Education, 21, 13-22.

Parsons, R. D., \& Meyers, J. (1978). The training and analysis of consultation processes using transactional analysis. Psychology in the Schools, 15, 545-553.

Phillips, P. (1990). Consultative teamwork in secondary school: A training exercise. Educational and Child Psychology, 7, 67-77. 
Piersel, W. C., \& Gutkin, T. B. (1983). Resistance to school-based consultation: A behavioral analysis of the problem. Psychology in the Schools, 20, 311-320.

Ponti, C. R., Zins, J. E., Graden, J. L. (1988). Implementing a consultation-based service delivery system to decrease referrals for special education: A case study of organizational considerations. School Psychology Review, 17, 89-100.

Pryzwansky, W. P. (1989). School consultation: Some considerations from a cognitive psychology perspective. Professional School Psychology, 4, 1-14.

Pylyshyn, Z. W. (1981). The imagery debate: Analogue media versus tacit knowledge. Psychological Review, 88, 16-45.

Rakover, S. S. (1980). Generalization from analogue therapy to the clinical situation: The paradox and the dilemma of generality. Journal of Consulting and Clinical Psychology, 48. $770-771$.

Reinking, R. H., Livesay, G., \& Kohl, M. (1978). The effects of consultation style on consultee productivity. American Journal of Community Psychology, 6, 283-290.

Reisberg, L., \& Wolf, R. (1988). Instructional strategies for special education consultants. Remedial and Special Education, 9, 29-40, 47.

Reschly, D. J. (1976). School psychology consultation: "frenzied, faddish, or fundamental?" Journal of School Psychology, 14, 105-113.

Reschly, D. J. (1988). Special education reform: School psychology revolution. School Psychology Review, 17, 459-475.

Reynolds, C. R., Gutkin, T. B., Elliott, S. N., \& Witt, J. C. (1984). School psychology: Essentials of theory and practice. New York: Wiley.

Rhoades, M. M., \& Kratochwill, T. R. (1992). Teacher reactions to behavioral consultation: An analysis of language and involvement. School Psychology Quarterly, 7, 4759.

Roberts, A. H., \& Rust, J. O. (1994). Role and function of school psychologists, 1992-93: A comparative study. Psychology in the Schools, 31, 113-119.

Rosenfield, S. (1992). Developing school-based consultation teams: A design for organizational change. School Psychology Quarterly, 7, 27-46.

Rosenfield, S., \& Houtz, J.C. (197?). Evaluation of behavior modification studies using criterion referenced measurement principles. The Psychological Record, 26, 269-278.

Rosenfield, S., \& Reynolds, M. (1990). Mainstreaming school psychology: A proposal to develop and evaluate alternative assessment methods and intervention strategies. School Psychology Quarterly, 5, 55-65. 
Rotter, J. B. (1966). Generalized expectancies for internal versus external control of reinforcement. Psychological Monographs: General and Applied, 80, 1-28.

Russell, S. C., \& Kaderavek, J. N. (1993). Alternative models for collaboration. Language, Speech, and Hearing Services in Schools, 24, 76-78.

Ryff, C. D. (1987). The place of personality and social structure research in social psychology. Journal of Personality and Social Psychology, 53, 1192-1202.

Safran, S. P. (1985). Correlates of special educators' self-efficacy beliefs. British Columbia Journal of Special Education, 9, 61-67.

Saklofske, D. H., Michayluk, J. O., \& Randhawa, B. S. (1988). Teachers' efficacy and teaching behaviors. Psychological Reports, 63, 407-414.

Salmon, D., \& Lehrer, R. (1989). School consultant's implicit theories of action. Professional School Psychology, 4, 173-187.

Salmon, D., \& Lehrer, R. (1991). Experience and representation of the consultant role: Exploring the implicit theories of school psychology trainers and students. School Psychology Quarterly, 6, 112-130.

Sampson, E. (1978). Scientific paradigms and social values: Wanted- a scientific revolution. Journal of Personality and Social Psychology, 36, 1332-1343.

Sandoval, J. (1986). Models of school psychological service delivery. In S. Elliott, \& J. Witt (Eds.), Psychological Services in Schools: Concepts, Processes and Issues (pp. 139-170). New Jersey: Erlbaum.

Sandoval, J., Lambert, N. M., \& Davis, J. M. (1977). Consultation from the consultee's perspective. Journal of School Psychology, 15, 334-342.

Sarason, S. B. (1982). The culture of the school and the problem of change (2nd ed.). Boston: Allyn and Bacon.

Schloss, P. J. (1992). Mainstreaming revisited. The Elementary School Journal, 92, 233243.

Schrag, J. A., \& Henderson, K. (1996). School-based intervention assistance teams and their impact on special education (Final Report Year 3 Deliverable \#5-3-4). Alexandria, VA: National Association of State Directors of Special Education. (ERIC Document Reproduction Service No. ED 392 196)

Schunk, D. H. (1982). Effects of effort attributional feedback on children's perceived selfefficacy and achievement. Journal of Educational Psychology, 74, 548-556.

Schunk, D. H. (1982). Progress self-monitoring: Effects on children's self-efficacy and achievement. Journal of Experimental Education, 51,89-93. 
Schunk, D. H. (1983). Ability versus effort attributional feedback: Differential effects on self-efficacy and achievement. Journal of Educational Psychology, 75, 848-856.

Schunk, D. H. (1983). Reward contingencies and the development of children's skills and self-efficacy. Journal of Educational Psychology, 75, 511-518.

Schunk, D. H. (1985). Self-efficacy and classroom learning. Psychology in the Schools, $\underline{22}, 208-223$.

Schunk, D. H. (1987). Peer models and children's behavioral change. Review of Educational Research, 57, 149-174.

Schunk, D. H. (1989). Self-efficacy and cognitive achievement: Implications for students with learning problems. Journal of Learning Disabilities, 22, 14-22.

Schunk, D. H., \& Cox, P. D. (1986). Strategy training and attributional feedback with learning disabled students. Journal of Educational Psychology, 78, 201-209.

Schunk, D. H., Hanson, A. R. (1989). Influence of peer-model attributes on children's beliefs and learning. Journal of Educational Psychology, 81, 431-434.

Schunk, D. H. \& Hanson, A. R. (1989). Self-modeling and children's cognitive skill learning. Journal of Educational Psychology, 81, 155-163.

Schunk, D. H., Hanson, A. R., \& Cox, P. D. (1987). Peer-model attributes and children's achievement behaviors. Journal of Educational Psychology, 79, 54-61.

Schunk, D. H., \& Rice, J. M. (1984). Strategy self-verbalization during remedial listening comprehension instruction. Journal of Experimental Education, 53, 49-54.

Schunk, D. H., \& Swartz, C. W. (1993). Goals and progress feedback: Effects on selfefficacy and writing achievement. Contemporary Educational Psychology, 18, 337-354.

Sears, D. O. (1986). College sophomores in the laboratory: Influences of a narrow data base on social psychology's view of human nature. Journal of Personality and Social Psychology, 51, 515-530.

Sechrest, L. \& Walsh, M. (1997). Dogma or data: Bragging rights. American Psychologist, 52, 536-540.

Sevick, B. M., \& Ysseldyke, J. E. (1986). An analysis of teachers' prereferral interventions for students exhibiting behavioral problems. Behavioral Disorders, 11, 109-117.

Shavelson, R. J., \& Stern, P. (1981). Research on teachers' pedagogical thoughts, judgments, decisions, and behavior. Review of Educational Research, 51, 455-498.

Sheridan, S. M. (1992). Consultant and client outcomes of competency-based behavioral consultation training. School Psychology Quarterly, 7, 245-270. 
Sheridan, S. M., \& Elliott, S. N. (1991). Behavioral consultation as a process for linking the assessment and treatment of social skills. Journal of Educational and Psychological Consultation, 2, 151-173.

Sheridan, S. M., Kratochwill, T. R., \& Elliott, S. N. (1990). Behavioral consultation with parents and teachers: Delivering treatment for socially withdrawn children at home and school. School Psychology Review, 19, 33-52.

Sheridan, S. M., Salmon, D., Kratochwill, T. R., \& Rotto, P. J. (1992). Conceptual and practical considerations for behavioral consultation training. Joumal of Educational and Psychological Consultation, 3, 193-218.

Sheridan, S. M., \& Steck, M. C. (1995). Acceptability of conjoint behavioral consultation: A national survey of school psychologists. School Psychology Review , 24, 633-647.

Short, R. J., \& Ringer, M. M. (1987). Consultant experience and attributions in school consultation. Professional School Psychology, 2, 273-279.

Silverman, W. H. (1974). Some factors related to consultee satisfaction with consultation. American Journal of Community Psychology, 2, 303-310.

Sindelar, P. T., Griffin, C. C., Smith, S. W., \& Watanabe, A. K. (1992). Prereferral intervention: Encouraging notes on preliminary findings. The Elementary School Journal, 92. 245-259.

Smelter, R. W., Rasch, B. W., \& Yudewitz, G. J. (1995). The times, they are a-changin.' Phi Delta Kappan, 76, 484-486.

Smith, D. K. (1984). Practicing school psychologists: Their characteristics, activities, and populations served. Professional Psychology: Research and Practice, 15, 798-810.

Smith, D. K., \& Lyon, M. A. (1985). Consultation in school psychology: Changes from 1981 to 1984. Psychology in the Schools, 22, 404-409.

Soodak, L. C., \& Podell, D. M. (1993). Teacher efficacy and student problems as factors in special education referral. Journal of Special Education, 27, 66-81.

State of Rhode Island \& Providence Plantations Department of Elementary and Secondary Education. (1992). Prereferral procedures, classroom alternatives process (CAP) Regulations of the Board of Regents for Elementary and Secondary Education governing the special education of students with disabilities (Section One, V., 3).

Stenger, M. K., Tollefson, N., \& Fine, M. J. (1992). Variables that distinguish elementary teachers who participate in school-based consultation from those who do not. School Psychology Quarterly, 7, 271-284.

Stone, B., \& Brown, R. (1986). Preparing teachers for mainstreaming: Some critical variables for effective preservice programs. Educational Research Quarterly, 11, 7-10. 
Tabachnick, B. G., \& Fidell, L. S. (1989). Using Multivariate Statistics (2nd ed.). Northridge, C. A.: Harper Collins.

Taylor, R., \& Justen, J. E. (1996). Full inclusion of students with mild disabilities: a question of external validity. The Clearing House, 70, 108-110.

Taylor, S. E., Peplau, L. A., \& Sears, D. O. (1997). Social Psychology, (9th ed.). Uppersaddle River, N. J.: Prentice-Hall.

Tingstrom, D. H., Little, S. G., \& Stewart, K. J. (1990). School consultation from a social psychological perspective: A review. Psychology in the Schools, 27, 41-50.

Tombari, M. L., \& Bergan, J. R. (1978). Consultant cues and teacher verbalizations, judgments, and expectancies concerning children's adjustment problems. Journal of School Psychology, 16, 212-219.

Trachtman, G. M. (1981). On such a full sea. School Psychology Review, 10, 138-181.

U. S. Department of Education. (1992). Fourteenth Annual Report to Congress on the Implementation of the Individuals with Disabilities Act. Washington, D. C.; U. S. Government Printing Office.

Waguespack, A. M., \& Moore, L. A. (1993). Teacher preferences for service delivery: A look at attribution research. School Psychology Quarterly, 8, 153-158.

Watzlawick, P., Beavin, J. H., \& Jackson, D. D. (1967). Pragmatics of Human Communication. New York: W. W. Norton \& Co.

Wenger, R. D. (1979). Teacher response to collaborative consultation. Psychology in the Schools, 16, 127-131.

West, J. F., \& Cannon, G. S. (1988). Essential collaborative consultation competencies for regular and special educators. Journal of Learning Disabilities, 21, 56-64.

West, J. F., \& Idol, L. (1987). School consultation (part 1): An interdisciplinary perspective on theory, models, and research. Journal of Learning Disabilities, 20, 388-408.

White, P. L., \& Fine, M. J. (1976). The effects of three school psychological consultation modes on selected teacher and pupil outcomes. Psychology in the Schools, 13, 414-420.

Will, M. (1988). Educating students with learning problems and the changing role of the school psychologist. School Psychology Review, 17, 476-478.

Williams, D. L. (1972). Consultation: A broad, flexible role for school psychologists. Psychology in the Schools, 9, 16-21. 519.

Wise, P. S. (1979). A training model in consultation. Psychology in the Schools, 16, 515- 
Witt, J. C. (1986). Teachers' resistance to the use of school-based interventions. Journal of School Psychology, 24, 37-44.

Witt, J. C. (1990a). Complaining, precopernican thought and the univariate linear mind: Questions for school-based behavioral consultation research. School Psychology Review, 19. 367-377.

Witt, J. C. (1990b). Face-to-face verbal interaction in school-based consultation: A review of the literature. School Psychology Quarterly, 5, 199-210.

Witt, J. C., Elliott, S. N., \& Martens, B. K. (1984). Acceptability of behavioral interventions used in classrooms: The influence of teacher time, severity of behavior problem, and type of intervention. Behavioral Disorders, 10, 95-104.

Witt, J. C., \& Martens, B. K. (1983). Assessing the acceptability of behavioral interventions used in classrooms. Psychology in the Schools, 20, 510-517.

Witt, J. C., \& Martens, B. K. (1988). Problems with problem-solving consultation: A reanalysis of assumptions, methods, and goals. School Psychology Review, 17, 211-226.

Witt, J. C., Martens, B. K., \& Elliott, S. N. (1984). Factors affecting teachers' judgment of the acceptability of behavioral interventions: Time involvement, behavior problem severity, and type of intervention. Behavior Therapy, 15, 204-209.

Witt, J. C., Moe, G., Gutkin, T. B., \& Andrews, L. (1984). The effect of saying the same thing in different ways: The problem of language and jargon in school-based consultation. Journal of School Psychology, 22, 361-367.

Wolf, M. M. (1978). Social validity: The case for subjective measurement or how applied behavior analysis is findings its heart. Journal of Applied Behavior Analysis, 11, 203-214.

Woolfolk, A. E., \& Hoy, W. K. (1990). Prospective teachers' sense of efficacy and beliefs about control. Journal of Educational Psychology, 82, 81-91.

Ysseldyke, J. E., \& Marston, D. (1990). The use of assessment information to plan instructional interventions: A review of the research. In T. B. Gutkin \& C. R. Reynolds (Eds.), The handbook of school psychology (2nd ed.) (pp. 663-682). New York: John Wiley \& Sons.

Ysseldyke, J. E., Pianta, B., Christenson, S., Wang, J. J., \& Algozzine, B. (1983). An analysis of prereferral interventions. Psychology in the Schools, 20, 184-190.

Ysseldyke, J. E., Thurlow, M., Graden, J., Wesson, C., Algozzine, B., \& Deno, S. (1983). Generalizations from five years of research on assessment and decision making. Exceptional Education Quarterly, 4, 75-93.

Zigmond, N., Jenkins, J., Fuchs, L. S., Deno, S., Fuchs, D., Baker, J. N., Jenkins, L., \& Couthino, M. (1995). Special education in restructured schools: findings from three multi-year studies. Phi Delta Kappan, 76, 531-541. 
Zins, J. E., Graden, J. L., \& Ponti, C. R. (1989). Prereferral intervention to improve special services delivery. Special Services in the Schools, 4, 109-130.

Zins, J., Kratochwill, T., \& Elliott, S. (Eds.) (1993). Handbook of consultation services for children. San Francisco: Jossey-Bass.

Zins, J. E., \& Ponti, C. R. (1990). Strategies to facilitate the implementation, organization, and operation of system-wide consultation programs. Journal of Educational and Psychological Consultation, 1, 205-218. 